the
Acid Deposition
Research Program

\section{BIOPHYSICAL RESEARCH}

\section{SURFACE WATER ACIDIFICATION LITERATURE REVIEW}

by:

\section{S.A. TELANG}

Kananaskis Centre for Environmental Research

The University of Calgary

Calgary, Alberta, Canada

February, 1987

PRIME RESEARCH CONTRACTOR:

The Kananaskis Centre for Environmental Research The University of Calgary Calgary, Alberta, Canada

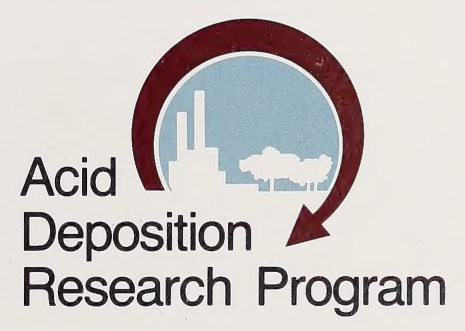


Digitized by the Internet Archive in 2015

https://archive.org/details/surfacewateracid00tela 
The Acid Deposition Research Program is funded and administered by the Province of Alberta, the Canadian Petroleum Association, Alberta's electrical utilities and the Energy Resources Conservation Board.

A distinctive feature of the ADRP is the development and funding of research in two major areas, biophysical and human health.

\section{Acid Deposition Research Program - Members Committee}

Ron L. Findlay (Co-Chairman)

Manager, Environmental Affairs

AMOCO Canada Petroleum Co. Ltd.

Carl L. Primus (Co-Chairman)

Assistant Deputy Minister

Alberta Environment

Dr. John Railton

Manager, Environmental Planning

TransAlta Utilities

Dr. Harby S. Sandhu

Senior Research Manager

Research Management Division

Alberta Environment

Ken Smith

Assistant Deputy Minister

Alberta Environment

\section{E. Millard Wright}

Manager, Environmental Planning

Gulf Canada Corporation

Ed Brushett

Manager, Environmental Protection

Energy Resources Conservation Board

Dr. Brian O'Connor

Director of Health Promotion and

Protection Programs

Alberta Community and Occupational Health

Dr. Martha Kostuch

Public Representative

Program Manager: Dr. Ron R. Wallace

Communications Co-ordinator: Jean L. Andryiszyn

\section{Scientific Advisory Board \\ Biophysical Research}

\section{Dr. Sagar V. Krupa}

University of Minnesota

(Department of Plant Pathology)

Dr. James P. Lodge

Consultant in Atmospheric Chemistry

and Editor, Atmospheric Environment

Dr. Robert K. Stevens

U.S. Environmental Protection Agency

Dr. C. M. Bhumralkar

National Oceanographic

and Atmospheric Administration (NOAA)

Bruce B. Hicks

National Oceanographic

and Atmospheric Administration

Atmospheric Turbulence Diffusion

Laboratory (NOAA)

Dr. M. Ali Tabatabai

lowa State University

Department of Agronomy
Dr. T. Craig Weidensaul

Ohio Agricultural Research

and Development Center

Ohio State University

Dr. Douglas P. Ormrod

University of Guelph

Department of Horticultural Science

Dr. Carl L. Schofield

Cornell University

Department of Natural Resources

Dr. Ron Kickert

Consultant (in modelling)

Dr. Herbert C. Jones

Tennessee Valley Authority

Fisheries and Aquatic Ecology Branch

Biophysical Research Prime Contractor:

Kananaskis Centre for Environmental Research The University of Calgary

Principal Investigator: Dr. Allan H. Legge 


\title{
SURFACE WATER ACIDIFICATION \\ LITERATURE REVIEW
}

\author{
by \\ S. A. Telang \\ Kananaskis Centre for Environmental Research \\ The University of Calgary \\ Calgary, Alberta T2N IN4
}

\author{
prepared for: \\ Dr. Allan H. Legge \\ Kananaskis Centre for Environmental Research \\ The University of Calgary \\ Calgary, Alberta, Canada \\ for submission to: \\ The Acid Deposition Research Program \\ 1500,633 Sixth Avenue S.W. \\ Calgary, Alberta, Canada T2P $2 Y 5$
Technical Editors:
Julie C. Lockhart and
Linda L. Jones \\ February $198 \%$
}


This publication may be cited as:

Telang, S.A. 1987.

Surface Water Acidification Literature Review. Prep for the Acid

Deposition Research Program by the Kananaskis Centre for Environmental Research. The University of Calgary, Calgary, Alberta.

ADRP-B-01-87.

$123 \mathrm{pp}$.

ISBN 0-921625-03-0 (Volume 1)

ISBN 0-921625-02-2 (Set of 11) 


\section{EXECUTIVE SUMMARY}

This report assesses the state of scientific knowledge on the effects on acidic atmospheric deposition on surface water chemistry. There appear to be two views on the mechanism of surface water acidification. Some researchers believe that surface water acidification is caused by the long-range atmospheric transport and deposition of acidic substances, while others believe that it is caused by internal generation of hydrogen ions in watersheds. The Integrated Lake-Watershed Acidification Study has shown that a lake's vulnerability to acidification depends on the biogeochemistry and hydrology of its entire catchment area, including soil depth, soil mineralogy, stage of forest development, and precipitation pathways through a terrestrial system before reaching the lake.

The main findings of the literature review are as follows:

1. Uncontaminated precipitation can have pH levels below 5.6. Chronically low precipitation $\mathrm{pH}$ values (4.3 to 4.9 ) observed in some parts of the world may result from anthropogenic emissions of sulphur and nitrogen oxides. A drop of $\mathrm{pH}$ from 5.6 to 4.3 may represent a fourfold increase in hydrogen ion concentration, not a twentyfold increase, as is often reported. Quantity and quality of atmospheric deposition and episodic events (e.g., snowmelt, rain) can increase concentrations of hydrogen ions and other organic and inorganic substances in lake and stream waters, particularly for aquatic systems near point source emissions. It appears that not only long-range transport and deposition of acidic substances cause surface water acidification; generation of hydrogen ions within a watershed and their transport to lakes or streams can also contribute to surface water acidification. During the critical snowmelt period both external and internal sources of hydrogen ions contribute to surface water acidification.

2. Some surface waters are naturally acidic. An example of this are the acidic surface waters in the New Jersey pine barrens. Organic acids appear to contribute to the acidity of these waters.

3. Internal generation of hydrogen ions in watersheds and their input to surface waters can be many times greater than input from atmospheric sources. The extent to which these two sources contribute to surface water acidification has not been documented in many studies other than the ILWAS study. The ILWAS study suggested that atmospheric deposition is about $25 \%$ greater than internal acidity production in the studied watersheds. 
4. Surface water susceptibility to acidification depends on (a) type of forest canopy; (b) bedrock geology; (c) soil type and depth; (d) topography and watershed-to-lake ratio; (e) land use practices; (f) surface water quality; and, (g) climatic and meterological conditions. The relative importance of each characteristic varies among watersheds.

5. In North America, trends of decreasing surface water pH have been observed in: (a) the Sudbury area and La Cloche Mountains of Ontario; (b) Nova Scotia; (c) the Adirondack Mountains of New York; and (d) northern New England states. In Ontario, localized point source emissions are responsible for trends in surface acidification. In Nova Scotia, New England states, and to a lesser degree in the Adirondack Mountains of New York, both atmospheric deposition and internal generation of hydrogen ions may be contributing to surface water acidification. Only the ILWAS study in the Adirondack Mountains has established this.

6. Comparison of historical data with the recent data to show acidification trends in surface waters needs to be viewed with caution; there are problems associated with the use of more than two different methods in data comparison and with inferring trends using only two data points separated in time by a number of years. It appears, however, that errors associated with the analytical methods are not large and the results obtained by the two different methods may be comparable.

7. The literature regarding the response of aquatic biota to acidification is at times conflicting, yet a number of effects has been well documented by observations and experimental studies. It appears that study of the response of aquatic biota to acid deposition must take into account not only increases in acidity but also increases in metal ion concentration, increased water clarity, accumulation of periphyton and detritrus, changes in trophic interactions, and physiological changes in aquatic organisms, because together they constitute the freshwater acidification process.

8. Numerous models have been developed to evaluate the effects of acid deposition on surface water quality. Most of the models assume that surface water acidification is caused by the atmospheric deposition of sulphuric acid alone. They largely ignore the role of nitric acid (atmospherically and biologically produced), organic acids (naturally produced), and sulphate sources within the watershed in surface water acidification, the exception being the ILWAS model. 
9. Available data indicate that lake and stream waters are being acidified in regions receiving acidic atmospheric deposition, and that both external and internal production of hydrogen ions within a watershed may be contributing to acidification of surface waters. Except for the ILWAS study, the relative contribution of these two sources to surface water acidification is unknown. In future studies, the relative contribution needs to be quantified. 
4. EFFECTS OF QUANTITY AND QUALITY OF ATMOSPHERIC DEPOSITION AND

5.1 Misconception 1: Naturally ACidic Lakes in Contrast to Anthropo-

Bedrock Geology .. . . . . . . . . . . . . . . . . . . . 36

Soil Type and Depth . . . . . . . . . . . . . . . . . . . . . . 36

6.4

Topography and Watershed-to-Lake Ratio . . . . . . . . . . . . . .

Watershed Vegetation and Land Use . . . . . . . . . . . . . . . .

Atlantic Provinces . . . . . . . . . . . . . . . . . . . 
8. EFFECTS OF ACID DEPOSITION ON AQUATIC BIOTA . . . . . . . . . . . 59

8.1 Organisms Occurring in Naturally Acidic Waters . . . . . . . . . . . 59

8.2 Organisms in Anthropogenically Acidified Lakes . . . . . . . . . . 6 60

8.2.1 Benthic Organisms ...................... . . . . . . 60

8.3 Macrophytes and Wetland Plants . . . . . . . . . . . . . . 60

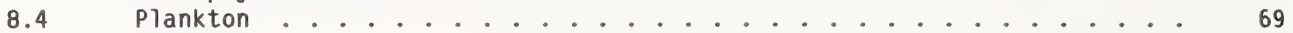

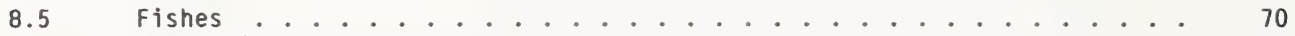

8.6 Other Biota . . . . . . . . . . . . . . . . . . . . . . . . . .

8.7 Fishes of Northern Alberta .................. . . . . . 74

9. MODELS OF FRESHWATER ACIDIFICATION . . . . . . . . . . . . . 77

9.1 Empirical Models - the Henriksen Models . . . . . . . . . . . . . . . 77

9.1 .1 Thompson Model . . . . . . . . . . . . . . . . . . 82

9.2 Static and Dynamic Models . . . . . . . . . . . . . . . . 83

9.2.1 The Hydrological Sub-Model . . . . . . . . . . . . . . . . . . 83

9.2.2 The Chemical Model ...................... . . . . . . . 85

9.2.2.1 The Sulphate Sub-Mode1 . . . . . . . . . . . . . . . . . 85

9.2.2.2 The Cation Sub-Model ................... . . . . . 85

9.2.2 Chemical Equilibrium Model . . . . . . . . . . . . . . . . 86

9.2.3 Computer Model . . . . . . . . . . . . . . . . . . . . 87

9.2 .4 ILWAS Model .. . . . . . . . . . . . . . . . . . . . 87

9.3 Conceptual Models . . . . . . . . . . . . . . . . . . 88

10. SURFACE WATER ACIDIfICATION STUDIES IN ALBERTA . . . . . . . . . . . 93

11. RECOMMENDATIONS FOR FURTHER STUDIES . . . . . . . . . . . . . . . . 95

11.7 Research Deficiencies . . . . . . . . . . . . . . . 95

12. REFERENCES CITED . . . . . . . . . . . . . . . . . . . 97

APPENDIX - ADDITIONAL REFERENCES ................. . . . 115 


\section{LIST OF TABLES}

Page

1. Environmental Hydrogen Ion Producing and Consuming Processes . . . . . 22

2. Watershed Characteristics that Influence Surface Water Susceptibility

to Acidification . . . . . . . . . . . . . . . 35

3. Characteristics of the ILWAS LakeS . . . . . . . . . . . . . . 38

4. Lower pH Limits for Various Groups of Organisms in Naturally Acidic

Waters ....................... . . . . 61 61

5. Effects of Increasing Acidity on Aquatic Ecosystems . . . . . . . . 63

6. Fish Species Common to Northeastern Alberta . . . . . . . . . . . 75

\section{LIST OF FIGURES}

1. Precipitation Pathways to a Lake . . . . . . . . . . . . . . 34

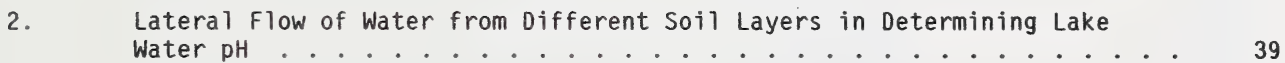

3. Chemical Species Associated with Water Flow Paths to a Lake . . . . . 39

4. "Acidification Indicator" . . . . . . . . . . . . . . . 78

5. "Predictor" Nomograph . . . . . . . . . . . . . . . . . . 80

6. Hydrologic Submodel . . . . . . . . . . . . . . . . . . 84

7. Changes in the Concentrations ( $\mu$ eql/L) of Sulphate, Base Cations, and Alkalinity During the Seven Stages of Acidification . . . . . . . . . 89 


\section{GLOSSARY OF TERMS}

$\mathrm{H}_{2} \mathrm{CO}_{3}$

$\mathrm{H}_{2} \mathrm{SO}_{4}$

$\mathrm{HNO}_{3}$

$\mathrm{HCl}$

DOC

DIC

Ions

$\mathrm{H}^{+}$

$\mathrm{SO}_{4}{ }^{2-}$

$\mathrm{NO}_{3}^{-}$

$\mathrm{NO}_{2}^{-}$

$\mathrm{Cl}^{-}$

$\mathrm{HCO}_{3}-$

$\mathrm{CO}_{3}{ }^{2-}$

$\mathrm{OH}^{-}$

$\mathrm{NH}_{4}+$

$\mathrm{Ca}^{2+}$

$\mathrm{Mg}^{2+}$

$\mathrm{Na}^{+}$

$\mathrm{K}^{+}$

$\mathrm{Al}^{3+}$

$\mathrm{Zn}^{2+}$

$\mathrm{Mn}^{2+}$

$\mathrm{Pb}^{2+}$

$\mathrm{CO}^{2+}$

$\mathrm{Cd}^{2+}$

Units

$\mu g$
$\mu e q$
$L$
$\mathrm{~cm}$
$y$

Carbonic Acid

Sulphuric Acid

Nitric Acid

Hydrochloric Acid

Dissolved Organic Carbon

Dissolved Inorganic Carbon

microgram

microequivalent

litre

centimetre

year

Hydrogen

chloride

Bicarbonate

Carbonate

Hydroxide

Ammonium

Magnesium

Sodium

Potassium

Aluminjum

Zinc

Manganese

Cobalt

Cadmium 


\section{ACKNOWLEDGEMENTS}

The author gratefully acknowledges the financial assistance of the Acid Deposition Research Program, Alberta, for this literature survey. The author expresses his sincere appreciation to Dr. A.H. Legge, Principal Investigator, Acid Deposition Research Program, Kananaskis Centre for Environmental Research, for securing the funds for this part of the project, for including me in the research team, and for his scientific assistance. The author expresses his gratitude to Julie Lockhart, whose graciousness and even temperament prevailed throughout her editing of this manuscript and made the editorial criticism much easier to accept. An excellent job of typing and retyping by Lynn Ewing and Della Patton is also appreciated. 
An English chemist named Robert Angus Smith, in the middle of the 19th century, first discovered many features of the acid rain phenomenon. In 1852, he called attention to the changes in precipitation chemistry as one moved from the middle of polluted Manchester city to its surrounding countryside by writing: "We may therefore find three kinds of air - that with carbonate of ammonia in the fields at a distance, that with sulphate of ammonia in the suburbs, and that with sulphuric acid or acid sulphate, in town." (cited by Cowling 1982). Twenty years later in a book entitled "Air and Rain: The Beginnings of a Chemical Climatology", Smith (1872) first used the term "acid rain" and expressed many of the ideas that are part of our present understanding (cited by Cowling 1982). Unfortunately, however, his pioneering work and book were overlooked by every subsequent investigator until the middle of the 20 th century. In a long series of papers beginning in 1955, Gorham described acidic precipitation in England and laid the foundations for our present understanding of the impact of acid precipitation on ecosystems.

Although the terms "acid rain" and "acid precipitation" have been popularized by scientists, the term "atmospheric deposition" is more appropriate and is now widely used. Atmospheric deposition refers to materials - liquid, solid, or gaseous - that are deposited in wet or dry forms from the atmosphere onto land and water surfaces. Wet deposition includes materials incorporated in rain, snow, dew, and fog. Dry deposition refers to dry fall-out of large particles such as soil particles, fly ash, and organic and inorganic particulates and aerosols.

Acid deposition was first recognized as a regional phenomenon in Scandinavia in the late 1960's (Haines 1981). Since then, its presence has been well established in northwestern Europe, northeastern and southeastern United States, and eastern Canada. The most comprehensive studies to date have been in Norway and Sweden (Overrein et al. 1980), the United States (Likens and Bormann 1974; Tetra Tech Inc. 1983, 1984; Herrmann and Johnson 1983; Gibson et a1. 1983; and National Wildlife Federation 1984), and Canada (Beamish 1974, 1976; Scruton 1983). In recent years, the consequences of acid deposition are becoming increasingly well defined with respect to vegetation (Clesceri and Vasudevan 1980; Stottlemyer 1982; Cronan and Reiners 1983; and Linthurst 1984), soils (Tabatabai 1985), and especially with respect to aquatic ecosystems (Haines 1981; Tetra Tech Inc. 1984).

The current concern about potential impacts of acid deposition on aquatic ecosystems arose for two reasons - its potential impact on aquatic biota, and on human health and lifestyle. It originated with the supposition by Dannevig (1959) that acid precipitation was the cause of large-scale freshwater acidification and losses of fish populations in Norway. Recent studies show that acidification of surface waters may have serious repercussions for aquatic biota, and that it may affect species diversity on all trophic levels (Müller 1980; Dale et a1. 1985; and Schindler et a1. 1985). Acidification appears to have a very profound effect on fish populations (Beamish 1974, 1976; Watt et a1. 1983, and Rahel and Magnuson 1983), and it appears to be largely due to leaching of toxic metals, particularly aluminum. Elevated levels of aluminum, which may result from acidification of terrestrial and aquatic ecosystems, appear to be toxic to fish (Baker et a1. 1979; Herrmann and Barron 1980; Schofield and Trojnar 1980; Somers 
and Harvey 1984; and Robinson and Deano 1985). These effects on fish become noticeable during the spring period when many indigenous fish species spawn in tributaries, and when fish fry hatch during or soon after spring snowmelt when high concentrations of hydrogen and aluminum ions make water quality poor (Johannessen et al. 1980; Bjarnborg 1983; and Cadle et al. 1984).

Human health and lifestyle are also affected by acidification of aquatic ecosystems. Many recreational areas which are considered to have high surface water quality are often used by recreationists for camping, boating, fishing, and other activities. A decline in water quality due to changes in water chemistry (for example, leaching of toxic metals) as a result of acidic atmospheric deposition not only affects recreationists but also the tourist industry that these regions attract. However, the most serious effect of acidification, as far as human health is concerned, is the mobilization of metals in water supply systems. This is caused by leaching of toxic and other metals (e.g., lead, mercury, cadmium, aluminum, and copper) from watersheds (e.g., soils) and by corrosion of water pipes in water distribution systems (Middleton and Rhodes 1984; Leibfried et a1. 1984). However, it is important to note that unless reliable historical data are available, it is difficult to distinguish between metals (for example, aluminum) released by natural acidification processes and those solubilized by acid deposition. Corrosivity in surface water supplies has been widely reported and its effects on humans are well documented. Where lead pipes are used for water distribution, lead toxicity has been reported as a consequence of conveyance of corrosive drinking water (Craum and McCabe 1975). A case of copper toxicity from a corroded water fountain was reported by Semple et al. (1960). With pipes of other metals, such as iron or galvanized steel, the corrosive products of iron, zinc, and cadmium may be problems.

Many investigators agree that near a point source of acid-forming emissions, surface water acidification is caused by the anthropogenic input of acidic substances, such as sulphuric and nitric acids. However, there are two views on how acidification of remotely located lakes and streams occurs as a result of long-range transport of acidic substances.

In the 1960's and the early 1970's, many researchers believed that a single factor, atmospheric deposition, determined the acid-base status of surface waters. However, several recent reports have suggested that this status may be regulated by sources other than acid deposition (Rosenqvist 1978a,b, 1980; Rosenqvist et a1. 1980; Krug and Frink 1983a,b; and Lefohn and Klock 1985). The investigators of these reports have suggested that acidic atmospheric deposition alone cannot adequately explain changes of acidity in soil and freshwater systems. Instead, they suggest that natural processes internal to soils and surface waters are primarily responsible for the observed acidification of freshwater. These investigators appear to suggest that organic acids of natural origin also determine the acid-base status of surface waters. Many investigators, however, now believe that both acid deposition and natural processes contribute to acidification of surface waters and that it is necessary to separate the anthropogenic contribution from the natural contribution of hydrogen ions to assess the effect of the former on surface waters (Lefohn and Brocksen 1984). The Integrated Lake-Watershed Acidification Study in the Adirondack Mountains clearly demonstrated the importance of this approach. The report on this study indicated that the acid-base status of surface 
waters is determined by the interaction of many factors (e.g., soil, hydrologic, vegetation, geologic, climatic, and atmospheric) and that the relative role of any one factor can be highly variable geographically and temporally (Goldstein et al. 1984a).

The objective of this report, therefore, is to analyse the present state of knowledge on relationships between acid deposition and surface water acidification with reference to chemical criteria that have been used to evaluate surface water acidification. To achieve this objective, the report provides brief background information on precipitation chemistry and the manner by which acidity of precipitation and surface waters is measured. It also provides information on why some waters are sensitive to acidification and others are not. After briefly describing reactions of hydrogen ions in aquatic and terrestrial systems, the report addresses three questions:

1. How do factors of quantity and quality of precipitation and episodic events affect the process of acidification of surface waters?

2. Does surface water acidification occur by anthropogenic or natural input of hydrogen ions?

3. Do watershed characteristics influence surface water susceptibility to acidification?

The report also includes a section describing acidification studies in North America with particular reference to Alberta, a section discussing acidification effects on aquatic biota, a summary of models that have been used in surface water acidification studies, and a list of recommendations for studies in Alberta. 
2.

\section{ACIDITY AND SENSITIVITY OF WATERS}

Acidity is a measure of hydrogen ion concentration, and it is measured as $\mathrm{pH}$. The concept of $\mathrm{pH}$ is based on the ion product of pure water, which dissociates very slightly at $23^{\circ} \mathrm{C}$ to give

$$
K_{W}=\left[\mathrm{H}^{+}\right]\left[\mathrm{OH}^{-}\right]=10^{-14}
$$

where $\mathrm{K}_{\mathrm{W}}$ and [ ] indicate ion production of water and the activity of $\mathrm{H}^{+}$and $\mathrm{OH}^{-}$in moles per litre of solution, respectively. At $23^{\circ} \mathrm{C}$ pure water contains one ten-millionth of a mole of each hydrogen and hydroxyl ions or $10^{-7}$ mole of each ion. The $\mathrm{pH}$ of a solution is defined as the negative logarithm to base 10 of the $\mathrm{H}^{+}$activity or the logarithm of the reciprocal of the $\mathrm{H}^{+}$activity:

$$
\mathrm{pH}=-\log _{10}\left[\mathrm{H}^{+}\right]=\log _{10} \frac{1}{\left[\mathrm{H}^{+}\right]}
$$

To arrive at a $\mathrm{pH}$ value, the negative exponent $\left(10^{-7}\right)$ is converted into the positive number 7 . Thus, the $\mathrm{pH}$ of pure water at $23^{\circ} \mathrm{C}$ is 7 , that of acidic water is less than 7 , and that of basic or alkaline water is greater than 7. Because the pH scale is logarithmic, there is a tenfold difference between one $\mathrm{pH}$ unit and the next. A drop in pH from 6 to 5 indicates a tenfold increase in acidity, from 6 to 4 is a hundredfold increase, and so on. It is important to note that the sensing electrode measures only the dissociated $\mathrm{H}^{+}$(strong acids); therefore, undissociated hydrogen (weak acid, e.g., organic acids and carbonic acid) is not part of the hydrogen activity and is not included in the $\mathrm{pH}$ measurement.

\subsection{ACIDITY IN ATMOSPHERIC DEPOSITION}

Before 1960, pH measurements were generally used to determine acidity of precipitation. Since then, Gran's titration method is being used in the majority of studies of determine hydrogen ion concentration in rain or meltwater samples. The method measures total hydrogen ion concentration in a water sample by determining the relative contribution of hydrogen ions by strong and weak acids. However, inherent errors have been identified with the method (Barnard and Bisogni 1985; Keene and Galloway 1985). It appears that dissociation of the weak organic acids found in precipitation causes overestimates of both strong and free acidity and underestimates of weak acid acidity. In addition, the reaction of $\mathrm{NH}_{4}^{+}$with $\mathrm{OH}^{-}$in the alkaline range of titrations causes overestimates of total acidity. Further, if $\mathrm{CO}_{2}$ contamination of the titrant is present, total acidity is overestimated.

The primary hydrogen ion donors in acid deposition are sulphuric acid $\left(\mathrm{H}_{2} \mathrm{SO}_{4}\right)$. nitric acid ( $\left.\mathrm{HNO}_{3}\right)$, carbonic acids, and organic acids ( $\mathrm{R}-\mathrm{COOH}$ ) such as formic acid and acetic acid (Keene and Galloway 1984). These acids are found at various concentrations in remote areas, marine areas, and in continental areas. Gorham et al. (1984) have shown that in wet depositions in eastern United States, hydrogen ions in precipitation are correlated much more closely with sulphate ion $\left(r^{2}=0.85\right)$ than with nitrate ion $(0.63)$, whereas ammonium ions, which are derived from agriculture and windblown soils, are 
correlated more closely with nitrate ion $\left(r^{2}=0.47\right)$ than with sulphate ion $\left(r^{2}=0.30\right)$. They suggested that target loadings of 14 to 16 kilograms of wet sulphate deposition per hectare per year are probably necessary to produce an average pH of 4.6 to 4.7 in precipitation.

Atmospheric deposition tends to be naturally acidic. Rainwater in equilibrium with carbon dioxide in the air has a pH of approximately 5.6 to 5.7 ; this is frequently assumed to be the $\mathrm{pH}$ of natural rainwater in the absence of no anthropogenic input. Therefore, precipitation with a pH of less than 5.6 is defined as acid rain. Based on this assumption, many reports have suggested that precipitation in Scandinavia, North America, and eastern Canada is more acidic now (average pH 4.6) than in the past forty years (average pH 6.5) (Cogbill and Likens 1974; Oden 1976; Hornbeck et a1. 1977; Dillon et a1. 1978; Leonard et a1. 1981; Grant and Lewis 1982; Gorham et al. 1984a; and Elias et a1. 1984) They have attributed low pH levels (4.3 to 4.9) found in precipitation to anthropogenic emissions of acid forming compounds, particularly sulphur and nitrogen oxides.

In one recent publication, it was reported that precipitation acidity had increased in the eastern United States from 1955 to 1982 (Cogbill and Likens 1984). These conclusions, however, are disputed. Galloway et al. (1984) suggested that these trends have too short a time frame and are too recent to be of use in establishing a background of precipitation acidity in the eastern United States. Hansen et al. (1981) cautioned against using precipitation chemistry from 1955/1956 as baseline values because of the abnormal drought conditions that existed during those years. It has been suggested that droughts generate atypically high atmospheric levels of dust and other alkaline substances, resulting in high precipitation pH values (Marcus et al. 1983). Hansen et al. (1981) noted various problems with the earlier analyses of acid precipitation. These include: (1) undependability of the data because of variations in employed analytical methods; (2) limited comparability of the data because of large temporal and spatial variations in sampling; and, (3) computational errors and possibly biased comparisons of data. Hansen et al. (1981) concluded that the earlier data cannot be used to distinguish long-term changes in precipitation chemistry from changes that could be attributed to annual variability in precipitation chemistry and volume. Further, they emphasized that neither precipitation chemistry from the existing networks nor ionequivalent sums of sulphates and nitrates since 1950 support the hypothesis that precipitation over most of the eastern states has a trend of decreasing $\mathrm{pH}$. The value for the baseline $\mathrm{pH}$ level for natural, unpolluted rain has thus not been established.

More recently, Charlson and Rodhe (1982) selected a range of pH of natural precipitation of 4.5 to 5.6 , based on background concentrations of $\mathrm{SO}_{2}$, NOx (oxides of nitrogen), and carbon dioxide in the atmosphere. Galloway et al. (1982), using data from the remote regions of the world, estimated the lower limits of the natural mean $\mathrm{pH}$ of precipitation in marine and continental areas to be $\geq 5$. Sulphuric acid with no anthropogenic sources appears to acidify precipitation falling on to some of the remote, isolated places on earth (Kerr 1981). Rain samples with pH as low as 3.7 have been collected in Hawaii, and on Amsterdam Island in the Indian Ocean, rainwater with $\mathrm{pH}$ values ranging from 4.5 to 5.0 has been reported. However, Galloway et al. (1984) 
concluded that many areas of eastern North America receive precipitation with substantially greater $\mathrm{H}^{+}, \mathrm{SO}_{4}{ }^{2-}$, and $\mathrm{NO}_{3}{ }^{-}$concentrations than do remote areas. For example, $\mathrm{SO}_{4}{ }^{2-}$ is enriched two to 16 times in eastern North American precipitation relative to its concentration in remote areas.

Krug and Frink (1983b) claim that reports of the magnitude of acidity in precipitation are often misleading. In heavily polluted areas of the northeastern United States and southernmost Norway, rain has an average pH of about 4.3 (Glover et al. 1980; Kerr 1981) and is said to be acidified twentyfold relative to rain at pH 5.6. Krug and Frink (1983b) have pointed out that most of the acidity of rain at $\mathrm{pH} 5.6$ is due to carbonic acid $\left(\mathrm{H}_{2} \mathrm{CO}_{3}\right)$, a weak acid that does not completely dissociate into $\mathrm{H}^{+}, \mathrm{HCO}_{3}{ }^{-}$, and $\mathrm{CO}_{3}{ }^{2-}$ ions. Measurements of $\mathrm{pH}$ determine only the free $\mathrm{H}^{+}$, which according to them in "unpolluted" rain represents less than $20 \%$ of the total acidity. Thus, they claim, the amounts of sulphuric or nitric acid present in acid rain at pH 4.3 represent a fourfold increase, not the twentyfold increase reported.

Many investigators accept the fact that atmospheric deposition is acidic to varying degrees. However, they do not all agree that it alone causes surface water acidification. Some believe that surface water acidification is caused by factors other than atmospheric deposition. This report, in subsequent sections, explores the potential contribution of various factors to surface water acidification.

\subsection{DETERMINATION OF ACIDITY IN SURFACE WATERS}

Two methods have been used to measure the acidity of surface water - $\mathrm{pH}$ and alkalinity. $\mathrm{pH}$ 's are generally measured to compare the historical $\mathrm{pH}$ data with the recent data in order to establish the surface water acidification trend. However, the difficulty associated with the measurement of dissociated and undissociated hydrogen ions with $\mathrm{pH}$ meters is overcome by measuring the alkalinity of solution. Acidification of water is measured as a loss of alkalinity.

The alkalinity of a water body is its acid neutralizing capacity or buffering capacity. The ability to resist decreases in $\mathrm{pH}$ is derived from aqueous species which neutralize $\mathrm{H}^{+}$ions as they are added and thereby offset the increase in free $\mathrm{H}^{+}$ion concentration. The major acid-neutralizing species in most surface waters is the bicarbonate ion, $\mathrm{HCO}_{3}{ }^{-}$, which combines with hydrogen ions to form carbon dioxide and water:

$$
\mathrm{HCO}_{3}{ }^{-}+\mathrm{H}^{+} \rightarrow \mathrm{CO}_{2}(\mathrm{aq})+\mathrm{H}_{2} \mathrm{O}
$$

The alkalinity is defined as the concentration of all such hydrogen-ion acceptors minus the free hydrogen ion concentration (Gherini et al. 1984):

$$
\underset{\text { Or }}{\text { Alk }}=\left[\mathrm{HCO}_{3}^{-}\right]+2\left[\mathrm{CO}_{3}{ }^{2-}\right]+\left[\mathrm{OH}^{-}\right]+\left[\text {other } \mathrm{H}^{+} \text {-ion acceptors }\right]-\left[\mathrm{H}^{+}\right]
$$

where

$$
\begin{aligned}
& {[]=\text { molar concentrations, }} \\
& \text { A]k }=\text { alkalinity, and } \\
& \text { ANC }=\text { Acid neutralizing capacity } .
\end{aligned}
$$


In low alkalinity waters, the concentration of the "other $\mathrm{H}^{+}$-ion acceptors" often becomes large relative to the total concentration of bicarbonate, carbonate, and hydroxide (Gherini et a1. 1984). These other $\mathrm{H}^{+}$-ion acceptors include organic substances with carboxyl (- $\mathrm{COOH}$ ) and phenolic hydroxyl groups $(-\mathrm{OH})$ and the monomeric aluminum species and their complexes, for example,

$$
\begin{aligned}
& \mathrm{R}-\mathrm{COO}^{-}+\mathrm{H}^{+} \rightarrow \mathrm{R}-\mathrm{COOH} \text { (organic acid) } \\
& \mathrm{Al}(\mathrm{OH})_{3}+\mathrm{H}^{+} \rightarrow \mathrm{Al}(\mathrm{OH})_{2}^{+}+\mathrm{H}_{2} \mathrm{O} \\
& \mathrm{Al}(\mathrm{OH})_{2}^{+}+2 \mathrm{H}^{+} \rightarrow \mathrm{Al}^{3+}+2 \mathrm{H}_{2} \mathrm{O}
\end{aligned}
$$

Thus, for low alkalinity waters, equation [4] has been modified (Tetra Tech Inc. 1984) to include the above terms:

$$
\begin{aligned}
\mathrm{ANC}= & {\left[\mathrm{HCO}_{3}{ }^{-}\right]+2\left[\mathrm{CO}_{3}{ }^{2-}\right]+\left[\mathrm{RCOO}^{-}\right]+\left[\mathrm{Al}(\mathrm{OH})^{2+}\right] } \\
& +2\left[\mathrm{Al}(\mathrm{OH})_{2}^{+}\right]+4\left[\mathrm{Al}(\mathrm{OH})_{4}^{-}\right]+\left[\mathrm{OH}^{-}\right]-\left[\mathrm{H}^{+}\right]
\end{aligned}
$$

To maintain charge balance between cations and anions in solution, (the electroneutrality conditions), equation [8] is further modified to:

$$
\begin{aligned}
2 & {\left[\mathrm{Ca}^{2+}\right]+2\left[\mathrm{Mg}^{2+}\right]+\left[\mathrm{Na}^{+}\right]+\left[\mathrm{K}^{+}\right]+3\left[\mathrm{Al}^{3+}\right] } \\
& \left.+2[\mathrm{~A}](\mathrm{OH})^{2+}\right]+\left[\mathrm{Al}(\mathrm{OH})_{2}^{+}\right]+\left[\mathrm{H}^{+}\right] \\
& =\left[\mathrm{HCO}_{3}{ }^{+}\right]+2\left[\mathrm{CO}_{3}{ }^{2-}\right]+\left[\mathrm{NO}_{3}\right]+2\left[\mathrm{SO}_{4}{ }^{2-}\right] \\
& \left.+\left[\mathrm{Cl}^{-}\right]+\left[\mathrm{OH}^{-}\right]+\left[\mathrm{RCOO}^{-}\right]+[\mathrm{A}](\mathrm{OH})_{4}^{-}\right]
\end{aligned}
$$

Combining the above two equations [8] and [9] yields

$$
\begin{aligned}
\text { ANC }= & \text { Ecations } \left.\left.- \text { Eanions }+3[\mathrm{~A}]^{3+}\right]+3[\mathrm{~A}](\mathrm{OH})^{2+}\right] \\
& \left.+3[\mathrm{~A}](\mathrm{OH})_{2}^{+}\right]+3\left[\mathrm{~A} 1(\mathrm{OH})_{4}^{-}\right],
\end{aligned}
$$

or

$$
=\text { Ecations }- \text { Eanions }+3 A L_{T}
$$

where,

$$
\begin{aligned}
& \text { Ecations } \equiv \text { the sum of base cations } \equiv 2\left[\mathrm{Ca}^{2+}\right]+2\left[\mathrm{Mg}^{2+}\right]+\left[\mathrm{Na}^{+}\right]+\left[\mathrm{K}^{+}\right] \\
& \text {Eanions } \equiv \text { the sum of acid anions } \equiv 2\left[\mathrm{SO}_{4}{ }^{2-}\right]+\left[\mathrm{NO}_{3}{ }^{-}\right]+\left[\mathrm{Cl}^{-}\right]+\left[\mathrm{RCOO}^{-}\right] \text {, and } \\
& \left.{ }^{A}\right]_{\mathrm{T}} \equiv \text { total dissolved aluminum, mole/L. }
\end{aligned}
$$

In neutral water, the concentration of dissolved aluminum species is near zero. In such water, ANC or alkalinity equals scations - Eanions, with these two terms defined as shown above. If the acid neutralizing capacity (ANC) or alkalinity has a negative value, it indicates acidification. In acidic waters where dissolved aluminum species are present, aluminum species must be included in calculations; otherwise, the ANC value will be incorrect (Tetra Tech Inc. 1984). This is a direct consequence of the electroneutrality condition. The alkalinity of a water can be measured by the direct 
titration method or by determination of cations and anions and calculations based upon charge-balance considerations as shown in equation [11] above.

Recently, Herczeg et al. (1985) developed a new method for monitoring temporal trends in the acidity of fresh waters. They contend that the present strategies for monitoring such trends will not yield results sensitive enough to detect changes in acidity even on a ten-year time scale. They proposed a method based on calculations using equilibrium relationships and precise measurements of dissolved inorganic carbon (DIC) and partial pressure of $\mathrm{CO}_{2}\left(\mathrm{PCO}_{2}\right)$. They claim that the new method eliminates biases inherent in $\mathrm{pH}$ electrode determinations, and minimizes the perturbations in acidity caused by changes in the $\mathrm{PCO}_{2}$ of lake waters associated with biological cycles.

\subsection{SENSITIVE WATERS}

Historically, alkaline data for freshwater were presented less commonly than were $\mathrm{pH}$. Alkalinity, measured by the titration method, now is often used as an index of lake sensitivity to acidification. Some confusion exists in the literature regarding the use of the term "sensitive." Chemical sensitivity has been defined on the basis of a $\mathrm{pH}$ and acid titration curve, where "sensitive" implies that small increments of added acid produce large changes in $\mathrm{pH}$ (Faust and McIntosh 1983). This chemically oriented definition can be biologically misleading. From an ecological standpoint a lake is sensitive when additional inputs of acid result in definite biological changes, not just a lowering of $\mathrm{pH}$ (Kling and Grant 1984). In many reviewed papers the term "sensitive" is loosely used.

Hendrey et al. (1980a) defined sensitive waters as those with alkalinities below $200 \mu \mathrm{eq} / \mathrm{L}$, a level low enough to be neutralized by acid deposition and runoff. Gibson et al. (1983) have further classified sensitive waters. They suggested that: waters with alkalinities of less than $50 \mu \mathrm{eq} / \mathrm{L}$ be termed extremely sensitive; those in the range of 50 to $100 \mu \mathrm{eq} / \mathrm{L}$ be termed very sensitive; those in the range of 100 to 200 $\mu \mathrm{eq} / \mathrm{L}$ be termed sensitive; and, those with alkalinities above $200 \mu \mathrm{eq} / \mathrm{L}$ to be termed nonsensitive. However, Canfield (1983) classified waters with alkalinities in the range of 200 to $400 \mu \mathrm{eq} / \mathrm{L}$ as moderately sensitive. Based on these criteria, many investigators have predicted the vulnerability of lakes and streams to acidification (Gibson et a1. 1983; Haines et a1. 1983; Scruton 1983; Kling and Grant 1984; and National Wildlife Federation 1984).

Kramer (1976) and Galloway et al. (1978) suggested that the calcite saturation index is a better index of vulnerability of lakes to acidification. The calcite saturation index (CSI) is defined as the negative logarithm of the degree of saturation of a natural water with respect to $\mathrm{CaCO}_{3}$, and is expressed as (Kramer 1981):

$$
\mathrm{CSI}=-\log \frac{(\mathrm{Ca})\left(\mathrm{HCO}_{3}\right)}{(\mathrm{H}) \mathrm{K}}
$$

where ( ) are ion molar activities and the equilibrium constant $\mathrm{K}$ is for $\mathrm{CaCO}_{3}+\mathrm{H}^{+}=$ $\mathrm{Ca}^{2+}+\mathrm{HCO}_{3}{ }^{-}$. In dilute solutions, concentrations, [ ], are assumed equal to activities. 
Rearrangement gives

$$
\mathrm{CSI}=\log \mathrm{K}-\log [\mathrm{Ca}]-\log \left[\mathrm{HCO}_{3}\right]-\mathrm{pH}
$$

where logk $=2.582-0.242 t$, $t$ being the temperature $\left({ }^{\circ} \mathrm{C}\right)$. Glass and Loucks $(1980)$ suggested that lakes with CSI values of less than 1 are not susceptible or damaged by acid loading, because such waters are saturated with respect to calcite. Lakes having CSI values between 1 and 2 may be susceptible to change, and lakes with values between 2 and 3 are classified as probably susceptible to change. Lakes with CSI values between 3 and 4 are classified as susceptible to change, and lakes with CSI values greater than 4 are classified as highly susceptible to change. Using this criterion, Haines et al. (1983) observed that of surveyed New England lakes and streams, 15\% had a CSI value below $1,26 \%$ had a CSI value between 1 and 3 , and $59 \%$ had a CSI value greater than 3 . Glass and Loucks (1980) calculated CSI's for 85 lakes in northern Minnesota, an area that does not receive acidic precipitation. They found that $11 \%$ had a CSI value of less than 1 , $53 \%$ had a CSI of 1 to 3 , and $36 \%$ had a CSI value greater than 3 . Canfield (1983), using this criterion, found $36 \%$ of sampled florida lakes to be highly unstable relative to acid loading and possibly vulnerable to reduction in $\mathrm{pH}$ and alkalinity by acidic precipitation.

Haines et al. (1983) have claimed that the CSI does not provide any predictive ability superior to $\mathrm{pH}$ and alkalinity measurements and represents an additional mathematical manipulation. This is not surprising because CSI is calculated from both $\mathrm{pH}$ and alkalinity as well as from calcium (equation [12]). Because alkalinity can be measured easily and does not require an additional mathematical manipulation, it appears that of the two indices, alkalinity is a better index of lake sensitivity to acidification. 
3.

ACIOIC WATERS AND THEIR REACTION PRODUCTS

Acidification of waters may be defined as the decrease in acid neutralizing capacity. In almost all natural waters the neutralizing capacity is governed by the amount of dissolved bicarbonate. Most of this bicarbonate is produced through the carbonic acid weathering reaction in the surrounding soil and bedrock as shown below for limestone, dolomite, and silicate:

$$
\begin{aligned}
& \mathrm{H}_{2} \mathrm{O}+\mathrm{CO}_{2} \rightarrow \mathrm{H}_{2} \mathrm{CO}_{3} \\
& \mathrm{CaCO}_{3}+\mathrm{H}_{2} \mathrm{CO}_{3} \rightarrow \mathrm{Ca}\left(\mathrm{HCO}_{3}\right)_{2} \text { or } \mathrm{Ca}^{2+}+2 \mathrm{HCO}_{3}{ }^{-} \\
& \mathrm{CaMg}\left(\mathrm{CO}_{3}\right)_{2}+2 \mathrm{H}_{2} \mathrm{CO}_{3} \rightarrow \mathrm{Ca}^{2+}+\mathrm{Mg}^{2+}+4 \mathrm{HCO}_{3}- \\
& \mathrm{CaAl}_{2} \mathrm{Si}_{2} \mathrm{O}_{8}+3 \mathrm{H}_{2} \mathrm{O}+2 \mathrm{CO}_{2} \rightarrow \mathrm{Ca}^{2+}+2 \mathrm{HCO}_{3}{ }^{-}+\mathrm{Al}_{2} \mathrm{Si}_{2} \mathrm{O}_{5}(\mathrm{OH})_{4}^{4-}
\end{aligned}
$$

Lakes, streams, and other water bodies with the presence of bicarbonate, carbonate, and anions are often referred to as alkaline lakes. In recent years it has been claimed that these alkaline lakes, particularly those with low alkalinity, have become acidic due to atmospheric deposition of acidic substances, particularly sulphuric and nitric acids.

Effects of acidic atmospheric deposition on surface water chemistry depend largely on the manner in which precipitation reaches the body of water. Atmospheric acids may reach a watershed in precipitation (rain or snow) or in dry deposition, and may be delivered directly to a waterbody or through its drainage basin. Hydrogen ions deposited directly on a water body may reduce the alkalinity of the water and depress its $\mathrm{pH}$. If $\mathrm{pH}$ is depressed to a considerable extent, for example to between 4 to 5 , it may mobilize toxic metals such as aluminum, zinc, lead, and so forth from the lake sediments. Above $\mathrm{pH} 6.5$, these metals generally precipitate out of water or are adsorbed on sediment particles.

Acids deposited on the terrestrial component of the watershed generally participate in more complex processes in the soil (Brady 1974; Dickson 1980). $\mathrm{H}^{+}$that is deposited from the atmosphere may be buffered by reactions in the soil. The atmospheric $\mathrm{H}^{+}$also competes with carbonic acid weathering. If carbonate minerals are present then the $\mathrm{H}^{+}$may react with them, releasing bicarbonate anion and calcium and magnesium cations, as shown below:

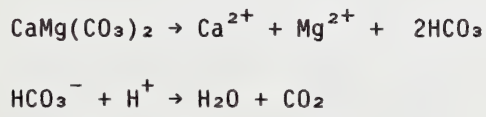

As the $\mathrm{pH}$ of soil decreases, so does the dissociation of carbonic acid to $\mathrm{H}^{+}$and $\mathrm{HCO}_{3}{ }^{-}$. At this stage, mineral acid weathering predominates over carbonic acid weathering and reaction of $\mathrm{H}^{+}$with carbonate minerals releases calcium and magnesium and reduces alkalinity (equations [18] and [19]). Some $\mathrm{H}^{+}$may react with silicates or other minerals in the soil, releasing metal cations (equation [17]). Thus, a substantial portion of $\mathrm{H}^{+}$may not reach the aquatic environment. $\mathrm{H}^{+}$from the atmospheric deposition may also participate in cation exchange reactions in the soil. In this type of reaction, 
$\mathrm{H}^{+}$is exchanged with metal cations in the soil if it has a high cation exchange capacity $(C E C)$. It has been suggested, that cations on the cation exchange complex react very rapidly with $\mathrm{H}^{+}$in solution, whereas the release of cations from primary or secondary minerals is very slow (Panel on Processes of Lake Acidification 1984). If the CEC is low (less than $20 \mu e q / 100 \mathrm{~g}$ ), then a smaller fraction of $\mathrm{H}^{+}$may be exchanged with cations, or none at all. When this occurs $\mathrm{H}^{+}$accumulates in soil. If the $\mathrm{H}^{+}$concentration continues to increase and the $\mathrm{pH}$ of the soil continues to drop below 6.0, toxic metals such as aluminum become more soluble in the aqueous medium and are mobilized. For example, aluminum is mobilized as free aluminum $(A)^{3+}$ ) or as the aluminum complex of fluoride, hydroxide, sulphate, and organic carbon ligands (Driscoll 1980) as shown by a few examples below:

$$
\begin{aligned}
& \mathrm{Al}(\mathrm{OH})_{3}+3 \mathrm{H}^{+} \rightarrow \mathrm{Al}^{3+}+3 \mathrm{H}_{2} \mathrm{O} \\
& \mathrm{Al}^{3+}+2 \mathrm{H}_{2} \mathrm{O} \rightarrow \mathrm{Al}(\mathrm{OH})_{2}^{+}+2 \mathrm{H}^{+} \\
& \mathrm{Al}^{3}+4 \mathrm{H}_{2} \mathrm{O} \rightarrow \mathrm{Al}(\mathrm{OH})_{4}^{-}+4 \mathrm{H}^{+} \\
& \mathrm{Al}^{3+}+\mathrm{F}^{-} \rightarrow \mathrm{AlF}^{2+} \\
& \mathrm{Al}^{3+}+\mathrm{SO}_{4}{ }^{2-} \rightarrow \mathrm{AlSO}_{4}^{+}
\end{aligned}
$$

The solubility of aluminum is $\mathrm{pH}$-dependent. Its inorganic form determines whether it increases with increasing acidity (equation [20]) or with increasing alkalinity (equation [22], Driscoll 1980). $\mathrm{H}^{+}$concentrations in soil may also be increased due to the internal production of $\mathrm{H}^{+}$by humic substances in soil. This internally produced $\mathrm{H}^{+}$can also undergo reactions outlined in equations [18] through [24] and mobilize toxic metals such as aluminum (Krug and Frink 1983a,b). In any event, $H^{+}$ that remains after mineral weathering and ion exchange processes, and that contributed by organic acids reaches the aquatic environment, along with leached metal cations and mobile anions - usually sulphate, nitrate, and organic anions. In most cases, a relatively small fraction of acidic substances is deposited directly on a water body from the atmosphere. The potential for surface water acidification, therefore, depends on the flow path that precipitation follows in a watershed before reaching a lake or stream.

When ions are transported from soil to the aquatic environment, equivalent amounts of cations and anions move together to maintain electrochemical neutrality. Thus, the transport of $\mathrm{H}^{+}$and metal cations from the soil to the aquatic environment requires equivalent amounts of mobile anions. These anions are provided by the acid deposition as sulphate and nitrate anions. Sulphate ions are quite mobile. However, their mobility depends on the sulphate adsorption capacity (SAC) of the soil (Galloway et a1. 1984). If the SAC of the soil is undersaturated, most of the $\mathrm{SO}_{4}{ }^{2-}$ is retained in the soil; if it is saturated, then $\mathrm{SO}_{4}{ }^{2-}$ becomes mobile. Reports on a number of North American and Scandinavian watersheds (Drablos and Tollan 1980) have indicated little retention of sulphate in the watershed. Nitrate ions, like sulphate ions, are also quite mobile but their mobility depends on the biogeochemical processes in the catchment area, for example, uptake of nitrate by vegetation (Overrein et a1. 1980), and on the 
rate of water movement. During the storm events $\mathrm{NO}_{3}{ }^{-}$becomes highly mobile. However, in most cases sulphate tends to be the anion that balances cations. Organic acid anions from the soil and from acid deposition can also contribute towards the maintenance of electrochemical neutrality.

In addition to the atmospheric contribution of $\mathrm{SO}_{4}{ }^{2-}$ and $\mathrm{NO}_{3}{ }^{-}$, sulphur minerals (e.g., pyrite and $\mathrm{NH}_{4}{ }^{+}$) can also contribute $\mathrm{SO}_{4}{ }^{2-}$ and $\mathrm{NO}_{3}{ }^{-}$ions and $\mathrm{H}^{+}$through oxidation reactions:

$$
\begin{aligned}
& \mathrm{FeS}_{2}+7 / 2 \mathrm{O}_{2}+\mathrm{H}_{2} \mathrm{O} \rightarrow \mathrm{Fe}^{2+}+2 \mathrm{SO}_{4}{ }^{2-}+2 \mathrm{H}^{+} \\
& 4 \mathrm{NH}_{4}{ }^{+}+8 \mathrm{O}_{2} \rightarrow 4 \mathrm{NO}_{3}{ }^{2-}+8 \mathrm{H}^{+}+4 \mathrm{H}_{2} \mathrm{O}
\end{aligned}
$$

In summary, in areas not receiving acidic precipitation and marine salts in aerosols, calcium and magnesium should be derived solely from weathering and leaching of carbonate minerals by $\mathrm{H}_{2} \mathrm{CO}_{3}$ and by organic acids. In such areas, calcium plus magnesium should be electrochemically equivalent to alkalinity. In areas receiving acidic precipitation, additional calcium and magnesium may be leached from watersheds and excess hydrogen ions may reduce alkalinity. Thus, lakes in such watersheds have calcium plus magnesium equivalencies greater than that of alkalinity, and excess cations are balanced by non-marine sulphate and nitrate (Almer et al. 1974; Dickson 1980). 
4.

EFFECTS OF QUANTITY AND QUALITY OF ATMOSPHERIC DEPOSITION ANO EPISODIC EVENTS ON SURFACE WATER CHEMISTRY

There is general agreement among investigators on two points concerning surface water acidification. The first point of agreement is that near a point source of acidforming emissions, surface water acidification is caused by anthropogenic input of acidifying substances (such as is observed in Sudbury, Ontario area studies; Beamish 1976). The second point is that factors of quantity and quality of atmospheric deposition affect the process of surface water acidification. However, disagreement arises concerning the mechanism of acidification of remotely located lakes and streams by long-range transport of atmospheric acid precursors. This controvery arises because inputs of acidic substances to surface waters can occur by three pathways: (1) directly from the atmosphere; (2) indirectly from the atmosphere via runoff over or through the watershed; and (3) from the watershed itself, from internal generation of hydrogen ions, for example, acidification of the soil which in turn leads to water acidification (Marcus et a1. 1983; Mason and Seip 1985). The disagreement has arisen because of a lack of quantitative data on the inputs of acidic substances to surface waters by each of these pathways. Gorham and McFee (1980) recognized the lack of such quantitative data and suggested the need for mass-balance studies to determine origins of acids, metals, and organic molecules entering aquatic ecosystems. It appears that attempts are now being made to quantify these inputs either by direct measurements of waters or by estimation with the use of models (Dillon et al. 1982; Wright 1983; and Gherini et al. 1984). Dillon et al. (1982) conducted mass-balance studies on 11 lakes and their watersheds in the Sudbury and Muskoka-Haliburton areas of Ontario. Wright (1983) studied input-output budgets for a small acidified lake and its catchment area at Langtjern, southern Norway. These authors have reported that they have quantified inputs of acidic substances to lakes by direct atmospheric deposition. Instead, it appears that they have quantified input of substances from the entire watershed via streamflow to lakes. They have not quantified indirect input of acidic substances from the atmosphere via runoff over and through the watershed (pathway 2) and input of substances from the watershed due to internal generation of hydrogen ions (pathway 3 ). To predict the relative contribution of acidifying substances from the various hydrologic pathways in a watershed, Gherini et a1.(1984), as a part of the Integrated Lake-Watershed Acidification Study (ILWAS), developed a model for two lakes (Woods and Panther) in the Adirondack Mountains. Simulation of their model showed that the routing of water through soils (shallow versus deep flow) largely determined the extent of lake acidification. Analysis of the two lake basins using the model and field data indicated that the internal production of acidity was approximately twothirds the amount of the atmospheric loading. The Integrated LakeWatershed Acidification Study conducted in the Adirondack Mountains was the first study to quantify inputs of acidifying substances to surface waters by various hydrologic pathways, using the simulated model.

4.1 EFFECT OF PRECIPITATION OUANTITY

Precipitation volumes influence surface water chemistry depending upon the relative inputs of acidifying substances by the three pathways mentioned above. Elzerman 
(1983) reported that changes in the chemical composition of stream water during precipitation events are important for the following three reasons: (1) significant portions of total annual fluxes of dissolved and particulate materials can occur during storm events; (2) some products of neutralization and other reactions of rainwater with watershed components will appear in stormflows; and (3) excursions in chemical composition beyond important threshold values may occur, for example, transient events in which aluminum reaches toxic concentrations in the streamwater.

It has been observed that inputs of hydrogen ions and other related ions to aquatic environments increase as precipitation volume increases (Powers 1929; Likens et a1. 1977; Rosenqvist 1978a,b; Elzerman 1983; and Harte et a1. 1985). During 1925-26, Powers (1929) observed that rapid increases in runoff volume following heavy precipitation to the Great Smoky Mountains was accompanied by a rapid drop in stream pH from 4.89 to 4.29. During the heavy precipitation event the stream water developed a yellow tinge which disappeared after a few days. Powers attributed this to leaching of naturally acidic soils.

Likens et al. (1977) observed that during the period 1964-1974, hydrogen ion concentrations in Hubbard Brook were directly correlated with discharge volumes $\left(r^{2}=0.73\right)$. Likens et al. suggested that increase in $\mathrm{H}^{+}$can be partially explained by the amount of precipitation and that factors other than precipitation may also be important for increased load of $\mathrm{H}^{+}$.

Rosenqvist (1978b) reported that in the summer of 1972, the $\mathrm{pH}$ in the Birkenes Creek, southern Norway, dropped from 5.6 to 4.4 (i.e., 5 times the acidity of rainwater, from $10^{-5.1}$ moles $\mathrm{H}^{+} / \mathrm{L}$ to $10^{-4.4}$ moles $\mathrm{H}^{+} / \mathrm{L}$ after a heavy rainfall of mainly unpolluted rain. Rosenqvist did not report the chemical composition of the rainwater. He attributed the changes in the $\mathrm{pH}$ of the creek water after the precipitation event to cation exchange processes in the soil and increased leaching rates for naturally occurring hydrogen ions.

These observations suggest that the changes in chemical composition of stream water during precipitation events are greatly influenced by the existing soil chemistry, rather than strictly by hydrogen ion concentration in the rain. For example, large amounts of $\mathrm{H}^{+}$and $\mathrm{Al}^{3+}$ occur in soluble form in naturally highly acidic coniferous forest watersheds and all that is required to flush these ions out is rain, whether it be $\mathrm{pH}$ 7.0 or 4.3. During storm events, large amounts of these ions will be washed out, particularly on steep slopes because of subsurface flow through 0 and $A$ horizons where most of the internally produced $\mathrm{H}^{+}$and $\mathrm{Al}^{3+}$ ions are generated. Moreover, if soil has a $\mathrm{pH}$ of 4.1 and contains large amounts of $\mathrm{H}^{+}$and $\mathrm{Al}^{3+}$ and is highly buffered by weak acids (e.g., 300-2000 keq/ha), the influence of rain of low pH 4.3 on changes in chemical composition of stream water will be difficult to assess, particularly when the rain event contains far less than one keq/ha of hydrogen ions. During the first phase of the rain event, all soluble chemical components of the soil (e.g., $\mathrm{SO}_{4}{ }^{2-}, \mathrm{NO}_{3}{ }^{-}, \mathrm{Cl}^{-}$) will be elevated in concentration and it may have nothing to do with the chemistry of the rain.

Elzerman (1983) studied storm-induced chemical changes in stream water of the Lake Issaqueema watershed in South Carolina for the period 1981-1982. He observed that during the stormflow, pH dropped slightly (maximum $0.6 \mathrm{pH}$ units), and so did the concentration of bicarbonate ion (base concentration, $198 \mu \mathrm{eq} / \mathrm{L}$; stormflow concentration 
$147 \mu \mathrm{eq} / \mathrm{L})$. The concentration of major cations $\left(\mathrm{Mg}^{2+}, \mathrm{Ca}^{2+}\right.$, and $\left.\mathrm{Na}^{+}\right)$, showed a dilution effect due to increased stream flow, causing temporary acidification of stream water (equation [11], Section 2.2). The concentrations of $\mathrm{SO}_{4}{ }^{2-}$ and aluminum showed increases (baseflow concentrations 85 and $10 \mu \mathrm{eq} / \mathrm{L}$, respectively, and stormflow concentrations 143 and $100 \mu \mathrm{eq} / \mathrm{L}$, respectively). Harte et al. (1985) made similar observations for surface waters in a high elevation watershed in the Colorado Rockies. They observed that the volume of precipitation caused changes in alkalinity by varying the hydrologic flushing rates in the watershed; however, they did not specify the degree of change in alkalinity. Changes in alkalinity can occur due to increased physical and chemical weathering of soils, subsoils, and bedrock as a consequence of increased hydrogen ion loadings and runoff rates accompanying increased rainfall volumes. This can result in increased concentrations of weathered chemicals in surface waters.

\subsection{EFFECTS OF PRECIPITATION QUALITY}

Like precipitation quantity, precipitation quality can also potentially affect surface water chemistry. Numerous chemical substances in addition to acids are transported in the atmosphere and deposited with precipitation. For example, in Norway, Lunde et a1. (1977) detected more than 450 organic compounds in precipitation. Organic compounds detected include alkanes, polycyclic aromatic hydrocarbons, phthlates, fatty acid esters, aldehydes, amines, pesticides, and polychiorinated biphenyls (Lunde et al. 1977; Strachan and Huneault 1979; and Alfheim et a1. 1980). Haines (1981) suggested that these compounds, which are of anthropogenic origin, are probably produced by combustion processes and thus are likely to be related to acidic precipitation. However, it is important to note that these compounds, unless present as organic acids or converted organic acids, do not contribute to surface water acidification.

The most noticeable examples of atmospheric precipitation impacts to watersheds and surface waters are associated with localized point source emissions. Examples include the area surrounding smelters near Sudbury, Ontario and that of Halifax County, Nova Scotia. Beamish (1976) cited Harvey's unpublished work on lakes near sudbury. Harvey measured the sulphate concentration of over 100 lakes and found concentrations were highest close to the smelters and decreased with distance from the smelters. Beamish (1976) made a similar observation for the concentration of $\mathrm{Ni}$ and $\mathrm{Cu}$ in lakes in the La Cloche Mountains, southwest of Sudbury. The mountain lakes contained high concentrations of $\mathrm{Ni}(5$ to $15 \mu \mathrm{g} / \mathrm{L}$ ) and $\mathrm{Cu}(2$ to $4 \mu \mathrm{g} / \mathrm{L}$ ) when compared to concentrations measured in lakes remote from major areas of industrialization ( $\mathrm{Ni}:<3 \mu \mathrm{g} / \mathrm{L}$; $\mathrm{Cu}$ : $<2 \mu \mathrm{g} / \mathrm{L})$.

Watt et al. (1979) compared concentrations of hydrogen and sulphate ions in 16 lakes from Halifax County. Concentrations of both ions decreased significantly with distance from the emission sources. They also observed that lake $\mathrm{pH}$ values had decreased significantly since the study of these lakes 21 years earlier. The decrease in $\mathrm{pH}$ was approximately $0.34 \mathrm{pH}$ units for lakes and ponds located on granitic rock (average pH in $1955=4.66$; in $1977=4.32$ ), and $0.65 \mathrm{pH}$ units for those located on metamorphic rocks (average $\mathrm{pH}$ in $1955=5.62$; in $1977=4.97)$. The increase in $\mathrm{SO}_{4}{ }^{2-}$ concentrations was about $27.91 \mu \mathrm{eq} / \mathrm{L}$, for lakes and ponds located on the granitic rocks (average $\mathrm{SO}_{4}{ }^{2-}$ in $1955=128.52 \mu \mathrm{eq} / \mathrm{L}$; in $1977=156.43 \mu \mathrm{eq} / \mathrm{L})$, and $47.5 \mu \mathrm{eq} / \mathrm{L}$ for those on metamorphic 
rocks (average $\mathrm{SO}_{4}{ }^{2-}$ in $1955=116.65 \mu \mathrm{eq} / \mathrm{L}$; in $1977=164.14 \mu \mathrm{eq} / \mathrm{L}$ ). Watt et a1. (1979) attributed the elevated hydrogen ion concentrations in lakes to sulphur emitting industries around Halifax. However, because these lakes and ponds contain high concentrations of dissolved organic carbon (average $D O C 10,000 \mu \mathrm{g} / \mathrm{L}$ ), natural humic substances may also be contributing to surface water acidification. It is difficult to speculate on this, however, because watt et a1. (1979) did not document colour values for these waters.

In addition to hydrogen, sulphate, copper, and nickel, other chemicals have been found above background concentration levels in surface waters as a result of localized emissions. These include lead, zinc, manganese, iron, nickel, mercury, vanadium, and cadmium (Gorham and McFee 1980). Haines (1981) observed that metal concentrations are higher in acidic precipitation than in non-acidic precipitation.

Although metal concentrations are highest in precipitation near smelters, highways, and urban areas, elevated levels have also been detected in remote areas. For example, mercury has been detected in precipitation at remote areas of Quebec and Ontario at concentrations an order of magnitude higher than in surface waters of those areas. Although mercury in the air may result from natural sources, increased acidity of precipitation appears to result in increased scavenging of mercury from air (Tomlinson et al. 1980).

\subsection{EFFECTS OF SNOWMELT}

Precipitation deposited as snow has been shown to affect surface water quality during snowmelts (Galloway et a1. 1980; Hendrey et al. 1980b; Johannes and Altwicker 1980; Johannessen et a1. 1980; Bjarnborg 1983; Cadle et al. 1984; and Schofield 1984). $\mathrm{pH}$ values in snow can range from 4.5 to 5.0 , and have been observed as low as 3.3 (Seip 1980a). The sulphate and nitrate values can average from 528 to $1056 \mu \mathrm{g} / \mathrm{L}$ and 686 to $1584 \mu \mathrm{g} / \mathrm{L}$, respectively (Cadle et al. 1984). The rapid release of acids from snowpack during the spring thaw can cause a temporary and sudden drop in the pH of poorly buffered lakes and streams. These $\mathrm{pH}$ drops have drastic effects on fish populations and are suggested to be the main cause of sphagnum moss invasion (Section 8.3 ) (Schofield 1976a,b; Hultberg 1977). While it is generally recognized that most of the acidity in snow is from $\mathrm{HNO}_{3}$ and $\mathrm{H}_{2} \mathrm{SO}_{4}$, two factors make their relative importance to the springtime acidification of lakes and streams uncertain. First, the stability of these species in the snowpack is questionable. Johannes et al. (1980) showed that sulphate is preferentially leached from the snowpack during the winter, thus increasing the importance of $\mathrm{HNO}_{3}$. Secondly, it is not clear how much of the $\mathrm{HNO}_{3}$ is biologically utilized during the melt period. Added to these uncertainties is the importance of the soil leaching of acidic substances by meltwater (Tetra Tech Inc. 1984). Cadle et al. (1984) inspected the snowpack concentrations of $\mathrm{SO}_{4}{ }^{2-}, \mathrm{NO}_{3}{ }^{-}, \mathrm{Cl}^{-}, \mathrm{H}^{+}, \mathrm{NH}_{4}^{+}, \mathrm{Ca}^{2+}, \mathrm{Mg}^{2+}, \mathrm{Na}^{+}$, and $\mathrm{K}^{+}$weekly and observed no loss of these species from the snowpack before the thaw period. Aging snow has been suggested to become progressively less acidic, perhaps due to hydrogen exchange with cations from organic materials (such as cone scales, seeds, leaves, twigs, bark fragments) in the snow pack (Hornbeck et al. 1977).

During the major spring thaw, the first meltwaters contain higher concentrations of ions than does bulk snow (Hendrey et al. 1980b; Johannes and Altwicker 1980; and Cadle et a1. 1984). It has been reported that $66-83 \%$ of $\mathrm{SO}_{4}{ }^{2-}, 50-61 \%$ of $\mathrm{NO}_{3}{ }^{-}$, and $40-52 \%$ of $\mathrm{H}^{+}$ 
in snow are released when the first $21-35 \%$ of the snow melts. This input of acid (pH "shock") results in a sudden drop of pH in streams or lakes (Galloway et a 1. 1980). The pH "shock" is commonly followed by peak flow and dilution of all major ions. Johannessen et al. (1980) observed that during and after snowmelt the streamwater concentration of ionic species relative to the baseflow value varies, and they suggested three stages of snowmelt. In the first stage, as the water flow increases with the initial melting, the concentrations of $\mathrm{Ca}^{2+}, \mathrm{Mg}^{2+}$, and $\mathrm{HCO}_{3}{ }^{-}$ions that are supplied by weathering are often for a short time at levels above those of baseflow. This is due to pressing out of older water in the catchment area (piston flow). This process is followed by a dilution of these ions due to mixing with snowmelt water, which contains a very low concentration of weathering ions, but a peaking concentration of the snowmelt ions $\mathrm{H}^{+}, \mathrm{NH}_{4}^{+}, \mathrm{Na}^{+}, \mathrm{NO}_{3}{ }^{-}$, $\mathrm{SO}_{4}{ }^{2-}$, and $\mathrm{Cl}^{-}$. Later, at the third stage, because the remaining snow contains most of the water but little of the ions, the snowmelt becomes more dilute with respect to these ions, and a dilution in concentration of the snowmelt ions in the stream water is observed. After spring snowmelt is complete and discharge again decreases to just above baseflow levels, the concentrations of $\mathrm{Ca}^{2+}, \mathrm{Mg}^{2+}, \mathrm{Na}^{+}, \mathrm{SO}_{4}{ }^{2-}, \mathrm{Cl}^{-}$, and $\mathrm{HCO}_{3}{ }^{-}$are usually lower than in baseflow prior to snowme1t. This suggests that the "baseflow reservoir" has been renewed and the catchment needs time to recover.

Jeffries et a1. (1979, cited in Marcus et al. 1983) showed that hydrogen ion discharges from three Canadian watersheds varied proportionally with discharge volumes during the two-month, spring snowmelt. Precipitation was very light during this period and thus had little effect on stream discharge volume and composition. It was found that runoff acidity was not relatively higher in the early periods of snowmelt as one would expect. This suggests that sources in addition to snowpack accumulation (for example, leaching of hydrogen ions from soil) contributed to the discharge hydrogen ion loadings. Seip (1980a), in his article on acid snow-snowpack chemistry and snowmelt, cited various articles dealing with snowmelt chemistry. He suggested that increased hydrogen ion concentrations in meltwater reflect not only snow accumulations of hydrogen ions, but also the influences of overwinter accumulations of ions in soils. He pointed out that the contact between soil and meltwater is very important and it is this contact which determines the meltwater chemistry. A number of factors that contribute to meltwater chemistry through this contact are the degree of soil freezing, air temperature, thickness of snow cover, texture of soil, and type of vegetation. Seip (1980a) cited the work of Rueslatten and Jorgensen in Norway, who explained the increase of hydrogen ion concentrations in meltwater as resulting from leaching of organic acids and from cation exchange processes in the humus layer of the soil. However, the samples were not analysed for dissolved organic carbon, sulphate, or chloride thus making their discussion of the mechanism speculative. Schofield (1984) reported temporal acidification of three lakes in the Adirondack Mountains during snowmelt. He attributed it to base cation dilution and increased strong acid anion levels, particularly $\mathrm{NO}_{3}^{-}$levels (equation [11], Section 2.2). These changes in surface water chemistry were related to an upward shift in flow paths from groundwater-dominated base flow (mineral horizon) to shallow interflow (humus layer) during increased snowmelt discharge. During the snowmelt period, elevated levels of aluminum were also observed. Most of the mobilized aluminum was in the inorganic form and very little was in the organically complexed form. 
Hydrogen ions in snow are primarily associated with sulphate and nitrate depositions (Johannes and Altwjcker 1980). In many parts of the world sulphate ion is dominant in the snowpack. The reverse is true in the Adirondack Mountains (Tetra Tech Inc. 1983, 1984) where nitric acid commonly dominates the acidity in winter snow storms and during snowmelt.

Thus, the surveyed literature indicates that factors of precipitation quantity and quality, and episodic events (snowmelt), affect surface water acidification. What these studies do not clarify, however, is how this acidification occurs, that is the manner or mechanism by which surface water are acidified. In the next section this topic is discussed by presenting two views on the cause of surface water acidification. 
One of the major controversies on the subject of surface water acidification concerns the source of protons or hydrogen ions causing the acidification. Some researchers believe that atmospheric inputs of anthropogenically derived acidic substances cause acidification of surface waters with resultant, serious effects on fish (Beamish 1976; Overrein et a1. 1980; Rahel and Magnuson 1983; and Somers and Harvey 1984); others propose that internal proton production in soils, intensified by changes in land use practices, is the primary contributor to surface water acidification (Rosenqvist 1978a,b; Krug and Frink 1983a,b). There are various processes that produce or consume protons or hydrogen ions in terrestrial and aquatic ecosystems. Van Breemen et a1. (1984) have identified seven such processes, as outlined in Table 1.

Atmospheric input of acidic substances represents an external source of hydrogen ions, whereas the other six processes outlined in Table 1 represent internal proton sources, i.e., protons produced within the watershed.

While acidification of surface waters by direct precipitation is generally thought to be a minor factor, acid rain falling directly on lake surfaces can contribute to acidification. It depends on the alkalinity of the watershed, and the ratio of drainage area to lake area (Dillon et al. 1978; Panel on Processes of Lake Acidification 1984). In watersheds with granitic soils, rates of weathering are very low, as is the alkalinity of their drainage waters. For lakes in such areas, with small ratios of drainage area to lake area, direct inputs of acid rain may exceed inputs of alkalinity from the watershed, resulting in acidification of those lakes. One such lake has been found in south central ontario, Canada where the lake itself occupies $42 \%$ of the watershed area and the drainage area to lake area ratio is $1: 4$. The alkalinity of the lake in 1967 was reported as $33 \mu \mathrm{g} / \mathrm{L}$; in 1977 it measured approximately $10 \mu \mathrm{g} / \mathrm{L}$. From its watershed characteristics, it seems reasonable to assume, therefore, that its acidification is occurring through direct inputs of acid rain to the lake (Dillon et al. 1978). Krug and Frink (1983b) suggested that for low alkalinity lakes with drainage area to lake area ratios of 3-7, inputs of acid rain may be equivalent to a measurable fraction of the alkalinity supplied by the watershed. Hence, the relative contribution of external hydrogen ions (process 1, Table 1) and internal hydrogen ions (processes 2-7, Table 1) to acidification of lakes of this type must be assessed on an individual basis.

Rosenqvist (1978b) pointed out that surface water acidification is a commonly occurring natural process. It is not necessarily dependent upon external atmospheric sources of hydrogen ions. He put forward the view that acid precipitation causes only minor acidity of brook, river, and lake waters, and that major acidity of lakes is caused by acidic runoff from acid soils. He pointed out that runoff from such soil will be acidic regardless of the $\mathrm{pH}$ of rain, and experimentally demonstrated that it is the content of electrolytes and not the $\mathrm{pH}$ of precipitation which is important for acidification of runoff water. Wiklander (1946, cited by Krug and Frink 1983b) has shown that additions of neutral salts generally acidify leachate from acid soils more effectively than do strong acids, at the concentration present in acid rain. Rosenqvist (1978b) described acidification of runoff in terms of hydrology and soil acidity. Runoff from rapid snowmelts and heavy rains moves primarily through the organic-rich, acidic humus horizons and, therefore, is more acidic than runoff from gentle rains or slower snowmelts 


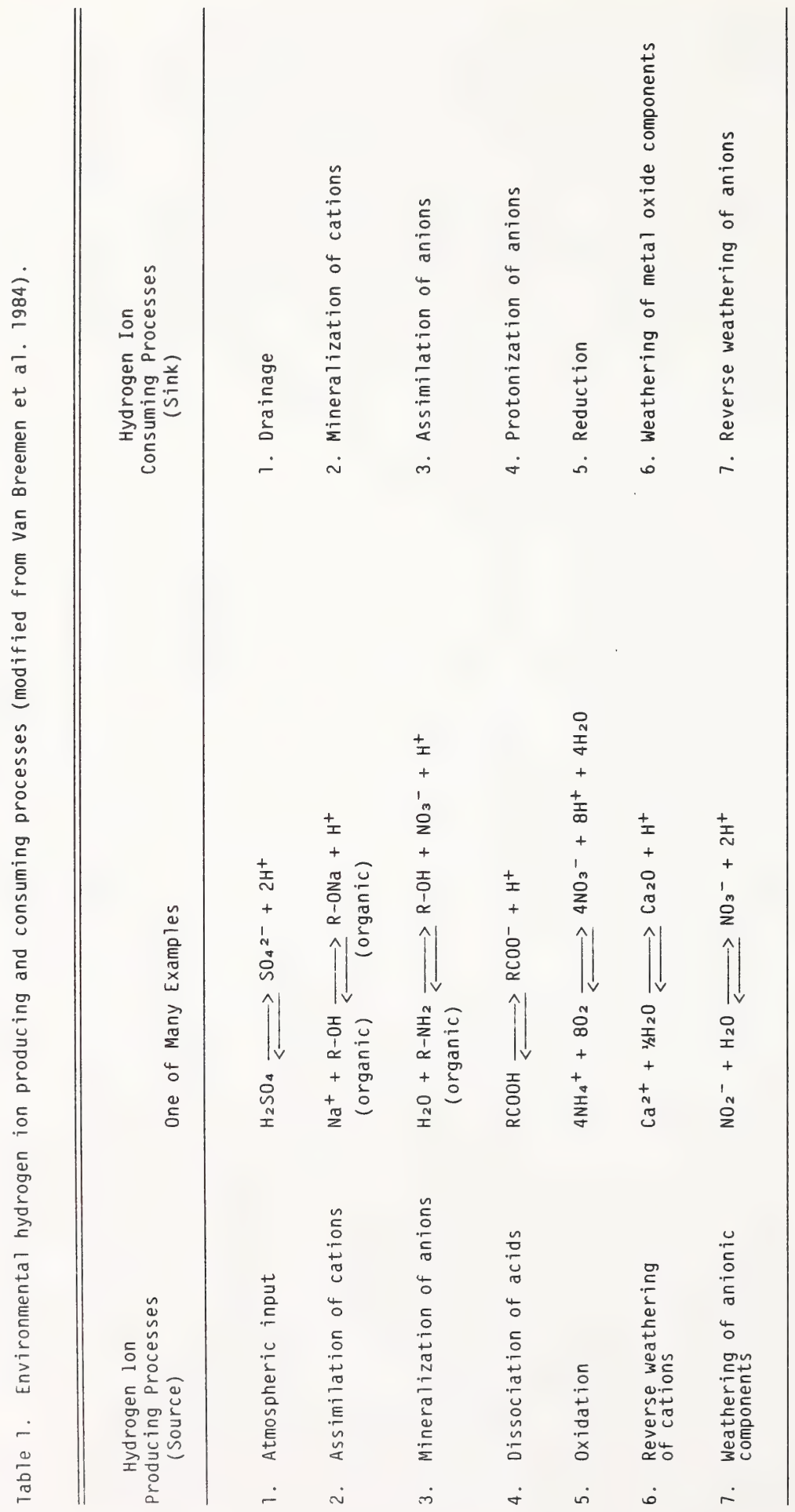


which percolate through near-neutral subsoil. He pointed out that areas of Scandinavia believed to be affected by acid rain are areas where there are also naturally acidic waters. This also appears to be true for some parts of North America (Patrick et al. 1981). Rosenquist et a1. (1980) reported that for high altitude regions of Norway where extensive areas of exposed bedrock exist, natural hydrogen ion production can range between 2000 and $5000 \mathrm{eq} / \mathrm{ha} / \mathrm{y}$, and airborne acidic inputs can range between 200 to 500 eq/ha/y. Based on these values, natural processes account for 85 to $95 \%$ of the total hydrogen ion flux in the region. Marcus et al. (1983) cited observations of Groterud (1981) which support the findings of Rosenqvist et al. (1980) for Norway. Groterud conducted lysimeter experiments with topsoils during heavy rains and snowmelt in the lake area near 0s10, Norway. He found that topsoils contributed about four times the hydrogen ion concentration to drainage as was contributed by natural precipitation to the area. Natural precipitation averaged $70 \mathrm{~cm} / \mathrm{y}$ at $\mathrm{pH} 4.4$.

Rosenqvist (1978b) also attributed acidification of surface waters in Norway to changes in land use practices. There, agricultural land has reverted to forest or heathland. The growing plants extract bases from the soil and at the same time contribute to considerable amounts of humus which becomes thicker and more acidic with time. The acidification potential of the humus is very high. He has estimated that the exchange acidity of the surface humus accumulated under a 90-year-old spruce forest is equivalent to approximately 1000 years of acid rain of $1 \mathrm{~m} / \mathrm{y}$ with $\mathrm{pH} 4.3$. Rosenqvist (1980) documented an increase in forested land and an increase of over 70\% in the volume of standing wood in southern Norway from 1927 to 1973. Rosenquist has stated that in Norway, particularly the southern part, the natural production of acid is many times higher than that derived from precipitation, and thus there is no reason to believe that acid deposition is the major reason for the acidification of surface waters. Based on this observation, it appears that humic soils are acidifying runoff in watersheds where there is incomplete neutralization of acids by mineral weathering.

Based on the reports of land use practices in the watersheds of acidified lakes, Krug and Frink (1983b), like Rosenqvist, have pointed out that regions experiencing acid rain are also undergoing dramatic regional changes in land use and, therefore, acid rain is not the only source of increasing acidity. One such example they cited is that of acidification of Nova Scotia lakes. For example, Watt et al. (1979) reported that a series of lakes and ponds in Nova Scotia were more acidic in 1977 than when examined 21 years earlier in 1955 (Section 4.2). Because the watersheds had been largely undisturbed between studies, acidification was attributed to acid rain. However, Krug and Frink (1983b) pointed out that the important factor in acidification is what happened in the watersheds before 1955. They noted that this area of Nova Scotia was treeless and barren due to destructive fires by miners in the early 1900's (Woodward 1906, cited by Krug and Frink 1983b). Therefore, they suggested that forest regrowth, accumulation of humus, and increased acidity of runoff water may have been the cause of the acidification.

Natural soil acidification has been reported by many investigators. Gorham et al. (1979) reported that augmented organic matter accumulations and soil microorganism biomasses increased carbonic acid and organic acid accumulations in soil. They also explained that nitrification of organic matter and ammonia to nitrate in the soil generates nitric acids. This process approximately adds $475 \mathrm{eq} / \mathrm{ha} / \mathrm{y}$ of hydrogen ions 
(Oden 1976). Gorham et a1. (1979) also stated that, in terms of biomass, organic sulphur equals about $10 \%$ of accumulated nitrogen. 0xidation of these sulphur compounds can yield enough sulphate ion and sulphuric acid to acidify soils. These acids which are produced in soils are washed out when the next runoff occurs.

Because of natural acidification processes, forest soils have become acidic over time. Soils in some coniferous forests have natural pH levels around 3.0 (Brady 1974). Sollins et a1. (1980, cited by Marcus et al. 1983) developed a hydrogen ion budget for a coniferous watershed in Oregon and established the predominance of internal hydrogen ion sources. They found that biological processes of vegetative cation exchange and microbial decomposition results in a net hydrogen ion flux of $3000 \mathrm{eq} / \mathrm{ha} / \mathrm{y}$, in the range found by Rosenqvist (1980), while during the study, the hydrogen ion concentration in the precipitation was $6.3 \mu \mathrm{g} / \mathrm{L}(\mathrm{pH} 5.2)$. They suggested that an increase in hydrogen ion concentration in precipitation to $100 \mu \mathrm{g} / \mathrm{L}(\mathrm{pH} 4.0$ ) would add only 300 eq/ha/y to the total natural hydrogen ion flux in the soil solution - about $10 \%$ more.

Studies by Likens et a1. (1977) at Hubbard Brook, New Hampshire, have shown that the acidic contribution from external atmospheric sources and internal watershed sources can be approximately equal. For Hubbard Brook Experimental Station they calculated that about $2000 \mathrm{eq} / \mathrm{ha} / \mathrm{y}$ of hydrogen ions are consumed by geological weathering. For 1963-74, the bulk precipitation supply of hydrogen ions averaged $865 \mathrm{eq} / \mathrm{ha} / \mathrm{y}$. Therefore, the remaining $1135 \mathrm{eq} / \mathrm{ha} / \mathrm{y}$ appeared to be contributed by internal watershed sources such as chemical and biological processes occurring within the soil.

Organic acids (humic acids) in humic soils can contribute to lowering of surface water $\mathrm{pH}$ due to runoff from soils. An example of this effect was reported by Ramberg (1981) for a small watershed in Central Sweden. A runoff brook fed by the water flowing through the upper organic layer of the forest soil had a two year mean pH of 4.9. When drainage ditches were dug one metre deep so that the water no longer flowed through the organic-rich soil and, therefore, had limited contact with it, the pH of the stream increased to a mean value of 5.8. The report did not indicate what proportion of hydrogen ions originated from soils or from atmospheric deposition. However, these were reported to be peat soils and Gorham et al. (1984b) have suggested that peat soils make a substantial contribution of hydrogen ions. Therefore, a high proportion of acidity in this Swedish brook may have been generated internally.

Johnson (1981) made similar observations for waters draining bog soils. He reported that natural, unpolluted waters draining surface and bog soils near Petersburg, Alaska, have $\mathrm{pH}$ levels below 4.7. He attributed the low pH values to leaching of organic acids.

Gorham et al. (1984b) have reported that where acid deposition is severe, the acidity of bog waters can be dominated by mineral acids. They cited, as an example, two bogs in the southern Pennine Mountains of England, whose waters were low in colour but high in hydrogen ions $(160 \mu \mathrm{eq} / \mathrm{L})$ and sulphate ions $(273 \mu \mathrm{eq} / \mathrm{L})$. Vangenechten et al. (1984) made similar observations for 25 poorly buffered campine-bog pools in the province of Antwerp, Belgium. A strong correlation between hydrogen ions and the excess sulphate, high aluminum concentration $(8000 \mu \mathrm{g} / \mathrm{L})$, and unusually high calcium content $(6400 \mu \mathrm{g} / \mathrm{L})$ in these bog pools suggested that acidification was due to atmospheric input. However, lack of information on precipitation $\mathrm{pH}$, geological and soil characteristics, and hydrological conditions makes interpretation of their results difficult. 
It thus appears that natural processes contribute to acidification of surface waters. Patrick et al. (1981) suggested that naturally occurring acidic lakes fall into two groups. The first group occurs in areas of igneous rock or sand substrata; the geographical location of the second group is similar, except for considerable accumulation of organic matter. Lakes of the first type are generally small with poorly buffered waters and low conductivity. Such lakes generally have $\mathrm{pH}$ of $5.6-5.7$ and are susceptible to acidification by carbonic acid. Acidic runoff can depress $\mathrm{pH}$ of these lakes even further. These lakes are even susceptible to plankton metabolic activity and, because of this, $\mathrm{pH}$ can change by as much as 4 units within a period of 2 hours (Allen 1972, cited by Marcus et a1. 1983).

The second group of lakes is associated with peat and bog plants. Such lakes can have $\mathrm{pH}$ levels as low as 3.7 (Gorham et al. 1984b). In some bogs, pH as low as 3.0 has been reported (Wetzel 1975).

Bog acidification can occur in three ways involving cation exchange by sphagnum (Sphagnum Sp.), organic acids, and oxidation of reduced sulphur compounds (Patrick et al. 1981; Gorham et al. 1984b). Sphagnum contains polygalacturonic acids. These plants remove metal cations from precipitation and replace them with hydrogen ions from the polygalacturonic acids, making bogs more acidic. Organic acids that contribute acidity to bog waters are mainly "humic" substances resulting from organic decay. Patrick et al. (1981) reported that although organic acids can contribute to bog acidity, it is sulphate, derived from the oxidation of reduced sulphur and from biological activities in the sediments, that causes low $\mathrm{pH}^{\prime} \mathrm{s}$ in bog waters.

Paleolimnological records suggest that natural processes have been acidifying lakes and ponds for at least 10,000 years (Whitehead et al. 1981). The study methods involve collecting cores from lake sediments and analysing pollen and plankton assemblages, particularly diatoms (Dickman and Fortescue 1984; Dickman et al. 1984; and Davis et al. 1985). Historical pH levels are then estimated, using data on sediment plankton assemblages and regression models developed using plankton communities existing in surface waters at presently occurring pH levels (Marcus et al. 1983). Two of the examples cited by Marcus et al. (1983) are given below.

Whitehead et a1. (1981) estimated historical pH levels of 3.8 in Adirondack lakes by studying sediment diatoms. Based on the analyses, they suggested that all lakes were basic in the late glacial period ( $\mathrm{pH} 7.8$ ), and became more acidic during the early Holocene $(\mathrm{pH} \leq 6)$. Diatom analyses suggested that in some lakes $\mathrm{pH}$ levels below 5 have existed for the past 2000 to 10,000 years. They hypothesized that historical depressions in $\mathrm{pH}$ were related to changes in terrestrial vegetation, which, in turn, depressed $\mathrm{pH}$ levels in soils. Sediment core pollen analyses indicated that lake $\mathrm{pH}$ levels decreased concurrently with the movement of hemlock and fir into watersheds.

However, Battarbee and Charles (1986) pointed out that of 11 Adirondack lakes studied, six of the seven lakes with a current pH of 5.0 or less show clear evidence of recent $\mathrm{pH}$ decreases. The remaining four lakes (current $\mathrm{pH}$ of $>5.2$ ) indicated no substantial $\mathrm{pH}$ decrease. Data on ${ }^{210} \mathrm{~Pb}$ indicate that the most rapid $\mathrm{pH}$ decreases (0.5 to 1.0 units) occurred between 1930 and 1970. Battarbee and Charles (1986) suggested that although the primary cause of recent acidification appears to be atmospheric deposition of acidic substances, a role played by watershed disturbance in acidification at some sites needs to be taken into account. 
Ford (1981) Investigated sediment cores of two ponds; one was located in New Hampshire and the other in Vermont. Diatom analyses indicated that the New Hampshire pond has been acidic for the last 10,000 years. Analyses of the Vermont pond indicated that the alkalinity in that pond declined to zero about 5000 years ago; the diatom analyses indicated that $\mathrm{pH}$ levels of both ponds decreased around this time.

A diatom stratigraphy and reconstruction study of 13 New England lakes suggested that for some seven lakes, pH declines started between 1920 and 1950 (Battarbee and Charles 1986). These lakes are situated in areas receiving the greatest acid loading, suggesting deposition of acidic substances as the cause of the $\mathrm{pH}$ decline. For two additional lakes, the decline appears to be caused by heavy lumbering of the catchments. The four remaining lakes show no change in diatom-inferred pH since the 1770's.

Most of the paleoliminological data suggest that acidification of many surface waters is caused by internal generation of hydrogen ions within watersheds and that atmospheric deposition may be the secondary source of acidification of surface waters.

However, misconceptions still exist regarding the effects of acid deposition on aquatic ecosystems and how they become acidic. Havas et a1. (1984) identified five misconceptions regarding the effects of acid deposition on an aquatic ecosystem in order to clarify some of the confusion they have created. These misconceptions are as follows:

1. The acidification of lakes is not a recent phenomenon because bog lakes have been acidic for thousands of years;

2. The early methods for measuring $\mathrm{pH}$ are in error and, therefore, no statements can be made regarding historical trends;

3. Acidification of lakes and streams results from changed land use practices (forestry, agriculture, animal husbandry) and not acid deposition;

4. The decrease in fish populations is caused by overfishing, disease, and water pollution, not acidification; and

5. Because lakes that receive identical rainfall can have considerably different $\mathrm{pH}$ 's, regional lake acidification cannot be due to acid precipitation.

5.1 MISCONCEPTION 1: NATURALLY ACIDIC LAKES IN CONTRAST TO ANTHROPOGENICALLY ACIDIFIED LAKES

Havas et al. (1984) have claimed that proponents of naturally acidic lakes divert attention from the central issue by confusing naturally acidic lakes with those that have been acidified by atmospheric deposition within the past few decades.

They have pointed out the considerable differences between naturally acidified lakes and anthropogenically acidified lakes. Naturally acidified lakes are generally characterized by brown to yellow coloured water, high dissolved organic carbon, low transparency, and the presence of few fish species. The coloured water is caused by the presence of humic substances and tannins. These compounds are organic acids and contribute to the low $\mathrm{pH}$ of water. Most importantly, the organic acids in coloured waters bind with toxic metals such as aluminum and reduce its toxicity. Aluminum is less toxic to fish when bound organically or inorganically than it is in free form. As a consequence, some fish species adapt to these waters and survive in these lakes at 
metal concentrations that otherwise would be toxic. Havas et al. (1984) have not commented on the presence of nitrate and sulphate ions in naturally acidified lakes, although potential exists for their contribution to natural acidity through oxidation of naturally occurring reduced nitrogen and sulphur compounds.

In contrast to naturally acidified lakes, anthropogenically acidified lakes have clear water, and greater transparency at lower $\mathrm{pH}$ due to reduced phytoplankton biomass and to precipitation of organic matter by aluminum. Inorganic acids such as sulphuric and nitric acids predominate in these lakes. Dissolved organic carbon concentrations are low, seldom exceeding a few milligrams per litre. In these inorganically acidified lakes, $\mathrm{pH}$ is strongly correlated with metal concentrations. As the $\mathrm{pH}$ decreases, the concentrations of several potentially toxic metals, such as aluminum, iron, manganese, copper, nickel, lead, zinc, cadmium, and mercury increase. The decreased pH and elevated metal concentrations lead to significant reduction or elimination of sensitive biotic species. Whether this reduction or elimination of aquatic organisms is due to an increase in concentration of hydrogen ions or toxic metals or both, needs further investigation.

During the literature search, no definite values were found to differentiate between coloured water and clear water (Richter 1983; Scruton 1983; and Krug et al. 1985). Krug et a1. (1985) pointed out that waters in southern Sweden with colour up to at least $56 \mathrm{Pt}$ units are described as being relatively clear, whereas such waters occurring in other parts of the world (e.g., Tasmania, Australia) are considered coloured or highly coloured. In southern Sweden, waters of $56 \mathrm{Pt}$ units are considered clear because a survey of 304 lakes showed $92 \%$ as humic coloured lakes with about one-third of the lakes brown or darker in appearance. Only one lake was clear with high transparency. It appears that the Adirondacks, Ontario, and Norway also have many coloured lakes (Richter 1983). During an acidification study of highly coloured Nova Scotia lakes (mean colour $103 \mathrm{Pt}$ units; mean pH 5.01), Underwood et al. (1982, cited by Krug et al. 1985) arbitrarily divided the data set between highly coloured lakes (Pt>65 units) and clear lakes $(\mathrm{Pt}<65)$ and showed that the $\mathrm{H}^{+}$ion concentration was higher in coloured lakes $(15.4 \mu \mathrm{eq} / \mathrm{L}$; $\mathrm{pH} 4.81)$ than in clearwater lakes $(5.5 \mu \mathrm{eq} / \mathrm{L}$; $\mathrm{pH} 5.26)$. Scruton (1983) divided lakes into clearwater lakes (colour value of 15 or less) and brown water lakes (colour value >15) to assess the role of organics in relation to lake chemistry morphometry. Unfortunately, in many surface water acidification studies, concentrations of total organic carbon and humic substances in lake or stream waters are generally not reported, making it difficult to differentiate between naturally and anthropogenically acidified lakes. In such cases, the presence of humic substances and acids are inferred from estimates of anion deficit.

It has been hypothesized that the present day clear water lakes were once coloured humic acid lakes and that precipitation of organic matter from coloured lakes may have led to clear water lakes. This hypothesis has recently been supported by the palaeolimnological results of Davis et al. (1985) for two southern Norway lakes. Their

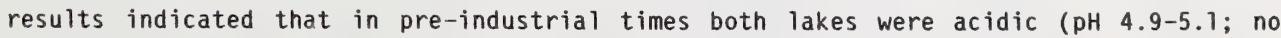
bicarbonate alkalinity) and relatively humic (total organic carbon $6-9 \mathrm{mg} / \mathrm{L}$ ). The acidification of the lakes by input of mineral acids started in 1920 to 1940, and was accompanied by a decrease in total organic carbon, leading to the present total organic carbon value of $3.0 \mathrm{mg} / \mathrm{L}$. Davis et al. (1985) have suggested that inputs of mineral 
acids directly from the atmosphere to lakes, and indirectly through watersheds, would have: (1) protonated organic acids, thus increasing their tendency to aggregate; and (2) mobilized $A T$ and other metals (such as $F e$ ) in inorganic form, providing chargeneutralization of organic functional groups, and leading to their precipitation. They suggested that acidification of such lakes was not analogous to a titration of bicarbonate alkalinity, because such alkalinity was absent. Rather, it was a titration of organic matter, perhaps by acid-mobilized metals. They further suggested that once this shift from humic acid-dominated lakes to mineral acid-dominated lake takes place, surface water chemistry of clear water lakes undergoes dramatic changes sufficient to reduce or eliminate aquatic species.

Havas et al. (1984) reported that coloured water lakes and clear water lakes with $\mathrm{pH}$ 's between 6 and 7 have similar acid neutralizing capacities. Below pH 5, the coloured lakes generally have a greater acid neutralizing capacity $(7.5 \mu e q / \mathrm{mg}$ of organic carbon; Gorham et a1. 1984b) than clear water lakes and, therefore, they should be less sensitive to the acidifying effects of precipitation. According to them, the major issue is not whether brown water lakes existed for hundreds of years, but how poorly buffered lakes, located in geologically sensitive areas, are responding to acid deposition.

\subsection{MISCONCEPTION 2: EARLY VERSUS PRESENT-DAY PH MEASUREMENTS}

To assess acidification of surface water, many investigators have compared historical data (prior to 1955) with the present pH data, giving little consideration to the two different methods that were used to measure pH (Kramer and Tessier 1982). This type of comparison has been criticized by many researchers who suggest that the two methods give different $\mathrm{pH}$ values for an identical water sample.

The glass electrode method, the most commonly used method now for measuring $\mathrm{pH}$, was not in use until about 1955. Prior to 1955, pH was measured by colorimetric comparator methods. This colorimetric method was criticized by Pfeiffer and Festa (1980) for overestimating true $\mathrm{pH}$ value.

This criticism prompted many investigators to compare these two techniques of $\mathrm{pH}$ measurements. All have reported a good correlation between the two methods with a difference of only 0.1 to $0.2 \mathrm{pH}$ units (Havas et al. 1984). Pfeiffer and Festa (1980) claimed that the $\mathrm{pH}$ difference between the two methods was about $1.0 \mathrm{pH}$ units with the glass electrode giving the lower value. Schofield (1982, cited by Havas et al. 1984) found this not to be true, and pointed out an error in Pfeiffer and Festa's (1980) $\mathrm{pH}$ measurements.

Havas et a1. (1984) cited work of Best et al. (in prep.) on the comparison of the $\mathrm{pH}$ of 46 lakes in the Adirondack Mountains using potentiometric and the Hellige colorimetric measurements. There was some positive bias with the Hellige colorimeter but it was not as great as that reported by Pfeiffer and Festa (1980). Depending on the colour reagent used, the deviations between the two methods was in the range of 0.2 to $0.7 \mathrm{pH}$ units. Havas et a1. (1984) suggested that part of the deviation between the two methods resulted from acidity-alkalinity of the colour reagent, which altered the $\mathrm{pH}$ of the original sample, giving a false $\mathrm{pH}$ reading. 
To determine whether historical acidification has occurred, Pfeiffer and Festa compared the old with the new Hellige colorimetric $\mathrm{pH}^{\prime} \mathrm{s}$, and found lake acidification has occurred in the Adirondack Mountains. Havas et al. (1984:179A) wrote, "Interestingly, articles in which the work of Pfeiffer and Festa is quoted in relation to colorimetric bias seldom present the 'unbiased' results and conclusions regarding trends in historic acidification of lakes in the Adirondack Mountains."

Haines (1981) reported that comparisons of recent and historical water chemistry data can be made if recent measurements are made by the same methodology and if the same sampling procedure and technique are used. Publications from Norway, Sweden, Canada, and the United States that used such a comparison approach have been reviewed by Haines (1981). It appears that during the last 30 to 40 years the $\mathrm{pH}$ of studied lakes in these areas has declined by 0.8 to 1.8 units. Most of the lakes were in regions of acidic precipitation and were poorly buffered soft water lakes on granitic bedrock. Lakes with harder water remained unaffected.

Havas et al. (1984) suggested that additional information from analysis of sediment profiles can corroborate historical data. Although trends in metal concentrations are not consistent, the point when profile changes begin is clearly evident. In work by Dickson (1980) at Lake Horsikan, Sweden the pH profile of sediments from the lake showed a progressive decrease from $\mathrm{pH} 6.0$ below a depth of $8.0 \mathrm{~cm}$ to $\mathrm{pH} 4.5$ at the surface, with a concomitant decrease of calcium. The concentrations of lead, zinc, and cadmium during the same period showed sharp increases from a sediment depth of $18-20 \mathrm{~cm}$ to one of $0-2 \mathrm{~cm}$, suggesting that these trends could have resulted from atmospheric deposition. Eisenreich (1980) similarly attributed accumulation of $\mathrm{Zn}, \mathrm{Mn}, \mathrm{Cd}, \mathrm{Pb}$, and Co in southern Lake Michigan surficial sediments to atmospheric deposition. Hanson et al. (1982) observed accumulation of $\mathrm{Zn}, \mathrm{Mn}$, and $\mathrm{Pb}$ in sediment cores of five lakes in New England states which had $\mathrm{pH}^{\prime}$ 's spanning 5.6 to 6.8. Based on a dating experiment of the sediment profile they suggested that the increase in $\mathrm{Pb}$ and $\mathrm{Zn}$ in the cores started about 1870-1880, consistent with increased fossil fuel consumption. They proposed that acidified precipitation may have occurred as early as 1880 . They also noted that in other studies, cores from historically acidified lakes $(\mathrm{pH}<5.3)$ indicated that as surface waters acidified, concentrations of $\mathrm{Zn}, \mathrm{Mn}$, and $\mathrm{Ca}$ decreased in the sediment.

Although accumulation of metals in sediments due to atmospheric deposition is not disputed, another mechanism should be considered: that is the leaching of metals from watersheds by acidified waters and the precipitation of the leached metals in lake waters of high pH. Hanson et al. (1982) have considered this possibility for zinc accumulation in the sediments of the lakes described above.

Shifts in diatom composition in sediment cores have also been used to predict historical changes in $\mathrm{pH}$. Some species of diatoms which are termed "acidiobiontic" occur below pH 5.5. Other species occur below pH 7.0 (acidophilous), at pH 7.0 (circumneutral), or above $\mathrm{pH} 7$ (alkaliphilous). In a number of lakes that are now acidic, a distinct shift in species composition is observed. Acidiobiontic and acidophilous species occur in surface sediments, whereas, circumneutral and alkaliphilous species occur in deeper sediments. Based on this type of data, $\mathrm{pH}$ 's calculated for Lake Gardsjon in Sweden showed the $\mathrm{pH}$ decline began in 1950 ( $\mathrm{pH} \mathrm{6)}$ and continued until 1979 (pH 4.5). The explanation provided is that surface sediments are acidified by overlying acidic waters. 
Historical $\mathrm{pH}$ measurements and changes in sediment chemistry, and in diatoms in sediment profiles clearly indicate that many poorly buffered lakes in regions receiving acid precipitation are more acidic now than they were a few decades ago. It does not indicate, however, how much of this lake acidification is due to atmospheric deposition in contrast to natural processes.

\subsection{MISCONCEPTION 3: ACIDIFICATION OF SURFACE WATERS AS CAUSED BY CHANGED LAND USE PRACTICES}

Havas et a1. (1984) pointed out that while disturbances within a drainage basin can affect its water quality, it is misleading to suggest that regional acidification is due to changes in land use practices rather than to atmospheric deposition. They presented three observations to dispel views regarding the acidification of lakes due to changes in land use practices.

First, many of the lakes that have been acidified in the last few decades are pristine, high elevation lakes in remote regions where land use practices have not changed significantly. Some of these lakes which have become acidic are reported by them to be above tree line. However, Havas et al. (1984) did not describe the thickness of the organic-rich soil or the type of surface or groundwater influences in these areas. Also, they did not mention whether these areas were affected by forest fires.

Secondly, sensitive lakes are in regions underlain by hard granitic bedrock. Soils, if existent, are shallow, infertile, and unfit for agriculture, and animal grazing is minimum. Therefore, Havas et a1. (1984) argued that for a large number of acidified lakes, land use practices have not changed and cannot be responsible for the observed acidification. As examples, they cited acidification of lakes in the Adirondack Mountains and in the La Cloche region of Ontario. However, Krug and Frink (1983b) reported that these regions are not pristine regions and have undergone changes in land use.

Thirdly, in regions where land use practices have changed, there is no clear relationship with lake acidification. Havas et al. (1984) cited the work of Drablos and Sevaldrud (1980) in this regard. Drablos and Sevaldrud studied poorly buffered lakes in southern Norway and found that the $\mathrm{pH}$ of the lakes had declined by $0.5 \mathrm{pH}$ units since 1965 and that there was severe damage to fish populations. Based on good historical data on fish status and land use, they eliminated changes in forestry and drainage as possible sources of increased acidity because most of the lakes were above the tree-line. They did not find correlation between dairy farming or sheep grazing and fish population losses. Acidified lakes and fish population losses were generally found in areas where reindeer pasturing had either increased or remained stable or had not occurred at all. However, Overrein et a1. (1980) noted that locally, changes in grazing vary considerably and that more detailed studies are required to relate changes in grazing to acidification of lakes.

It has been suggested that watershed disturbances generally tend to favour an upward shift in pH. Watt et al. (1979) observed that four of five lakes in Nova Scotia, with disturbances during the period of 1957 to 1978, showed an increase in $\mathrm{pH}$ of 0.2 to $2.0 \mathrm{pH}$ units. Close examination of their data shows that increase in pH has definitely occurred in one lake and may have occurred in another one or two lakes. Schindler and 
Ruszczynski (1983) found similar results for lakes in western Ontario between 1973 and 1978, where disturbances occurred as major windstorms, fire, or logging. This area has not been exposed to acid rain. However, Havas et a1. (1984) cited the work of Likens (in press) in the White Mountains of New Hampshire where forest clearcutting increased the hydrogen ion concentration in stream water for two years. Waters then became less acidic than prior to the forest clearcutting. Havas et al. pointed out that such immediate dramatic effects after disturbances are often short lived.

Because some investigators (Rosenqvist 1978b; Krug and Frink 1983a,b) have suggested that land use practices can alter hydrogen ion concentration of surface waters, this mechanism for surface water acidification needs to be taken into consideration. However, Havas et a1. (1984) have shown by documentation that this mechanism cannot explain convincingly the regional acidification of lakes and streams exposed to acid deposition. They have shown that on a regional scale, the correlation between areas receiving acid rain and containing acid lakes is so strong that land use does not seem to matter. However, in most of the above documented studies the hydrology of the basin was not described. Therefore, it is difficult to assess whether acidification of the lakes was due to anthropogenic or natural input of hydrogen ions or both.

\subsection{MISCONCEPTION 4: FISH LOSSES NOT DUE TO ACIDIFICATION}

It has been suggested that the decline of fish populations in acidifying lakes and rivers is caused by overfishing, disease, or water pollution, and not by acidification. While this is true in some cases, in the majority of cases studied little scientific evidence supports this point of view (Havas et al. 1984). The available evidence suggests that acidification is causing the declining fish populations. What is not clear is whether it is caused by mobilized toxic metals such as aluminum or by increases in $\mathrm{H}^{+}$concentration.

In poorly buffered waters receiving acid deposition and with pH below 5.5, a strong correlation is observed between increasing acidity and decreasing fish populations. Havas et al. (1984) cited references where such correlations were observed. Fish kills have been observed during episodic events which are known to be extremely acidic and high in mobilized metal concentration. Episodic increases in acidity and $\mathrm{Al}^{3+}$ can be caused by the flushing of internally generated $\mathrm{H}^{+}$and $\mathrm{Al}^{3+}$ in humic soils. Therefore, increases in $\mathrm{H}^{+}$and $\mathrm{Al}^{3+}$ concentration may not necessarily be due to acid deposition. During an episodic event the chemistry of runoff is a function of the horizons the precipitation passes through on its way to the stream or lakes (Chen et al. 1984). Acidity can have subtle effects on fish. Morphological deformities, spawning failure, changes in age class distribution, and changes in blood chemistry due to electrolyte imbalance have been linked to acidification, both in field observations and laboratory experiments (Haines 1981; Havas et al. 1984; and Schindler et al. 1985).

Liming experiments have been carried out to improve reproductive success (Haines 1981). Gunn and Keller (1980) limed George Lake in Ontario (pH 5.3) to study the effect on rainbow trout. They observed that the addition of limestone raised the water $\mathrm{pH}$ and significantly improved hatching success as well as survival of sac fry and emerging alevins. Although this experiment does not prove that acidity was the only cause of the poor reproduction, it does show that reproduction can be improved by neutralizing the acidity. 
The effects of surface water acidification on aquatic biota are outlined in Section 7.

5.5 MISCONCEPTION 5: REGIONAL LAKES WHICH RECEIVE IDENTICAL RAINFALL BUT HAVE DIFFERENT $\mathrm{pH}$ 's

This misconception seems to have arisen from the Integrated Lake-Watershed Acidification Study (ILWAS) in the Adirondack Mountains, New York (Tetra Tech Inc. 1983, 1984). Three lakes and their watersheds were extensively studied by a team of scientists for four years. The investigation focussed on how lakes become acidic. These lakes were chosen because although they received the same precipitation, they had significantly different $\mathrm{pH}^{\prime} \mathrm{s}$. Of the three lakes, two (Woods and Panther) are morphometrically similar, yet differ considerably with respect to $\mathrm{pH}$. Woods is an acid lake with $\mathrm{pH}$ ranging from 4.7 to 5.1. Panther is a circumneutral lake with $\mathrm{pH}$ ranging from 5.3 to 7.8 .

The differences in their $\mathrm{pH}^{\prime} \mathrm{s}$ were related to the differences in their watershed soil characteristics and movement of water through the soil profile. The till around Woods Lake is thinner $(2.2 \mathrm{~m})$ and less permeable than that around Panther Lake $(17 \mathrm{~m})$. Thus, a large fraction of water from the woods watershed moves through the organic-rich, acidic soil horizon before entering the lake. Conversely, a large portion of water entering the Panther Lake watershed moves first through a large volume of till, where neutralization occurs. The mechanism of acidification of these two lakes will be discussed in more detail in Section 6., which deals with a total watershed approach for the evaluation of lake acidification. The ILWAS scientists concluded that the differences in till depth, permeability, buffering capacity, and hydrology of the two watersheds can account for much of the pH difference between woods and Panther Lakes.

Havas et a1. (1984) reported that differences in the $\mathrm{pH}$ 's of lakes quite close to each other spatially have been reported from Ontario, Norway, and Sweden. They suggested that such differences in most cases can be ascribed to watershed characteristics. Although this statement is true, a detailed watershed study on the causes of lake acidification has not been carried out in these regions. The ILWAS is the only study to date that has followed a total watershed approach to investigate causes of lake acidification.

It is important to understand that lakes vary in their susceptibility to acidification because of biogeochemical parameters, surface topography, residence time of water in a watershed, hydrology, lake depth, volume, and flushing time. Therefore, it is unrealistic to expect all lakes receiving identical precipitation to have identical pH's (Havas et al. 1984). 
6. SURFACE WATER SUSCEPTIBILITY TO ACIDIFICATION

Lake acidification studies in the Adirondack Mountains, New York, have clearly shown that surface waters are not equally susceptible to acidification. A lake's vulnerability to acidification by atmospheric deposition depends on biogeochemistry and hydrology of its entire catchment area, including the type and condition of vegetation cover, the bedrock characteristics, and the type and depth of soil (Goldstein et al. 1984a). Because precipitation follows various pathways through a terrestrial ecosystem before it reaches a lake (Figure 1), it is important to discuss the respective roles of these factors in contributing to or resisting surface water acidification. A summary of these characteristics is presented in Table 2.

\subsection{FOREST CANOPY}

It has been reported by many investigators that the forest cover modifies the $\mathrm{pH}$ of incident precipitation as it moves through the forest canopy as throughfall (Clesceri and Vasudevan 1980; Stottlemeyer 1982; Cronan and Reiners 1983; Moore 1983; Cadle et al. 1984; and Johannes et al. 1984). The chemical composition of precipitation penetrating the forest canopy is altered due to washing and leaching of absorbed and adsorbed deposits and excreted metabolites on the leaf surface (Moore 1983). Although potential susceptibility of lake waters to acidic inputs is not directly affected by throughfall chemistry, it is, nevertheless, important because the throughfall moves through and over the litter layer and through the soil mantle to the lake. This overall movement modifies the $\mathrm{pH}$ of precipitation.

Moore (1983) observed that at Little Millseat Watershed in Kentucky, the average $\mathrm{pH}$ of incident precipitation was $4.7\left(\mathrm{H}^{+}\right.$concentration $\left.19.95 \mu \mathrm{g} / \mathrm{L}\right)$, whereas, throughfall $\mathrm{pH}$ under a hardwood canopy averaged 5.9, and under a coniferous canopy $4.0 \mathrm{(H}^{+}$concentration $100 \mu \mathrm{g} / \mathrm{L}$ ). Moore (1983) observed that loss of hydrogen ions under the hardwood canopy was made up principally by increased $\mathrm{K}$ and $\mathrm{Ca}$ in throughfall.

Cronan and Reiners (1983) made similar observations for coniferous and hardwood forests in New England. They reported that in New Hampshire, where precipitation pH is $4.1\left(\mathrm{H}^{+}\right.$concentration $\left.86.0 \mu \mathrm{g} / \mathrm{L}\right)$, the northern hardwood canopies produce a through-

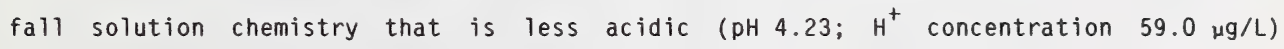
and higher in basic cations $(237 \mu \mathrm{g} / \mathrm{L})$ than either direct precipitation $(131 \mu \mathrm{g} / \mathrm{L})$ or throughfall solutions derived from nearby subalpine balsam fir forests $\left(\mathrm{pH} 4.00 ; \mathrm{H}^{+}\right.$ concentration $100 \mu \mathrm{g} / \mathrm{L}$; basic cation $217 \mu \mathrm{g} / \mathrm{L}$ ). They suggested that neutralization of acid precipitation in the hardwood canopy occurs through two major processes, ion exchange removal of free $\mathrm{H}^{+}$by foliage and Bronsted base leaching from the plant canopy. The increase in hydrogen ion concentration in coniferous throughfall was attributed in part to ammonium uptake or nitrification, washout of acidic dry deposition, or leaching of plant derived acids. Johannes et al. (1984) reported that in the Adirondack Mountains, throughfall measured under various species of trees showed enrichment in most base cations and anions. Deciduous trees were found to increase the $\mathrm{pH}$ of incident precipitation while coniferous canopies tended to decrease $\mathrm{pH}$. 


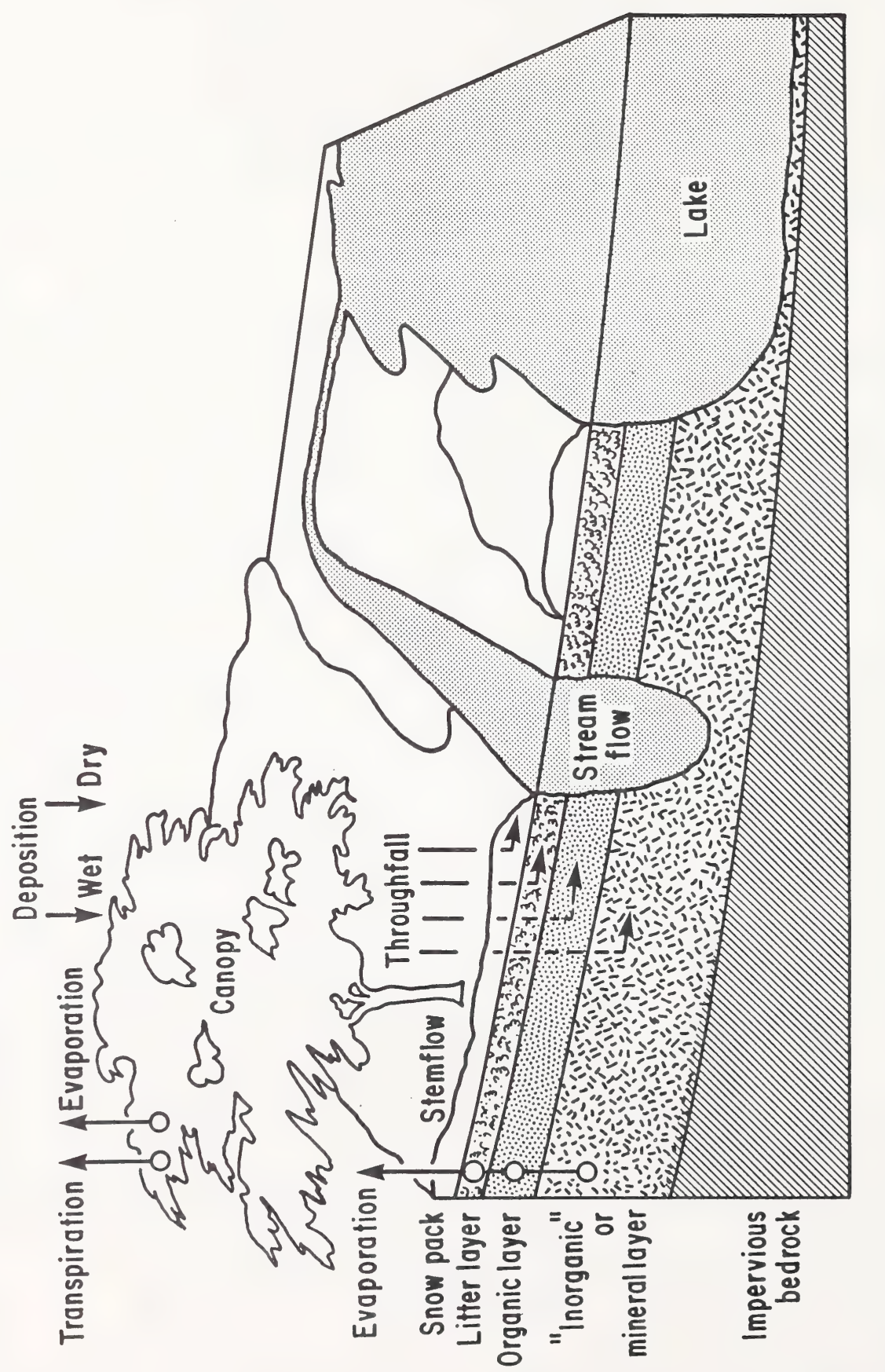

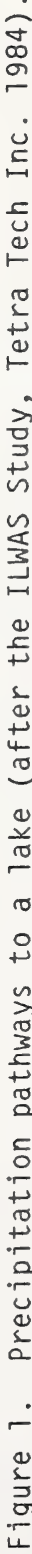


Table 2. Watershed characteristics that influence surface water susceptibility to acidification.

\begin{tabular}{|c|c|c|}
\hline Category & $\begin{array}{c}\text { Increased } \\
\text { Susceptibility }\end{array}$ & $\begin{array}{c}\text { Decreased } \\
\text { Susceptibility }\end{array}$ \\
\hline Bedrock geology & $\begin{array}{l}\text { Resistant to weather- } \\
\text { ing (metamorphic, } \\
\text { igneous) }\end{array}$ & $\begin{array}{l}\text { Easily weathered (sedi- } \\
\text { mentary, calcite- } \\
\text { containing) }\end{array}$ \\
\hline $\begin{array}{l}\text { Soils } \\
\text { Buffering capacity }\end{array}$ & Low & High \\
\hline Depth & Shallow & Deep \\
\hline $\begin{array}{l}\mathrm{SO}_{4} \text { adsorption } \\
\text { capacity }\end{array}$ & Low & High \\
\hline Topography & Steep-s loped & Shallow-sloped \\
\hline $\begin{array}{l}\text { Watershed to surface } \\
\text { water area ratio }\end{array}$ & Low & High \\
\hline Lake flushing rate & High & Low \\
\hline \multicolumn{3}{|l|}{$\begin{array}{l}\text { Watershed vegetation } \\
\text { and land use }\end{array}$} \\
\hline $\begin{array}{l}\text { Dominant vegetation } \\
\text { Forest management }\end{array}$ & $\begin{array}{l}\text { Coniferous } \\
\text { Reforestation }\end{array}$ & $\begin{array}{l}\text { Deciduous } \\
\text { Clearcutting }\end{array}$ \\
\hline \multicolumn{3}{|l|}{ Water quality } \\
\hline Alkalinity & Low $(<200 \mu \mathrm{eq} / \mathrm{L})$ & $\mathrm{High}(>200 \mu \mathrm{eq} / \mathrm{L})$ \\
\hline Trophic status & Highiy oligotrophic & $\begin{array}{l}\text { Less oTigotrophic, } \\
\text { mesotrophic, eutrophic }\end{array}$ \\
\hline $\begin{array}{l}\text { Cultural eutro- } \\
\text { trophication }\end{array}$ & Forestry & Agriculture, municipal \\
\hline Humic substances & Absent & Present \\
\hline Sphagnum moss & Present & Absent \\
\hline $\begin{array}{l}\text { Sulfate reduction } \\
\text { potential }\end{array}$ & Low & High \\
\hline \multicolumn{3}{|l|}{ Climate/meteorology } \\
\hline Precipitation & High & Low \\
\hline Snow accurnulation & High & Low \\
\hline Growing season & Short & Long \\
\hline Alkaline dusts & Low & High \\
\hline
\end{tabular}

Source: Marcus et al. (1983) 


\subsection{BEDROCK GEOLOGY}

Bedrock geology has been most frequently used to assess potential susceptibility of surface waters to acidic inputs (Hendrey et al. 1980a; Kaplan et al. 1981). The chemical characteristics of the bedrock generally determine a region's susceptibility to acidification. Hendrey et a1. (1980a) described four types of bedrock which distinguish susceptibility to acidification:

Type 1. Granite/syenite, granitic gneisses, quartz sandstones, or metamorphic equivalents. Low to no buffering capacity.

Type 2. Sandstones, shales, conglomerates, high-grade metamorphic felsite to intermediate igneous rocks, calcsilicate gneisses (no free carbonates). Medium/low buffering capacity.

Type 3. Slightly calcareous, low-grade, intermediate to mafic volcanic, ultra mafic and glassy volcanic rocks. Medium/high buffering capacity.

Type 4. Highly fossiliferous sediments or metamorphic equivalents. Limestones or dolostones. High buffering capacity.

Areas underlain by limestone or other bedrocks containing calcite or other carbonate minerals yield extensive acid neutralizing (buffering) capacity. Even small deposits of limestone in watersheds has been reported to influence buffering capacities of surface waters in areas that would otherwise be considered potentially susceptible to acidic precipitation (Norton 1980, cited by Marcus et al. 1983).

On the other hand, areas underlaid by granites and related igneous rocks, their metamorphic equivalent, and noncalcareous sandstones yield minimal buffering because of slow weathering. Lakes located in such bedrock areas generally have low concentrations of dissolved substances $(12,500 \mu \mathrm{g} / \mathrm{L} ;$ Scruton 1983) and low alkalinities ( $<200 \mu \mathrm{g} / \mathrm{L}$; Gibson et al. 1983), and tend to be more susceptible to acidification. Thus, the potential susceptibility of surface waters to acidic inputs is generally assessed by characterizing the geology of the surrounding area.

\subsection{SOIL TYPE AND DEPTH}

Except when it falls directly into a waterbody or on to exposed bedrock, most precipitation either flows across, or percolates through, soils before entering streams or lakes. During this movement it often interacts with the soils and the chemical composition of the water that flows over or through the soils is altered significantiy from that of the original precipitation. This interaction and change in precipitation chemistry ultimately influence surface water quality.

Humic content of the soil surface horizons can play an important part in surface water acidification. Runoff from sandstone calcareous soils can be acidic during episodes if rain water moves through the litter 0 and $A$ horizons on the way to the water body. Most of the acid input to a stream or lake probably occurs during an episodic event; therefore, it is important to monitor organics and other parameters during an episodic event rather than on a weekly or monthly basis.

Kaplan et al.(1981), using cluster analysis, a multivariate classification method, examined the relationships among bedrock, geology, soils, and surface water 
quality in the northeastern United States and observed that for most counties the alkalinity and $\mathrm{pH}$ of surface waters were closely related to soil type. Counties with soils of low buffering capacity were more susceptible to acidification. Less susceptible areas were dominated by soils having medium to high buffering capacities. Cation exchange capacity of soils can also play an important part. Soils with high cation exchange capacity, such as organic soils, are not sensitive to acidification.

Soil depth is also important in determining the surface water quality. Differences in soil depth and hydrologic conditions (the relative route of water through a watershed) have been suggested as main factors causing differences in $\mathrm{pH}$ levels observed in three Adirondack lakes (Tetra Tech Inc. 1984). The chemical characteristics of three lakes is given in Table 3. Of the three, Woods and Panther Lake catchment areas are relatively homogenous in nature. These two lakes are located within $30 \mathrm{~km}$ of each and receive approximately the same amount and quality of precipitation, yet woods Lake is acidic and the Panther is alkaline. It has been shown that the paths the tributary water takes as it passes through the terrestrial system determine the acid-base status of these lakes (Chen et a1. 1984; Schofield 1984).

Direct precipitation, surface runoff, and lateral flows from soil strata have their characteristic pH ranges and chemical species (Figures 2 and 3 ). Runoff inputs to lakes are more acidic if the water flows through the shallow organic horizon and more alkaline if the water flows through the inorganic horizons (a layer below the organic horizon). Thus, if lateral flow occurs only in deeper soil layers, the lake water will tend to be alkaline. If the majority of the water enters the lake as direct precipitation or as surface runoff and lateral flow through the upper horizons of the soil, the lake water will tend to be more acidic if the alkalinity of the lake is low.

Chen et al. (1984) conducted hydrologic analyses of these two lakes to provide evidence that the acid-base state of a lake depends on the paths the tributary water takes as it passes through the terrestrial system. They calculated the lateral flow through inorganic horizons for both woods and Panther lakes and divided the calculated value by the surface of the tributary land to compare the contribution of lateral flow to that of direct precipitation. For woods Lake, the water flow value through inorganic horizons was $19 \mathrm{~cm} / \mathrm{y}$; for Panther Lake it was $715 \mathrm{~cm} / \mathrm{y}$. The annual precipitation in the area was approximately $120 \mathrm{~cm} / \mathrm{y}$ and evapotranspiration about $40 \mathrm{~cm} / \mathrm{y}$. Thus, approximately $80 \mathrm{~cm} / \mathrm{y}$ of precipitation flowed to the lake. The lateral flow through inorganic horizons value of $19 \mathrm{~cm} / \mathrm{y}$ for woods suggested that most of the water reaching woods Lake did not flow through the inorganic horizons but flowed through the shallow acidic organic soil horizons. Therefore, precipitation water in woods Basin was less neutralized by soil reactions.

For Panther Lake Basin, the lateral flow value of $715 \mathrm{~cm} / \mathrm{y}$ indicated that the flow capacity of the inorganic horizons was able to accommodate the precipitation falling onto the basin. However, during the snowmelt period, water reaching Panther Lake became slightly acidic. This was because an accumulation of three months of precipitation in the snowpack (water equivalent to about $900 \mathrm{~cm} / \mathrm{y}$ ) was released over a two week period. The limit of lateral flow through inorganic horizons in the Panther Basin was exceeded, forcing a portion of the water to flow through the shallow acidic organic rich soil horizon before entering the lake. 
Table 3. Characteristics of the ILWAS lakes ${ }^{2}$.

\begin{tabular}{|c|c|c|c|}
\hline & $\begin{array}{l}\text { Panther } \\
\text { Lake }\end{array}$ & $\begin{array}{l}\text { Sagamore } \\
\text { Lake }\end{array}$ & $\begin{array}{l}\text { Woods } \\
\text { l.ake }\end{array}$ \\
\hline Basin area $\left(\mathrm{km}^{2}\right)$ & 1.2 & 48.9 & 2.1 \\
\hline Lake area $\left(\mathrm{km}^{2}\right)$ & 0.18 & 0.66 & 0.26 \\
\hline Alkalinity $(\mu \mathrm{eq} / \mathrm{L})$ & -35 to 240 & -30 to 80 & -60 to 30 \\
\hline Mean alkalinity $(\mu e q / L)$ & 147 & 31 & -10 \\
\hline $\mathrm{pH}$ & 4.5 to 7.2 & 4.7 to 6.5 & 4.4 to 5.9 \\
\hline Mean pH & 6.2 & 5.6 & 4.7 \\
\hline \multicolumn{4}{|l|}{ Strong acid anions ( $\mu \mathrm{eq} / \mathrm{L})$} \\
\hline $\mathrm{SO}_{4}{ }^{2-}$ & 123 & 163 & 126 \\
\hline $\mathrm{NO}_{3}^{-}$ & 23.4 & 24.1 & 19.4 \\
\hline $\mathrm{Cl}^{-}$ & 12.6 & 16.6 & 9.1 \\
\hline$C_{A}$ (sum of acid anions) & 159 & 204 & 154 \\
\hline \multicolumn{4}{|l|}{ Base cations ( $(\mu \mathrm{eq} / \mathrm{L})$} \\
\hline $\mathrm{NH}_{4}^{+}$ & 1.64 & 0.68 & 3.16 \\
\hline $\mathrm{Ca}^{2+}$ & 207 & 147 & 73.1 \\
\hline $\mathrm{Mg}^{2+}$ & 52 & 55 & 18.6 \\
\hline $\mathrm{Na}^{+}$ & 41 & 35 & 19.3 \\
\hline$k^{+}$ & 12 & 12 & 6.2 \\
\hline Al (monomeric, inorganic) & 0.50 & 1.51 & 13.65 \\
\hline$C_{B}$ (sum of base cations) & 314 & 251 & 134 \\
\hline Dissolved organic carbon & & & \\
\hline$(\mu \mathrm{g} / \mathrm{L})$ & 3470 & 4920 & 2250 \\
\hline \multirow[t]{3}{*}{ Disturbance history } & Logging(?) & Wind throw & Fire \\
\hline & & Logging & Logging \\
\hline & & Beaver & Beaver \\
\hline
\end{tabular}

${ }^{1}$ Chemical parameters sampled at lake outlet.

Source: Tetra Tech Inc. (1984) 


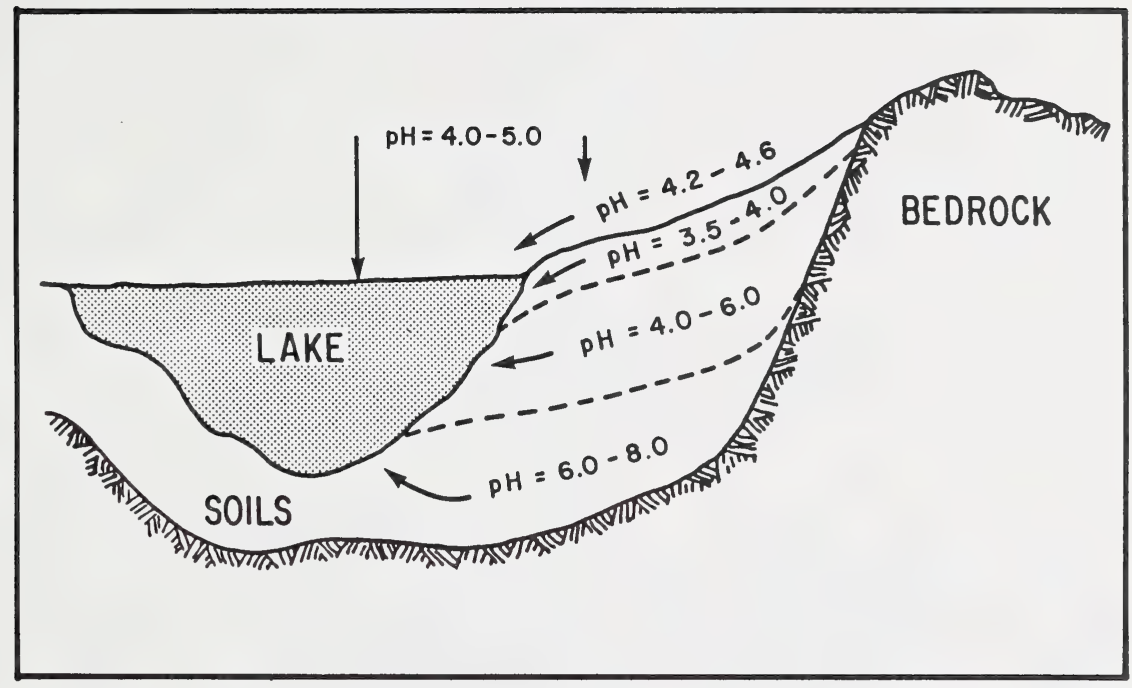

Figure 2. Lateral flow of water from different soil layers in determining lake water pH (after chen et al. 1984).

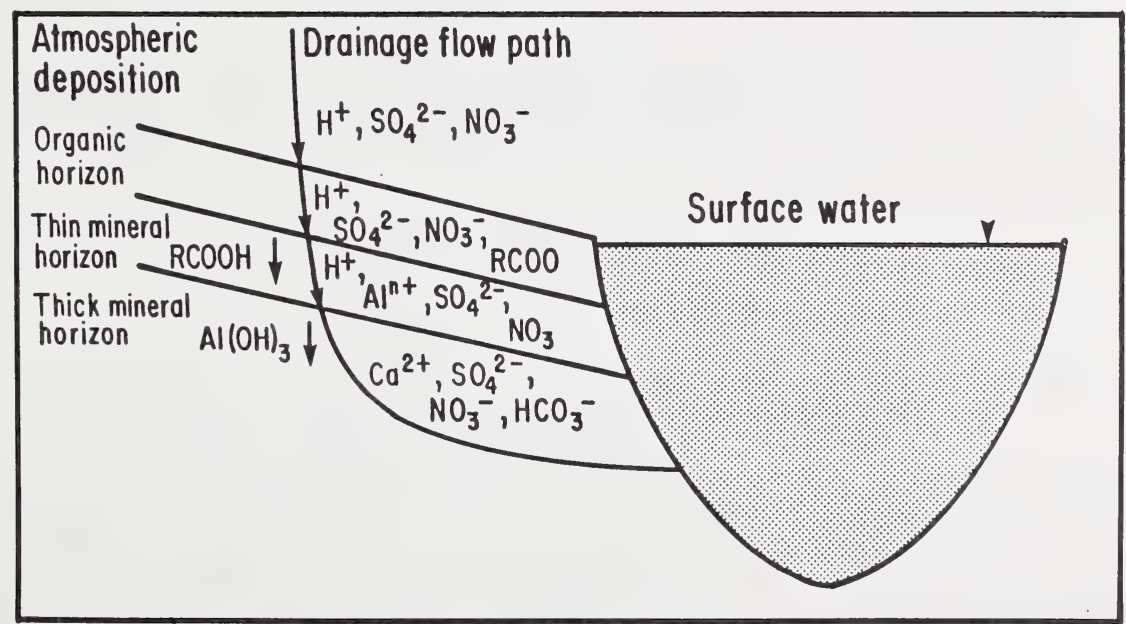

Figure 3. Chemical species associated with water flow paths to a lake (after Oriscoll and Newton 1985). 
Surface water chemistry studies of Woods and Panther lakes (Schofield 1984) support the observations of Chen et al. (1984) observation. The relatively high proportion of base-rich groundwater input to Panther Lake resulted in high pH and alkalinity ( $\mathrm{pH}$ 6.2; alkalinity $147 \mu \mathrm{eq} / \mathrm{L})$, whereas, the lateral flow of water through the shallow organic soil horizon to woods Lake resulted in low pH and alkalinity (pH 4.7 ; alkalinity $-10 \mu \mathrm{eq} / \mathrm{L})$. During snowmelt, temporal acidification was observed in these two lakes. It occurred as a result of base cation dilution $\left(\mathrm{Ca}^{2+}, \mathrm{Mg}^{2+}, \mathrm{Na}^{+}, \mathrm{K}^{+}\right.$, and $\mathrm{Al}^{\mathrm{n+}}$ ) and increased strong acid anion levels $\left(\mathrm{SO}_{4}{ }^{2-}, \mathrm{NO}_{3}{ }^{-}, \mathrm{Cl}^{-}\right.$). In Woods Lake, during snowmelt, base cation levels averaged $110 \mu \mathrm{eq} / \mathrm{L}$ and anions $150 \mu \mathrm{eq} / \mathrm{L}$, giving an alkalinity value of $-50 \mu \mathrm{eq} / \mathrm{L}$. In Panther Lake, the base cation and anion values averaged 250 $\mu \mathrm{eq} / \mathrm{L}$ and $150 \mu \mathrm{eq} / \mathrm{L}$, respectively, giving an alkalinity value of $100 \mu \mathrm{eq} / \mathrm{L}$. Schofield (1984) observed that due to small differences in organic carbon levels of the two lakes (3.30 mg/L for Panther and $3.28 \mathrm{mg} / \mathrm{L}$ for Woods) organic acids were not important in determining the $\mathrm{pH}$ differences between the lakes. The levels of organic acids going into the lakes were not stated. Acidification was attributed to the elevated inorganic aluminum levels and increase in nitrate concentration derived from nitric acid from the snowpack and nitrification processes in the soils. Aluminum export rates for both lake basins were different. For Woods Lake Basin it was 23 percent of the total base cation output; for Panther Lake Basin it was less than three percent. The low export rate in Panther Basin was attributed to soil weathering zones acting as a sink for aluminum mobilized in upper soil horizons by mineral and organic acids. Temporal acidification changes in both lakes, particularly Panther Lake, were attributed by Schofield (1984) to an upward shift in flow paths from groundwater-dominated baseflow to shallow interflow during the snowmelt period, as suggested by Chen et al. (1984). Gherini et al. (1984), using a simulated model, estimated that atmospheric deposition accounted for approximately $60 \%$ of the acid in these basins; the rest was due to internal production of hydrogen ions.

Eilers et al. (1983) sampled 275 north central Wisconsin lakes in the summer of 1979 to assess the factors controlling susceptibility of lakes to acidification. A cluster analysis was carried out using alkalinity, colour, and chlorophyll a data. They noted that hydrologic factors, not soil type, were most important in differentiating the low alkalinity and high alkalinity lakes.

Marcus et al. (1983) reported that watersheds containing soils with high sulphate adsorption capacity may be less sensitive to sulphate based acid deposition. For example, of five eastern United States soils tested for sulphate adsorption capacities, the greatest values were observed for soils from Coweeta, North Carolina (Johnson et al. 1980, cited by Marcus et a1. 1983). Based on this observation, these watersheds were considered relatively insensitive to acidification, although on a bedrock geology basis, this region has been classified as highly sensitive.

\subsection{TOPOGRAPHY AND WATERSHED-TO-LAKE RATIO}

Both topography and watershed-to-lake ratio affect the susceptibility of surface waters to acidification (Panel on Processes of Lake Acidification 1984). During episodic events these factors influence pH depressions of lakes or streams. 
Watersheds with steep slopes have rapid runoff. This limits interaction of the water with the soil. It has been suggested that surface waters in these areas receive atmospheric precipitation largely unchanged in its chemical composition (Marcus et al. 1983). However, this may not be true in watersheds where water movement through the organic layer occurs. In either case, lakes or streams in such areas become more susceptible to acidification. A smaller watershed-to-lake ratio also increases susceptibility of lakes to acidification due to direct input of atmospheric deposition. This was observed for a lake in south-central Ontario by Dillon et al. (1978). However, more than one study is required on lakes with smaller watershed-to-lake ratios to substantiate this hypothesis.

Lakes in drainage areas with high watershed-to-lake area ratios tend to be less susceptible to acidification. This is because acidity in precipitation water is mostly neutralized with the greater residence in, and contact time water with, surface soils.

\subsection{WATERSHED VEGETATION AND LAND USE}

Rosenqvist (1978b) and Krug and Frink (1983a,b) have claimed that terrestrial vegetation in watersheds markedly influences surface water pH. They have documented that soil acidity in watersheds increases with succession and accumulation of terrestrial vegetation. In particular, soils in coniferous forests can become markedly acidic, with $\mathrm{pH}$ values frequently as low as 3.5 (Brady 1974). Thus, vegetation can influence the apparent susceptibility of surface water to acidification, particularly when precipitation moves through humus layers of soil which is of plant origin (as discussed in Section 6.3).

Changed land use practices also can influence the susceptibility of a water body to acidification (Rosenqvist 1978b; Braekke 1981). Timber harvesting appears to decrease, and reforestation appears to increase, surface water acidity.

Thus, regardless of bedrock type and soil characteristics, vegetation and changed land use practices can alter the apparent susceptibility of a water body to acidification.

\subsection{SURFACE WATER QUALITY}

Alkalinity is the most important factor that determines the susceptibility of a water body to acidification. Waters with alkalinities greater than $200 \mu e q / L$ have low susceptibility to acidification, whereas those with less than $200 \mu e q / L$ have high susceptibility to acidification (Hendrey et al. 1980a). As discussed earlier, bedrock geology, soil, changed land use practices, and vegetation types generally influence the surface water alkalinities. Runoff from agricultural land which is spread with nitrate fertilizer and limestone, or from clearcut forest, appears to increase surface water alkalinity and pH (Rosenqvist 1978; Braekke 1981). In contrast, it has been suggested that runoff from agricultural land which is spread with ammonium and sulphate-containing fertilizers, or from conifer reforestated land, can decrease alkalinity and pH (Rosenqvist 1978; Braekke 1981; and Hunt and Boyd 1981). 


\subsection{CLIMATIC AND METEOROLOGICAL CONDITIONS}

As discussed in Section 4.1, water bodies in areas receiving high precipitation volumes tend to be more susceptible to acidification than those in areas receiving lower precipitation volumes. Another factor that contributes to short-term increase of acidity in surface waters is an episodic event, particularly snowmelt. During snowmelt much of the winter accumulation of acid deposition and naturally produced acids is released to surface waters during a relatively short time (see Section 4.3). In areas without large accumulations of snowpack, this phenomenon is less noticeable.

Alkaline dust in the atmosphere can also influence the acid-base status of lakes. Increases in proportions of alkaline dusts tend to reduce acidity of atmospheric deposition, thus reducing the possibility of surface water acidification (Marcus et al. 1983). 
A number of important points must be noted prior to a discussion of recent trends in surface water acidification due to atmospheric deposition. The first is that for poorly buffered waters, the available data base is limited (Marcus et al. 1983). Secondly, prior to 1955, most surface water pH measurements were done using colorimetric methods; in recent years potentiometric methods have been used. Use of these two different methods to establish acidification trends in surface waters has been criticized by many authors (see Section 5.2). Moreover, alkalinity measurements were rarely done on surface waters before 1955 (Haines 1981).

It should also be noted that trends in surface water acidification have been established using data sets which are several years apart. In many cases, data may have been collected at different times of the day or on different days of the year when the hydrological and meteorological conditions may have varied. Use of such comparisons ignores normal temporal variations in $\mathrm{pH}$ levels of surface waters caused by metabolic activities of aquatic organisms (Marcus et al. 1983). Respiration releases carbon dioxide to water, generating carbonic acid and thereby increasing surface water acidity. Photosynthesis consumes carbon dioxide and reduces surface water acidity. Allen (1972, cited by Marcus et a1. 1983), while investigating the effect of community metabolism on $\mathrm{pH}$ levels of a soft water lake in Vermont, observed this effect. He noticed that $\mathrm{pH}$ levels increased from 5.65 at 0800 hours to 9.57 at noon and then decreased to 6.35 at 1600 hours.

The fourth point is that the factors of land use practice (e.g., use of fertilizer, logging, and so forth) have often been ignored in establishing trends in acidification due to atmospheric deposition. As well, studies have not included investigation of the major flowpaths followed by precipitation in the watershed before reaching a lake, or the major processes that alter the chemical characteristics of precipitation as it moves along these flowpaths. The Integrated Lake-Watershed Acidification Study (Tetra Tech Inc., 1983-1984) is the only exception.

Finally, the parameters of colour and dissolved organic carbon (DOC) are often not included in the discussion of trends in the acidification of lakes and streams.

Therefore, in examining data on trends in surface water acidification due to atmospheric deposition, it is important to consider: (1) the time period of the data; (2) analytical methods used to obtain the two sets of data; (3) possible hydrological and meteorological changes between years; (4) time, month, and season of the year when data have been collected for comparison purposes; and, (5) the watershed land use practices and the chemical composition of the water as it moves through various flow paths in the watershed.

Numerous studies have been carried out on the effects of acid deposition on surface waters. The most commonly used parameters to assess lake water acidification have been the measurements of acidity, $\mathrm{pH}$, alkalinity, base cations, and aluminum concentrations. Some investigators report a trend in surface water acidification by comparing historical data and recent data on $\mathrm{pH}$ and loss of alkalinity, while others report lakes that may be susceptible to acidification based on bedrock characteristics and the present day lake or stream chemistry. These reports predict surface water acidification based on watershed characteristics and do not give conclusive evidence of 
surface water acidification due to atmospheric deposition of mineral acids. Rather than discussing the numerous studies of this type, a few studies conducted in Canada and the United States have been selected for review.

\subsection{ONTARIO}

Beamish $(1974,1976)$ has reported acidification of several lakes in the Sudbury and La Cloche Mountains regions of Ontario by comparing the chemistry of acidified lakes with that of unpolluted lakes from a similar geographical area. Beamish found loss of fish populations in many of these lakes and attributed the losses to atmospheric emissions of acid precursors and toxic metals from extensive smelting operations near Sudbury. The concentration of hydrogen ions ( $\mathrm{pH} 4.4-4.9 ; 30 \mu \mathrm{eq} / \mathrm{L}$ ) in one acidic lake represented $11 \%$ of the total cations. In unpolluted lakes it represented less than $1 \%$ of total cations. In general, hydrogen ion concentrations were two to three orders of magnitude greater in acidic lakes than in unpolluted lakes.

The concentration of base cations did not show significant differences between acidic and non-acidic lake waters, except for calcium which was twice as high in acidic waters $(160 \mu \mathrm{Eq} / \mathrm{L})$ as in non-acidic waters $(80 \mu \mathrm{Eq} / \mathrm{L})$.

In acidic lakes, sulphate $(320 \mu \mathrm{eq} / \mathrm{L})$ represented approximately $90 \%$ of the anions compared to an average of $40 \%$ in unpolluted lakes $(60 \mu \mathrm{eq} / \mathrm{L})$. Beamish's work clearly indicated lake acidification caused primarily by the local point source.

Smelting operations also appear to have contributed to some degree of acidification of approximately 50 lakes in the Wawa area of Ontario (Somers and Harvey 1984). Alkalinity in these lakes ranged from 0.0 to $95,900 \mu \mathrm{g} / \mathrm{L} \mathrm{HCO}_{3}{ }^{-}$, and $\mathrm{pH}$ ranged from 3.1 to 7.9. Six lakes were very acidic ( $\mathrm{pH} 3.09$ - 4.05), contained zero alkalinity, and the authors reported high concentrations of $\mathrm{Ca}^{2+}$ and $\mathrm{Mg}^{2+}$; however, concentration values were not given. The authors suggested that observed high concentrations of $\mathrm{Ca}^{2+} \mathrm{and}^{2+}$ in acidic lakes may be due to an ion-exchange mechanism because the acidified lakes have lost all of their bicarbonate. The acidified lakes also contained high concentrations of aluminum (3100 to $5400 \mu \mathrm{g} / \mathrm{L})$, and manganese $(3600$ to $6300 \mu \mathrm{g} / \mathrm{L}$ ). Iron concentrations were also noted to be high.

One lake (Molybdenite Lake) in this study was outside the fume-kill area and showed zero alkalinity and a pH of 5.0; it was suggested by Somers and Harvey that it may not have been acidified in recent decades.

Keller et al. (1980) studied 200 lakes within a $200 \mathrm{~km}$ radius of the sudbury stack and found $30 \%$ of the lakes had a pH of less than 5.5 , and $40 \%$ of lakes had calcite saturation indices between 3 and 5 , indicative of high sensitivity to acidification. The cause of acidification was attributed to local smelting operations.

Glass et a1. (1981) reported that about $6 \%$ of 1527 lakes surveyed in Ontario may be classified as acidified. Alkalinities in these acidified lakes were near to or less than $0 \mu \mathrm{eq} / \mathrm{L}$. Of the 103 acidified lakes, 83 are subjected to local problems related to smelting operations in Sudbury and Manitoulin Districts.

Although lake acidification in Ontario is primarily caused by a local point source, acidification of some lakes (e.g., Molybdenite Lake discussed above) by natural processes and changed land use practices cannot be ruled out; factors such as the presence of iron pyrite (Somers and Harvey 1984), erosion, terrestrial defoliation, and occasional ground fires may have contributed to the acidification. 
It is estimated that the Province of Quebec contains more than one million lakes located in the Canadian Shield and in the Appalachian region (Glass et al. 1981). The vast majority of these lakes have not been surveyed.

Jones et al. (1980) studied recent acidifcation trends of lakes in Laurentide Park located in the Precambrian Canadian Shield area of Quebec. By Chi-square analysis and by comparison of historical data (1838-1941) with the recent data (1979-1980) they observed significant increases in the number of lakes in the pH ranges 4.40-5.09, 5.10-5.74, and 6.50-7.19. They attributed this increase to atmospheric addition of acids. The decline in surface water $\mathrm{pH}$ was more evident in lakes in the southern part of the park than in the northern part and this was attributed to wind patterns. The authors reported that lakes were influenced by road salt and that some lakes had a high humic content (colour > $60 \mathrm{Pt}$ units). The authors did not discuss their methodology for analysing samples or data, making it difficult to interpret their results. However, the presence of coloured water lakes suggests that weak organic acids of natural origin may have been contributing to the acidity of the lakes.

Lachance et al. (1985) analysed the physico-chemical data from 229 Quebec lakes to obtain a general diagnosis of lake acidification in Quebec. Lakes were sampled in the spring and summer of 1980 and were grouped into two categories - those located on the Canadian Shield (199 lakes) and those in the Appalachian region.

The aquatic ecosystems in the Appalachian region were classified as non-sensitive to acid deposition, because the watersheds demonstrated unlimited capability of buffering $\mathrm{H}^{+}$input due to the abundant presence of carbonate-containing minerals (the $\mathrm{HCO}_{3}{ }^{-}: \mathrm{SO}_{4}{ }^{2-}$ ratio was greater than 2 ). The average values and standard deviation (given in brackets) for the major parameters in the lakes were: conductivity $66( \pm 44) \mu \mathrm{s} \mathrm{cm}^{-1}$; $\mathrm{H}^{+} 0.6( \pm 1.3) \mu \mathrm{eq} / \mathrm{L} ; \mathrm{Ca} 505( \pm 443) \mu \mathrm{eq} / \mathrm{L} ; \mathrm{Mg} \mathrm{139}( \pm 91) \mu \mathrm{eq} / \mathrm{L} ; \mathrm{SO}_{4}{ }^{2-} 104( \pm 32) \mu \mathrm{eq} / \mathrm{L} ; \mathrm{HCO}_{3}{ }^{-}$ $286( \pm 464) \mu \mathrm{eq} / \mathrm{L}$; $A 176( \pm 75) \mu \mathrm{eq} / \mathrm{L}$; colour $30( \pm 26) \mathrm{Pt}$; total organic carbon $12,000( \pm 5000)$ $\mu \mathrm{g} / \mathrm{L}$.

Lakes in the Canadian Shield were classified as potentially sensitive to acid deposition. The Canadian Shield is underlain by igneous and metamorphic rocks that are nighly resistant to chemical alteration $\left(\mathrm{HCO}_{3}{ }^{-}\right.$to $\mathrm{SO}_{4}{ }^{2-}$ ratio less than 1$)$. This was reflected in the flow conductivity value of $27( \pm 20) \mu \mathrm{s} \mathrm{cm}^{-1}$, and low concentrations of Ca $(141( \pm 154) \mu e q / L), \quad M g(50( \pm 30) \mu e q / L)$, and bicarbonate $(66( \pm 162) \mu e q / L)$ in the Shield lakes. When these values are compared with those in the lakes of the Appalachian region, the Canadian Shield concentrations are approximately $70 \%$ lower. However, the concentrations of hydrogen and aluminum ions in the lakes of the Canadian Shield were higher:

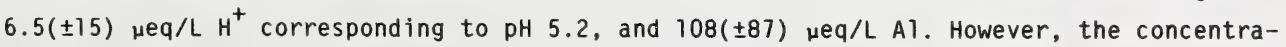
tions of $\mathrm{SO}_{4}{ }^{2-}(104( \pm 33) \mu \mathrm{eq} / \mathrm{L})$, and total organic carbon (average $\left.12,000( \pm 4000) \mu \mathrm{eq} / \mathrm{L}\right)$, and the colour value (average $34( \pm 44) \mathrm{Pt}$ ) in the lakes of the two regions showed no significant differences. The sulphate concentration in the lakes showed a strong southwest $(180 \mu \mathrm{eq} / \mathrm{L})$ to northeast $(30 \mu \mathrm{eq} / \mathrm{L})$ gradient. This was attributed to wind patterns and long range atmospheric transport of sulphur oxides (Jones et al. 1980).

The southern part of the Canadian Shield had a relatively high proportion of lakes with $\mathrm{pH}$ levels less than 5,5. Based on the $\mathrm{pH}$ frequency distribution, Lachance et al. (1985) suggested that acid deposition may have shifted $\mathrm{H}^{+}$of these lakes from 
the well buffered $\mathrm{pH}$ range to the present acidic condition. Jones et al. (1980) also made similar observations.

A substantial change in pH and alkalinity was observed for shield lakes during the spring period compared to the summer period. In the spring period of 1980, alkalinity, conductivity, and hydrogen ion concentrations were approximately 30 to 50 percent lower than the summer period concentrations, whereas colour and total organic carbon concentrations showed increases of $20 \%$ over the summer values. Lachance et al. (1985) suggested that the higher values of colour and total organic carbon during the spring could be explained by a higher contribution of overland and sub-surface flow and consequently on increased transport of organic matter.

The average colour (30 Pt units) and total organic carbon $(12,000 \mu \mathrm{eq} / \mathrm{L}$ ) values for these lakes suggest that these lakes may be undergoing acidification due to both natural and anthropogenic inputs of acidic substances. The extent to which they have been acidified may be dependent on the mineral characteristics of the particular study areas.

\subsection{ATLANTIC PROVINCES}

Most watersheds in the Atlantic provinces have little buffering capacity because much of the bedrock is granite overlain by Podzol soils (Glass et al. 1981).

Watt et al. (1979) surveyed 19 lakes in Nova Scotia which had originally been surveyed in 1955, and found that pH had declined in all of them, apparently from atmospheric deposition. However, Krug and Frink (1985) suggested that the observed pH declines may have been due to internal processes rather than acid deposition because the watersheds were disturbed before 1955 by changes in land use practices. Watt et al. (1979) did not give colour or dissolved organic carbon values for the Nova Scotia lakes and, therefore, it is difficult to conclusively state whether acidification was caused by watershed processes or by atmospheric input.

Recentiy, watt et al. (1983) surveyed 23 rivers in Nova Scotia which had been originally surveyed in 1952-54. They found that river pH's had fallen significantly over the past 27 years at an apparent average rate of $0.017 \mathrm{pH}$ units/year, supposedly due to acid deposition. The pH's were measured by glass electrodes both in 1952-54 and in 1980-81. Concomitant with pH decrease (average difference in $\mathrm{H}^{+}$concentration $+.009 \mathrm{mmol} / \mathrm{L}$ ) was a decline in $\mathrm{HCO}_{3}{ }^{-}$concentrations (average difference in concentration $-0.036 \mathrm{mmol} / \mathrm{L}$ ) and increases in $\mathrm{Al}^{3+}$ and $\mathrm{SO}_{4}{ }^{2-}$ concentrations (average differences in concentration +0.009 and $+0.039 \mathrm{mmol} / \mathrm{L}$, respectively). On an average, $73 \%$ of the increase in acid was attributed to increased $\mathrm{SO}_{4}{ }^{2-}$. Changes in $\mathrm{Na}^{+}, \mathrm{K}^{+}, \mathrm{Ca}^{2+}, \mathrm{and}^{2+}$ concentrations were not significant.

Although watt et al. (1983) suggested that these rivers have become acidic due to acid deposition, careful examination of the paper would suggest that natural processes may also be contributing factors. There are three reasons for this suggestion. The first is that some of the rivers are typified by light brown to dark brown colour (average 30 to greater than 100 Hazen colour units) and high dissolved organic carbon (greater than 4000 to greater than $10,000 \mu \mathrm{g} / \mathrm{L}$ ). The high dissolved organic carbon and high colour values suggest the presence of acidic humic substances in the river waters. 
The second reason is that most of the river basins appear to have been occupied by heath and peat bogs which are coloured and acidic due to the presence of humic substances. Moreover, the basins appear to have experienced changed land use practices such as forest burning, lumbering operations, and agricultural practices. All of these practices may potentially contribute to river acidification (Krug and Frink 1983b).

The third reason is that the $\mathrm{SO}_{4}{ }^{2-}$ levels reported by watt et al. (1983) may be high. They used the methylthymol blue colorimetric (MTB) method to determine $\mathrm{SO}_{4}{ }^{2-}$ levels in the river waters and compared the results so obtained with the results of 1954-55 obtained by the turbidimetric method. Kerekes and Pollock (1983) have reported that the two methods are not comparable, because the MTB method is more susceptible to colour interferences than the turbidimetry method. As we11, with coloured water the MTB method gives higher $\mathrm{SO}_{4}{ }^{2-}$ values than the turbidimetry method. Kerekes and Pollock (1983) suggested that in coloured water, the MTB $\mathrm{SO}_{4}{ }^{2-}$ determination gives biased results and that water chemistry in the above rivers as it relates to acidity must be considered in terms of organic anions that are present in coloured waters and that can contribute to the acidity of these waters.

Watt et al. (1983) reported that with the MTB method no significant interference occurred at colour levels of less than 50 units, and, therefore their $\mathrm{SO}_{4}{ }^{2-}$ values for coloured waters of less than 50 Hazen units may be correct. However, they conceded that the $\mathrm{SO}_{4}{ }^{2-}$ value for coloured waters of greater than 80 Hazen units may be too high. They also reported that Kerekes and Pollock's suggestion with regard to organic anions needs further study because a good correlation was found between colour and dissolved organic carbon in their data. Apparently, organic anion concentrations and colour values have declined appreciably in these rivers over the 26 years due to decreases in $\mathrm{pH}$. However, since $\mathrm{HCO}_{3}{ }^{-}$has largely disappeared due to low $\mathrm{pH}^{\prime} \mathrm{s}$ in these waters, the organic anions remain the important acid buffers in these waters to resist further pH declines (Watt et al. 1983):

Scruton (1983) surveyed 109 lakes on the island of Newfoundland from August 16 to October 18, 1985 for possible effects from acid deposition. Lake pH varied from 4.90 to 8.39, with 10 lakes having $\mathrm{pH}^{\prime} \mathrm{s}$ less than 5.5. Alkalinity values of less than $200 \mu \mathrm{eq} / \mathrm{L}$ were observed for 93 lakes, indicating moderate to high sensitivity to acidification.

However, several lake waters in the study area were highly coloured (colour values 16 to $225 \mathrm{TCU}$ ) and the region contains sulphate-bearing pyrite and gypsum minerals, making it difficult to isolate the roles of natural organic acidicity and mineral acidity of anthropogenic origin. Non-marine sulphate values ranged from 5.7 to $91.4 \mathrm{\mu eq} / \mathrm{L}$ (average, $34.5 \mu \mathrm{eq} / \mathrm{L}$ ) which is less than those reported for lakes experiencing moderate to high acid deposition $(125 \mu \mathrm{eq} / \mathrm{L})$. Almer et al. (1974) and Harvey et al. (1981) have reported natural background levels of sulphate of biological origin in lake waters ranging from 20 to $60 \mu \mathrm{eq} / \mathrm{L}$. Scruton concluded, therefore, that the sulphate in the lakes of the study area may be of geological, biological, or anthropogenic origin. Scruton observed that organic acidity (of natural origin) may be contributing to $\mathrm{pH}$ declines because a high correlation was found between colour and organic acidity for many of the lakes; there is presently no widespread acidification problem in the study area although the region is most sensitive to acid deposition. 
Liaw (1982) analysed some 300 lakes in Saskatchewan's Shield and fringe shield regions for total alkalinity, calcium, magnesium, and $\mathrm{pH}$ in order to assess the sensitivity of these lakes to potential acid deposition. Concentrations of alkalinity in these lakes varied from 10 to $1740 \mu \mathrm{eq} / \mathrm{L}$ as $\mathrm{CaCO}_{3}$ with a mean value of $360 \mu \mathrm{eq} / \mathrm{L}$. Fortyfour percent of the lakes surveyed had alkalinities equal to or less than $200 \mu e q / L$, while $27 \%$ had alkalinities between $200-400 \mu e q / L$. Although Liaw considered these two groups of lakes to be highly to moderately sensitive to acid deposition, alkalinity values of some lakes in the first group suggest that they may be moderately sensitive to acid deposition.

Lake $\mathrm{pH}^{\prime} \mathrm{s}$ ranged from 5.56 to 8.2 , indicating that at present Saskatchewan Shield lakes are not very acidic; lakes with $\mathrm{pH}$ values between 6.5 to 7.5 accounted for nearly $80 \%$ of the surveyed lakes.

Concentrations of calcium ranged from 16 to $1576 \mu \mathrm{eq} / \mathrm{L}$ with an average value of $284 \mu \mathrm{eq} / \mathrm{L}$; those of magnesium were between 0 to $890 \mu \mathrm{eq} / \mathrm{L}$ with an average value of $164 \mu \mathrm{eq} / \mathrm{L}$. Concentrations of calcium alone or together with magnesium were highly correlated to alkalinity.

Liaw attempted to predict the anticipated rate of acidification (to $\mathrm{pH} 5.5$ ), taking into account the mean depth and alkalinity of the lake, and assumed a sulphur deposition rate of $0.4 \mathrm{~g} / \mathrm{m}^{2} / \mathrm{y}$. Liaw speculated that in the event of acid deposition, shallow and poorly buffered Shield lakes in northern Saskatchewan may be acidified in a matter of a few decades. However, Henriksen's (1979, 1980) empirical model suggests that none of Saskatchewan's Shield lakes are presently being affected by acid deposition.

\subsection{NEW ENGLAND STATES}

Haines et al. (1983) surveyed 226 headwater lakes and low order streams in Connecticut, Maine, Massachusetts, New Hampshire, Rhode Island, and Vermont. The waters were low in colour and relatively undisturbed by human activities. Highly coloured lakes were not surveyed.

Waters with a pH of less than 5 were found in every state. Approximately $8 \%$ of the waters surveyed had a pH below 5; and $29 \%$ had a pH below 6 . Waters with low alkalinity content were more common than low pH waters. Approximately $24 \%$ of the waters had alkalinity concentrations of $20 \mu \mathrm{eq} / \mathrm{L}$ or 1 ess, $41 \%$ had concentrations of $100 \mu \mathrm{eq} / \mathrm{L}$ or less, and $53 \%$ had concentrations of $200 \mu \mathrm{eq} / \mathrm{L}$ or less. Calcite saturation index results were similar to alkalinity and both showed high correlations. Approximately $59 \%$ of the waters surveyed had a CSI value greater than 3, indicating high susceptibility to acidification. Hydrogen ion content was not correlated with colour, indicating that acidity of lakes was not primarily due to natural organic acids. Colour was measured as an index of organic acids. The regression equation TOC (Total organic carbon) $=1.32+$ 0.0613 colour (colour unit) was used to calculate TOC for all samples. The lakes and streams contained appreciable levels of non-marine sulphate ( 80 to $120 \mu e q / L$ ); however, $\mathrm{SO}_{4}{ }^{2-}$ was not positively correlated with hydrogen ion. The authors suggested two reasons for this. The first was that precipitation, and thus sulphate deposition, is relatively uniform. The second was that there may have been a regional "background" level of sulphate. The background $\mathrm{SO}_{4}{ }^{2-}$ could originate from terrestrial dusts or anthropogenic sulphate that is not acidic. 
Aluminum and manganese concentrations in the New England lakes and streams were correlated with hydrogen ion content. Aluminum concentrations in surveyed waters ranged from 100 to $200 \mu \mathrm{eq} / \mathrm{L}$. High aluminum concentrations $(200 \mu \mathrm{eq} / \mathrm{L})$ were generally found in low pH waters; at this level aluminum may be toxic to some species of fish (Schofield and Trojnar 1980).

of the physical parameters measured, the ones most closely related to buffering capacity and acidity were bedrock geology and, to a lesser extent, soil cation exchange capacity. A sensitive lake or stream, as determined by alkalinity, was found in an area where bedrock was low in buffering capacity or soils were low in cation exchange capacity.

Historical pH and alkalinity data (determined as early as 1937 and 1978, respectively) indicated that waters located in areas where buffering capacity is low have been acidified. Of the 95 lakes with usable historical pH data, 61 (64\%) were lower in $\mathrm{pH}$ units in the recent study. Of 56 lakes for which historical alkaline data were available, $39(70 \%)$ had lower values in the recent study. The hydrogen ion concentration for an average lake increased five fold (from $0.8 \mu \mathrm{eq} / \mathrm{L}$ historically to $4.3 \mu \mathrm{eq} / \mathrm{L}$ recently) and alkalinity decreased by $60 \%$ (from $166 \mu \mathrm{eq} / \mathrm{L}$ historically to $68 \mu \mathrm{eq} / \mathrm{L}$ recently). The correction factor $(32 \mu \mathrm{Eq} / \mathrm{L})$ was applied to the historical alkalinity data to offset overestimation of alkalinity.

The historical alkalinity data were all obtained by fixed end point titrations to $\mathrm{pH} 4.5$ (methyl orange end point). This method overestimates true alkalinity because the actual endpoint is not fixed but rather increases with decreasing alkalinity. Haines et a1. (1983) measured both fixed endpoint and inflection point alkalinity (Gran's method) for their samples and found that the two values were highly linearly correlated (Inflection point $=-32+1.00$ fixed endpoint; $\left.r^{2}=0.999\right)$. Therefore, for all historical data, fixed endpoint alkalinity data were corrected for the overestimation by subtracting $32 \mu \mathrm{eq} / \mathrm{L}$.

Although the historical pH data were largely determined colorimetrically and the recent $\mathrm{pH}$ determinations potentiometrically the limit of accuracy of +0.2 units between the two methods (Schofield 1982; Haines et al. 1983) indicates that observed acidification trends may be real.

The relationship between $\mathrm{pH}$ and the calcium content of surface waters (Henriksen model) predicted that $57 \%$ of the waters surveyed had been acidified, a value in good agreement with that obtained from lakes for which historical water chemistry data were available. The model further predicted an average loss of $50 \mu \mathrm{eq} / \mathrm{L}$ of alkalinity. Historical data indicated a decline of about $100 \mu \mathrm{eq} / \mathrm{L}$. This was considered to be reasonably good agreement given the large range of chemical conditions.

Haines et a1. (1983) and Marcus et al. (1983) cited various other studies (Davis et a1. 1978; Hendrey et a1. 1980a; and Norton et a1. 1981) in the New England states in which historical $\mathrm{pH}$ data (method used colorimetric) were compared with the recent data (method used: potentiometric) to measure trends in survey water acidification.

Davis et a1. (1978) analysed pH data from 1368 Maine lakes and reported that the $\mathrm{pH}$ declined from 6.18 in 1937-1943 to 6.09 in 1969-1974. Most of the decline was reported to have occurred between 1950 and 1960, with smaller declines since then, but no fish losses have been reported as accompanying these decreases. This small decline 
most likely results from the fact that the lakes surveyed were large, lowland lakes that were not highly vulnerable to acidification (Haines et al. 1983).

Hendrey et al. (1980a) compared pH values measured in the 1930's with those measured in 1979 for 42 New Hampshire streams and found that pH had declined in 37 (88\%) from $\mathrm{pH} 6.66$ to 6.12. Marcus et a1. (1983) suggested that the colorimetric method may have been biased in favour of elevated $\mathrm{pH}$ values. Thus, the pH decline from 1930 to 1979 may have been less than reported, or negligible. Also, the comparison of only two points in time does not permit estimation of the influence of natural variations.

Norton et a1. (1981) reported historical (1939-1946) versus recent (1978-1980) $\mathrm{pH}$ comparisons for 69 low humic, coloured lakes in Maine, New Hampshire, and Vermont and found that 51 (74\%) had decreased $\mathrm{pH}$ values. Identical colorimetric methods were used to determine $\mathrm{pH}$ in both historical and recent water samples. This finding agrees well with those of Haines et a1. (1983). However, Marcus et al. (1983) suggested that because the study only compared two points in time over extended intervals (1939-1946 and 19781980), it is unclear whether these are actual trends, or artifacts of normal temporal variations in surface water $\mathrm{pH}$.

The longest continuous data on stream water and precipitation chemistries in North America have been reported for the Hubbard Brook Experimental Forest in New Hampshire from 1964 to 1974 (Likens et a1. 1977). This area receives acidic atmospheric deposition (average $\mathrm{pH} 4.12$ ) and the area is classified as highly sensitive to acidification due to its bedrock geology and soil characteristics (Hendry et al. 1980a). Yet, for this period of ten years, Likens et al. (1977) reported the maintenance of relatively constant stream water chemistry and no apparent trends in stream pH's. The stream $\mathrm{pH}$ during this period remained near 5.0 .

\subsection{THE ADIRONDACK MOUNTAINS}

The Adirondack region of New York receives a considerable amount of acid deposition ( 0.5 to $0.75 \mathrm{keq} / \mathrm{ha} / \mathrm{y} \mathrm{SO}_{4}{ }^{2-} ; 0.25$ to $4 \mathrm{keq} / \mathrm{ha} / \mathrm{y} \mathrm{NO}_{3}{ }^{-}$; Driscoll and Newton 1985). The region is underlain by acid sensitive bedrock. Soils within the region are generally spodosols with minimum sulphate adsorption capacity. Thus, this northeastern US region is one of the poorly buffered lake districts where fish losses have been attributed to the effects of acid deposition (Schofield 1976a,b).

Two data sets, one collected in 1930-1934 and the other in 1975-1979, have been used to determine historical acidification trends in the lake waters (Schofield 1976a,b; Pfeiffer and Festa 1980). Based on comparison of the two data sets, it was reported that in 1930-1934 only 4\% of 217 high elevation lakes had pH levels below 5.0 and were devoid of fish; in 1975, 51\% of these lakes had a pH of less than 5.0 and $90 \%$ were devoid of fish (Schofield 1976a,b).

Pfeiffer and Festa (1980) also compared temporal changes in pH for a set of 138 Adirondack lakes. They compared only the old colorimetic pH data with the new Hellige colorimetric pH data in order to reduce much of the bias introduced by different methods. Their results indicated that lake acidification has occurred in the Adirondack Mountains. There were fewer lakes with $\mathrm{pH}^{\prime} \mathrm{s}$ above 7 and more lakes with pH's below 6 in their recent (1979) survey compared with the historic (1930-1934) survey. Most of the acidified lakes originally had pH values above 6.5. In the 1930 's, the lakes had a median $\mathrm{pH}$ of 6.75 , while in 1979 the median pH was 6.51 , a decline of $0.24 \mathrm{pH}$ units (Marcus et a1. 1983). 
Although lake acidification has occurred in the Adirondack region, it is unclear whether the nistorical acidification trends reported by the above authors are due to acidic atmospheric deposition or natural processes, or to both. Krug and Frink (1983b) suggested that this region underwent changed land use practices around 1920, and therefore natural processes must have been a major factor that has contributed to lake acidification.

In the Adirondack Mountains, in 1977, the Integrated Lake-Watershed Acidification study (ILWAS) was initiated in response to questions on the effect of acid deposition on surface water chemistry (Tetra Tech Inc. 1983, 1984). The fundamental concept on which the design of ILWAS was based is that a lake's vulnerability to acidification by atmospheric deposition can only be understood in the context of the acid-base chemistry and hydrology of its entire catchment. Based on this concept, the concentrations of chemical constituents in the major flowpaths followed by the precipitation before reaching a lake were measured, and the major processes that alter the chemical characteristics of water as it moves long the flowpaths were determined. Three lakes, Sagamore, Panther, and Woods, were studied. The chemical characteristics of the three lakes are given in Table 3, Section 6.3. The vulnerability of Panther and Woods Lakes to acid deposition has been discussed in Section 5.5 .

Recently, Driscoll and Newton (1985) sampled twenty lakes and their watersheds in the Adirondacks in an effort to evaluate mechanisms that control the sensitivity of lakes to acidification. Two of the lakes were seepage lakes (lakes with no surface inlets or outlets) and the other 18 were drainage lakes (lakes with outlets that receive water by stream discharge and seepage). Oriscoll and Newton selected five lakes (two seepage and three drainage lakes) to illustrate the range of chemical composition.

The two seepage lakes - Barnes Lake ( $\mathrm{pH} 4.7$ ) and Little Echo Pond (pH 4.3) receive most of their water directly from precipitation and therefore are highly sensitive to acid deposition. They are isolated from the groundwater system and receive no runoff water; therefore the concentrations of base cations and dissolved si are very low. Also, they have low concentrations of Al despite their low pH values. Although both lakes are acidic, there are significant differences in their physical and chemical characteristics. Barnes Lakes is a perched clearwater lake and much of its acidity is attributed to atmospheric deposition of $\mathrm{H}_{2} \mathrm{SO}_{4}$ that is reflected by the high concentration of $\mathrm{SO}_{4}{ }^{2-}$ anions in the lake water. Little Echo Lake is a brown water lake and its acidity is attributed both to atmospheric deposition of $\mathrm{H}_{2} \mathrm{SO}_{4}$ and release of organic acids from peat deposits of 28 meters thickness which surround the lake. Oriscoll and Newton (1985) reported comparable concentrations of $\mathrm{SO}_{4}{ }^{2-}$ and organic anions in this lake.

The drainage lakes (Merriam Lake, West Pond, and Cascade Lake) are quite different from the seepage lakes. They have high concentrations of base cations and dissolved Si as a result of contact between the drainage water and the soil.

Merriam Lake is an acidic lake ( $\mathrm{pH} 4.5)$. The catchment lacks base cations and therefore neutralization of mineral acid is accompanied in part by dissolution of $A 1$ in the soil. Consequently, $\mathrm{SO}_{4}{ }^{2-}, \mathrm{H}^{+}$, and $\mathrm{Al}^{\mathrm{n}+}$ are found in significant concentrations. Although $\mathrm{SO}_{4}{ }^{2-}$ is the predominant anion in Merriam Lake, Driscoll and Newton (1985) reported that $\mathrm{NO}_{3}{ }^{-}$and organic acids may also contribute to acidity. However, they did not mention the colour of the lake. They suggested that $\mathrm{NO}_{3}{ }^{-}$may be of anthropogenic or biological origin or both. 
West Pond is a bog drainage lake with peat deposits adjacent to ponds. Its acidity $(\mathrm{pH} \mathrm{5.2)}$ is therefore attributed to sulphuric acid and organic acids alike.

Cascade Lake ( $\mathrm{pH}$ 6.5) is relatively insensitive to acid deposition of mineral acids. The high concentrations of $\mathrm{SO}_{4}{ }^{2-}$ in the drainage water due to atmospheric deposition of $\mathrm{H}_{2} \mathrm{SO}_{4}$ is balanced by the high concentrations of base cations, predominantly $\mathrm{Ca}^{2+}$, due to weathering reactions and the dissolution of base cations from the mineral soil. The extent of the weathering reaction is indicated by high concentrations of $\mathrm{HCO}_{3}{ }^{-}(95 \mu \mathrm{eq} / \mathrm{L})$ and dissolved Si.

Driscoll and Newton (1985) have shown that sensitivity of lakes to acidification varies from lake to lake and it depends on hydrology, mineralogy, and vegetative covering in the study area. They suggest that in Adirondack lakes organic acids are the main cause of brown water lake acidity, and that $\mathrm{H}_{2} \mathrm{SO}_{4}$, and to a lesser extent $\mathrm{HNO}_{3}$, are the main causes of clear water acidity.

\subsection{NEW JERSEY}

Johnson (1979a,b) reported a seventeen-year trend toward acidification of 2 headwater streams which drained a relatively undisturbed watershed in the New Jersey Pine Barrens. The decline in $\mathrm{pH}$ amounted to approximately 0.4 units, with an estimated increase in $\mathrm{H}^{+}$concentration of about $50 \mu \mathrm{eq} / \mathrm{L}$. Because hydronium ion concentration correlated with $\mathrm{SO}_{4}{ }^{2-}$ concentration in the two headwater streams, Johnson (1979a) suggested that acidification of the streams may have resulted from acidic atmospheric deposition. However, he noted that the streamwater was yellow in colour, particularly in summer, as a result of organic matter. Johnson (1979b) then suggested that the cause of acidification could not be determined conclusively from the data. However, because there was no statistical evidence for biological acidification, oxidation of geological sulphides, or changed land use practices as causes of the long-term trend of acidification, he hypothesized that the major mechanism involved acid precipitation.

It is important to note that the pinelands are generally underlain by sandy soils which are naturally characterized by low pH (3.4-4.6), poor cation exchange capacity, and few exchangeable bases. Pine-oak communities are generally dominant and the streams are bordered by acid wetlands and sphagnum moss (Johnson 1979b; Morgan 1984). Gorham et al. (1984b) suggested that surface waters in such areas are naturally acidic and they have no adverse effect on aquatic life. Morgan (1984) reported that in most undisturbed pineland waters, $\mathrm{pH}$ values were generally below 4.5 and at that $\mathrm{pH}$ these waters maintained biological communities. He also stated that pineland aquatic communities have long existed at very low pH. For these reasons, State and Federal regulatory agencies have included the maintenance of low pH (below 5.0) in pineland waters as a primary focus of regional planning and protection strategies.

Morgan (1984) re-examined the water chemistry data of these two headwater streams in the New Jersey pinelands and reported that acidification of the two streams by acid deposition as suggested by Johnson $(1979 a, b)$ is not supported by more recent data and a re-evaluation of the original data. For one stream, MacDonalds Branch, he observed no significant decline in pH from 1958 to 1982 . For the other, Oyster Creek, a significant decline in $\mathrm{pH}$ was observed from 1965 to 1982, but the data indicated that this was probably a return to normally low pH levels following a short-term watershed 
disturbance in the mid-1960's. Thus, the surface waters of the Pine Barrens appear to be naturally acidic, with little evidence to suggest that a trend of declining $\mathrm{pH}$ is due to acidic atmospheric deposition. However, acid deposition must be viewed as just one of many processes capable of altering the stream pH of pineland waters.

\subsection{VIRGINIA}

Shaffer and Galloway (1982) surveyed two watersheds in the Shenandoah National Park for the impact of acid precipitation on two headwater streams. The streams were surveyed weekly from 1980 through 1981. The stream $\mathrm{pH}^{\prime} \mathrm{s}$ were 6.06 and 5.66 . The alkalinity, determined by subtracting the sum of cations from the sum of anions, averaged $3.0 \mu \mathrm{g} / \mathrm{L}$. The authors found that both streams showed a high degree of chemical stability, rather than aquatic acidification. The stability appeared to be controlled by sulphate absorption, bicarbonate production, and cation exchange equilibria in the soil. Sulphate adsorption capacity in these watersheds appeared to be finite and there was a net export of base cations $\left(\mathrm{K}^{+}, \mathrm{Mg}^{2+}\right)$ from the soil; therefore, current stability appears to have been achieved at the cost of long-term degradation of the soil systems.

SOUTH CAROLINA

Elzerman (1983) surveyed lakes in the South Carolina Piedmont and southern Appalachian Mountain region for evidence of actual or potential susceptibility to acidification. The overall conclusion of this study was that acid deposition is not a problem as yet but has a potential to become a problem. Using the Kramer and Tessier model (1982), they found that acidification was occurring in some lakes and that watershed soils were being weathered faster than expected from the action of carbonic acid alone. If the weathering material is exhausted, it appears that those lakes may become vulnerable to acidification.

\subsection{FLORIDA}

Florida has highly weathered, sandy soils with low cation exchange capacities and low buffering capacity (Brezonik et al. 1980). Several soft water lakes were surveyed by Brezonik et al. (1980) in the Sandhill region of north and central Florida. They obtain most of their water directly from precipitation and seepage through sandy soils. Since the late 1950's and 1960's the average pH of the lakes has dropped by 0.3 to $0.9 \mathrm{pH}$ units. Because the methodology for the earlier pH measurements is not reported, it is difficult to assess whether the observed acidification trend is real or not.

Canfield (1983) surveyed 165 lakes in Florida between August 1978 to September 1980 for effects of acid deposition. The lakes were located in the major physiographic and geological regions of Florida. Mean lake pH, total alkalinity, and calcium hardness concentrations ranged from 4.1 to $8.9,0$ to 4100 ( $\mu \mathrm{eq} / \mathrm{L})$, and 20 to $4300(\mu \mathrm{eq} / \mathrm{L})$, respectively. The mean colour value averaged 50 colour units. In $49 \%$ of the sampled lakes, alkalinity averaged less than $200 \mu \mathrm{eq} / \mathrm{L}$; in $36 \%$ of the sampled lakes, calcite saturation index values were greater than 4. Based on these data, a large number of Florida lakes should be susceptible to acid deposition. However, Canfield (1983) reported that data on chlorophyll a concentrations $\left(18,000 \mu \mathrm{g} / \mathrm{m}^{3}\right)$ and on zooplankton abundance 
(227,000 organisms/L) and recent fisheries data suggest that Florida lakes may not be as biologically sensitive as the alkalinity and calcite saturation indices might suggest. While there was some reduction in animal and plant populations in acidic florida lakes, it has been attributed to low phosphorus and nitrogen concentrations. Canfield, therefore, suggested that predictions of future impact or trends in surface water acidification based on sensitivity indices should be regarded with caution.

Flora and Rosendahl (1982) studied the impact of atmospheric deposition on the water quality of the Shark River slough in Everglades National Park from June 1980 through August 1981, and found that the water of the slough was not threatened by atmospheric deposition because of its high buffering capacity. The mean pH of precipitation was 4.9 and the mean alkalinity of the slough was $189,000 \mu \mathrm{g} / \mathrm{L}$ (as $\mathrm{CaCO}_{3}$ ). The specific conductivity of the surface water was quite high (average 718 mhos). Alkalinity as determined by subtracting the sum of cations from the sum of anions averaged $2100 \mu \mathrm{eq} / \mathrm{L}$.

\subsection{CALIFORNIA SIERRA NEVADA}

The Sierra Nevada region is characterized by high elevation, the predominance of granitic bedrock, thin acidic soils, large amounts of precipitation, coniferous vegetation, and very dilute waters.

Tonnesson and Harte (1982) sampled 35 subalpine lakes on the western slopes of the Sierra Nevada between 1979 and 1987 and reported a pH range of 6.3 to 7.7 and alkalinity values between 29.0 and $192 \mu \mathrm{eq} / \mathrm{L}$. Because there were no reliable and representative measurements of alkalinity in high altitude lakes prior to those reported by these authors, it is difficult to establish whether a change in alkalinity has occurred over the years. However, based on the alkalinity value, these lakes may be susceptible to acid deposition.

Melack et a1. (1982) surveyed 70 lakes in the alpine region and eastern flank of the Sierra Nevada in the summers of 1981 and 1982 and reported a pH range of 6 to 8 . Seventy percent of the lakes had summer alkalinities below 90 req/L and a few had alkalinities above $200 \mu \mathrm{eq} / \mathrm{L}$. The major cation in the lakes was calcium $(43 \mu \mathrm{eq} / \mathrm{L})$, and bicarbonate $(50 \mu \mathrm{eq} / \mathrm{L})$ was the major anion; a few lakes had as much or more $\mathrm{SO}_{4}{ }^{2-}$ or $\mathrm{Cl}^{-}$ion as bicarbonate. Most lakes had $\mathrm{SO}_{4}{ }^{2-}$ concentrations of less than $40 \mu \mathrm{eq} / \mathrm{L}$ (average $17 \mu \mathrm{eq} / \mathrm{L}$ ) and $\mathrm{NO}_{3}{ }^{-}$less than $4 \mu \mathrm{eq} / \mathrm{L}$ (average $0.15 \mu \mathrm{eq} / \mathrm{L}$ ). Melack et al. (1982, 1985) speculated that if the acidity of precipitation increases, acidification of these lakes may occur because the basin possesses low buffering capacity.

\subsection{UPPER GREAT LAKES STATES}

In the summer of 1979, Eilers et al. (1983) sampled 275 lakes located in north central wisconsin to assess the factors controlling susceptibility of these lakes to acidification. The soils in this region are mostly acidic ( $\mathrm{pH} 4-5)$, with low cation exchange capacity $(\sim 10 \mu \mathrm{eq} / 100 \mathrm{~g})$ and low base saturation $(10-30 \%)$. The igneous and metamorphic bedrock underlying this region is part of a southern extension of the Precambrian Canadian Shield.

Alkalinity in these lakes ranged from -25 to $1111 \mu \mathrm{mol} / \mathrm{L}$ (average $287 \mu \mathrm{mol} / \mathrm{L}$ ); $\mathrm{pH}$ ranged from 4.1 to 8.9 (average 6.9 ); and conductance ranged from 10 to $128 \mu \mathrm{S} / \mathrm{cm} 25^{\circ}$ (average $48 \mu \mathrm{S} / \mathrm{cm}$ ). The authors reported that many lakes had moderately high colour 
values (range $0-400 \mathrm{pcu}$; average $50 \mathrm{pcu}$ ) caused by organic acids derived from plant materials. To assess the factor controlling susceptibility of lakes to acidification, they carried out cluster analyses using alkalinity, colour, and chlorophyll A data. Three clusters emerged that appeared to be controlled by hydrology. Cluster $A$ included 97 lakes with high chlorophyll values $(15 \mu \mathrm{g} / \mathrm{L})$, high colour (95 pcu) and moderate alkalinity $(345 \mu \mathrm{mol} / \mathrm{L})$. The high colour and the high watershed-to-lake surface area ratio (20.9) suggested a dominant influence from surface runoff. These lakes may be undergoing acidification due to natural input of hydrogen ions by way of organic acids. Cluster $B$ included 76 lakes with high alkalinity $(618 \mu \mathrm{mol} / \mathrm{L})$, high conductance $(75 \mu \mathrm{S} / \mathrm{cm})$, low colour $(19 \mathrm{pcu})$, and small watershed-to-lake surface area ratio $(5.0)$. These lakes appeared to be influenced by waters of groundwater origin. Cluster $C$ was comprised of 102 lakes with low alkalinity $(34 \mu \mathrm{mol} / \mathrm{L})$, low conductance $(20 \mu \mathrm{S} / \mathrm{cm})$, low colour ( $8 \mathrm{pcu})$, and a low watershed-to-lake area ratio (3.4). This suggested a minimal groundwater and surface runoff water influence. The low alkalinity values indicated that these lakes may be highly susceptible to the atmospheric acidic inputs. Based on statistical analyses, Eilers et al. (1983) speculated that hydrologic factors may be more important in differentiating the low and high alkalinity lakes. However, they have not carried out detailed hydrological studies as has been done by chen et al. (1984) in the ILWAS study.

Rahel and Magnuson (1983) examined 138 lakes in northern Wisconsin during the summer months of 1979-1981 for fish assemblages. These lakes were not studied for the effect of long range transport of acidic atmospheric deposition. However, most of these lakes were naturally acidic seepage or brown water bog lakes and had low pH's ranging from 4.0 to 6.5 .

Glass (1984) surveyed lakes in northern Minnesota and Wisconsin and, based on calcite saturation index values, speculated that approximately $75 \%$ of the lakes sampled are susceptible or potentially susceptible to acidification. In northern Minnesota about 103 lakes had pH above 6.0; whereas, in northern Wisconsin 50 of the 350 lakes had pH below 6.0. Glass did not give any analytical results for lake waters nor did he mention whether the surveyed lakes were clear water or brown water lakes. However, he did mention in his report that many of the Wisconsin lakes are naturally acidic and that there is insufficient data to predict with confidence whether these low alkalinity lakes are susceptible to change from acid precipitation.

\subsection{COLORADO ROCKY MOUNTAINS}

No convincing evidence has yet been published on acidification of lakes and streams in the Colorado Rocky Mountains, although several areas have been reported to be potentially sensitive to acid deposition (alkalinities less than $200 \mu \mathrm{eq} / \mathrm{L}$ ).

Lewis (1982) resurveyed 104 lakes in Colorado that had been previously surveyed in 1938-1960. Lakes were sampled on the same day of the year as in 1938-1960. He found that the mean $\mathrm{pH}$ of these lakes had declined from a value of 7.09 during 1938-1960 to 6.87 in 1979. Concurrently, alkalinity declined from 22,000 to $18,000 \mathrm{\mu g} / \mathrm{L}\left(\mathrm{CaCO}_{3}\right)$. The two pH measurements were done by two different methods. The 1938-1960 pH measurements used the colorimetric method, whereas in 1979 the potentiometric method was used. Although alkalinity measurements were carried out by the same titration method, the end 
points were determined differently. In the 1938-1960 samples, methyl orange indicator was used to determine the end point, whereas, in the 1979 samples the end point was determined electrochemically. Lewis (1982) reported that the difference between the two end point determinations could be as much as two drops of titrant which represented less than $3 \%$ of average alkalinity. The observed decrease in $\mathrm{pH}$ and alkalinity could be an artifact of the difference in analytical methods, annual variations in precipitation volume, and/or biological activity.

Turks and Adams (1983) studied the chemistry of high elevation lakes in the Flat Tops Wilderness area of Western colorado and found most lakes with alkalinity values as low as $70 \mu \mathrm{eq} / \mathrm{L}$ to less than $200 \mu \mathrm{eq} / \mathrm{L}$. They suggested that about 370 lakes, based on their alkalinity value, may be sensitive to acidification. The bedrock in this area is composed of basalt with some granitic outcrops.

Gibson et al. (1983) made similar observations for creeks and rivers in Rocky Mountain National Park (RMNP). In these waters, PH ranged from 6.0 to 7.5 and alkalinity values ranged from 40 to $331 \mu \mathrm{eq} / \mathrm{L}$. They reported that the chemical composition of the waters in RMNP is a product of the interactions between atmospheric deposition and bedrock geology and surficial materials. Soils apparently play a minor role. Primary mineral weathering was suggested to be the dominant mechanism determining the concentrations of base cations, silica, and alkalinity throughout the park. Base cations also appear to be supplied by airborne dust and salt. In streams in the Park, $\mathrm{Cl}^{-}, \mathrm{NO}_{3}{ }^{-}$, and $\mathrm{SO}_{4}{ }^{2-}$ were derived from atmospheric deposition except for two river basins where the source of $\mathrm{SO}_{4}{ }^{2-}$ was reported to be the weathering of sulphur-bearing minerals. Gibson et al. reported that the concentrations of $\mathrm{Cl}^{-}$and $\mathrm{SO}_{4}{ }^{2-}$ in stream waters did not change appreciably with elevation; however, $\mathrm{NO}_{3}{ }^{-}$concentration increased above timberline due to low biological activity.

Harte et al. (1985) surveyed surface waters in a high elevation watershed on the western slope of the Colorado Rockies from 1981 to 1983 and reported the presence of both low (10 to $70 \mu \mathrm{eq} / \mathrm{L})$ and medium alkalinity (100 to $900 \mu \mathrm{eq} / \mathrm{L})$ surface waters within the watershed. They suggested that low alkalinity surface waters may be susceptible to acidification. In order to assess watershed acidification, they tried to study long-term trends in alkalinity by comparing 1981-1982 alkalinity values with 1972 values. Their earlier alkalinity values were generally at or below the levels reported for 1972 . However, they could not rule out differences in methodology as the source of the difference between the two measured alkalinity values. The annual variations in their alkalinity were also large. Therefore, they could not establish surface water alkalinity trends over the 10-year period.

Kling and Grant (1984) surveyed published work on soil and surface water chemistry in order to establish a framework from which predictions could be made regarding significant ecological effects of acid precipitation on aquatic ecosystems in the colorado front Range. The region is potentially sensitive to the impacts of acid precipitation due to: (1) the noncalcareous, crystalline bedrock which yields minimal buffering capacity to soils and water bodies; (2) the generally sandy nature and medium to low pH and base saturation of the soils; (3) high $\mathrm{H}^{+}$loading at high elevations where soils have low buffering capacity; and (4) the pulsing effect of rapid $\mathrm{H}^{+}$release in spring snowmelt. 
Regression analysis of 88 lakes and streams showed significantly decreasing $\mathrm{pH}$ and alkalinity trends with increasing elevation. A similar trend was found for soil pH and base saturation. Considering soil and water chemistry, Kling and Grant suggested that regions above 3300 metres are most sensitive to continued inputs of acidic materials. They further suggested that if the present level of acid deposition (average pH 4.7) continues, a strong potential exists for buffering losses in surface waters, changes in soil acidification, and adverse effects on biota in a matter of decades. However, it is important to note that these observations are predictions based on published work on soil and surface water chemistry.

In summary, surface water acidification studies in North America can be categorized into three groups. The first group consists of lakes for which the cause of acidification has been attributed to long-range atmospheric transport. and inputs of acidic substances. Studies conducted in the Atlantic Provinces, New England states, and New York state fall into this category. In the case of lakes in the second group, acidification has been attributed to the internal generation and contribution of hydrogen ions. Studies in the New Jersey Pine Barrens fall into this category. For the lakes in the third group, acidification has not been established but has been predicted based on alkalinity values, bedrock geology, and soil characteristics. Lakes in Sierra Nevada, California and the Colorado Rocky Mountains fall into this category.

In the past (mostly before 1980), surface water acidification trends have been established by comparing historical $\mathrm{pH}$ data with recent data. Although this approach has been criticized by some researchers, it appears to be reasonable. Before 1980, surface water acidification was attributed solely to atmospheric inputs of acidic substances. However, this view is changing. Now, surface water acidification is considered in terms of atmospheric input of acidic substances, biogeochemical processes, and hydrology of the entire catchment area. The ILWAS Study in the Adirondack Mountains was based on this approach.

For studies conducted in Scandinavia on lake and stream water acidification readers are referred to articles in "Proceedings of an International conference on Ecological Impact of Acid Precipitation", edited by Drablos and Tollan (1980). For studies in the United States, readers are referred to "Acid Rain - Its State By State Impacts", by the National Wildlife Federation (1984). 
Acidification of freshwaters is a complex process involving not only increases in acidity but also increases in metal ion concentration, increased water clarity, accumulation of periphyton (microflora attached to the bottom substrate) and detritus, changes in trophic interactions (e.g., loss of fish as predators), and physiological changes in aquatic organisms. Magnuson (1983) has suggested that a study of the response of aquatic systems to acid deposition must take into account all these types of changes because together they constitute the acidification process.

The impact of acid deposition on aquatic biota was first observed in fish populations. The earliest recorded impact was a decline in Atlantic salmon ( $\underline{\text { Salmo }} \underline{\text { salar }}$ ) in a few southern Norway rivers in the 1920's (Jensen and Snekvik 1972). Since then, declining fish populations have been reported for many lakes and rivers in parts of Europe and North America receiving acidic atmospheric deposition (Beamish and Harvey 1972; Drablos and Tollan 1980; and Schofield 1982). These fish extinctions were found to be associated with changes in water chemistry, particularly with increases in acidity of water. Later, studies on the effects of acidification on aquatic organisms broadened and included studies on organisms such as those associated with bottom substrates (benthos), zooplankton and phytoplankton, and rooted aquatic plants (macrophytes). The literature on this topic is very vast and it is beyond the expertise of this reviewer to critically evaluate it. Therefore, from a few recent publications, an overview of the effects of acid deposition on aquatic biota is presented.

As discussed in section 5, there is considerable debate among researchers over the topic of natural versus anthropogenic acidification of lakes and streams that are far removed from a point source of acid-forming emissions (e.g., nickel smelter plants in the sudbury, Ontario area). To provide baseline data to elucidate this controversy, it is appropriate to first identify the organisms which are adapted to naturally acidic waters.

\subsection{ORGANISMS OCCURRING IN NATURALLY ACIDIC WATERS}

Naturally acidic lakes and streams occur throughout the world (Patrick et al. 1981; Gorham et a1. 1984b). These waters can provide insight into the pH range tolerated by aquatic organisms and thus help in assessing declines of aquatic organisms attributed to the input of anthropogenic acidic substances.

Naturally occurring acidic waters fall into three groups (Magnuson and Rahel 1983). The first group is made up of inorganic acidotropic waters associated with geothermal areas or lignite burns, with $\mathrm{pH}$ values between 2.0 and 3.0 . The second consists of brown water lakes and streams associated with peatlands and swamps (Gorham et al. 1984b). These waters commonly have $\mathrm{pH}^{\prime} \mathrm{s}$ in the range of 3.5 to 5.0 and their acidity is derived from organic acids leached from decayed plant material. The third group consists of ultraoligotrophic waters generally found where glaciation has removed calcareous deposits and has exposed granitic and siliceous weather resistant bedrock. They have $\mathrm{pH}^{\prime} \mathrm{s}$ in the range of 5.5 to 6.5 and their acidity is due to carbonic acid $\left(\mathrm{H}_{2} \mathrm{CO}_{3}\right)$.

While naturally acidic lakes appear to support aquatic life, the general conclusion is that species diversity declines as $\mathrm{pH}$ decreases. The lower trophic level 
organisms appear to be most tolerant to low $\mathrm{pH}^{\prime} \mathrm{s}$, with some bacteria and algae able to survive at $\mathrm{pH}^{\prime} \mathrm{s}$ as low as 1.0. Invertebrates are rarely found below $\mathrm{pH} 3.0$ and fish are generally found in waters with pH's above 4.0 (Magnuson and Rahel 1983). However, it is important to note that most organisms occurring in acidic environments can survive at neutral pH but are excluded from such environments by competitively superior species (Magnuson and Rahel 1983). Table 4 indicates the lowest pH tolerated by various groups of freshwater organisms. It appears that in naturally acidic waters, hydrogen ion concentration may limit the occurrence of invertebrates with calcified exoskeletons at levels below pH 5.5 (e.g., mayflies, Gammarus, snails, and clams), of blue-green algae below pH 4.0, of some species of minnows (Cyprinidae) and darters (Percinidae) below $\mathrm{pH} 6.0$, and of several species of sunfish (Centrarchidae) below 4.5 .

\subsection{ORGANISMS IN ANTHROPOGENICALLY ACIDIFIED LAKES}

Although the literature regarding the response of aquatic biota to acidification is at times conflicting, various effects have been well documented. These effects that are supported by numerous observations and experimental studies are summarized in Table 5 .

\subsubsection{Benthic Organisms}

The term "benthos" refers to the community of organisms which live in and on bottom sediments of lakes and streams. The important components of benthos are microbes, periphyton, macroinvertebrates, crustaceans, insects, molluscs, and annelids (Singer 1983). These organisms are affected by changes in the chemical and biological components of water and serve as a food source for fish, waterfowl, and riparian mammals. Most of the energy and nutrients in the water passes through the benthos; therefore, alteration of this community can affect plankton and fish communities. Literature on the effects of acid deposition on the benthic community is very limited. However, some responses of benthos to acidification can be summarized as outlined below.

The bottom benthic community is reduced in number in clear waters low in $\mathrm{pH}$ as compared to neutral pH clearwaters (Singer 1983). Between pH 6.0 and 4.0 bacterial metabolic rates are decreased, and shredding invertebrates are reduced in numbers, bringing about an increase in detrital accumulation (undecomposed organic materials) (Haines 1981).

In acidic lakes and streams with $\mathrm{pH}$ below 5.0 , most substrates are covered with a mat of algae and detritus (Hall and Likens 1980; Hendrey and Vertucci 1980).

In lakes and streams with $\mathrm{pH}$ below 6.0, many predatory insects (beetles, dragonflies) increase in numbers (Hall and Likens 1980). However, their effect on the plankton and on benthic detritivores is not known.

Below pH 5.0, several preferred food sources for game fish (e.g., Gammarus snails, many mayflies, and stoneflies) do not survive and fisheries impacts due to food shortages have been hypothesized (Sutcliffe and Carrick 1973; Hall et al. 1980).

\subsection{MACROPHYTES AND WETLAND PLANTS}

The term "macrophyte" refers to large aquatic plants. Response of macrophytes to acidification is largely unknown. However, a few observations have been made, as summarized below. 
Table 4. Lower pH limits for various groups of organisms in naturally acidic waters.

\begin{tabular}{|c|c|c|c|}
\hline Group & $\begin{array}{l}\text { Approximate } \\
\text { Lower pH } \\
\text { Limit }\end{array}$ & $\begin{array}{l}\text { Examples of Organisms } \\
\text { Occurring at Lower pH Limit }\end{array}$ & Reference \\
\hline \multirow[t]{2}{*}{ Bacteria } & 0.8 & $\begin{array}{l}\text { Thiobacillus thiooxidans, } \\
\text { Sulfolobus acidocaldarius }\end{array}$ & Brock (1978) \\
\hline & $2-3$ & Bacillus, Streptomyces & Brock (1978) \\
\hline Fungi & 0 & Acont ium velatum & Brock (1978) \\
\hline Eucaryotic algae & $\begin{array}{c}0 \\
1-2\end{array}$ & $\begin{array}{l}\text { Cyanidium caldarium } \\
\text { Euglena mutabilis, } \\
\text { Chlamydomonas acidophila, } \\
\text { Chlorella }\end{array}$ & $\begin{array}{l}\text { Brock }(1978) \\
\text { Brock }(1978)\end{array}$ \\
\hline Blue-green algae & 4.0 & Mastigocladus, Synechococcus & Brock (1978) \\
\hline Vascular plants & $2.5-3$ & $\begin{array}{l}\text { Eleocharis, Carex, } \\
\text { Ericacean plants } \\
\text { Phragmites }\end{array}$ & $\begin{array}{l}\text { Brock (1978) } \\
\text { Hargreaves } \\
\text { et al. (1975) } \\
\text { Ueno }(1958)\end{array}$ \\
\hline Mosses & 3.0 & Sphagnum & Brock (1978) \\
\hline Protozoa & 2.0 & Amoebae, Heliozoans & Brock (1978) \\
\hline Rotifers & $\begin{array}{l}3.0 \\
3.5\end{array}$ & $\begin{array}{l}\text { Brachionus, Lecane, Bdelloid } \\
\text { Colotheca, Ptygura }\end{array}$ & $\begin{array}{l}\text { Hutchinson } \\
\text { et al. (1978) } \\
\text { Edmondson (1944) }\end{array}$ \\
\hline Cladocera & 3.0 & Simocephalus, Chydorus & Ueno (1958) \\
\hline \multirow[t]{2}{*}{ Copepods } & 3.0 & Macrocyclops & Ueno (1958) \\
\hline & 3.6 & Cyclops & $\begin{array}{l}\text { Hutchinson } \\
\text { et al. (1978) }\end{array}$ \\
\hline \multirow[t]{3}{*}{ Insects } & 2.0 & Ephydra thermophila & Brock (1978) \\
\hline & 3.0 & Chironomus riparius & $\begin{array}{l}\text { Hutchinson } \\
\text { et al. (1978) }\end{array}$ \\
\hline & 5.8 & Mayflies & $\begin{array}{l}\text { Sutcliffe and } \\
\text { Carrick (1973) }\end{array}$ \\
\hline Amphipods & 5.8 & Gammarus & $\begin{array}{l}\text { Sutcliffe and } \\
\text { Carrick (1973) }\end{array}$ \\
\hline Clams & $\begin{array}{l}4.5 \\
6.0\end{array}$ & $\begin{array}{l}\text { Pisidium } \\
\text { Most other species }\end{array}$ & $\begin{array}{l}\text { Griffiths (1973) } \\
\text { Pennak (1978) }\end{array}$ \\
\hline Snails & $\begin{array}{l}5.8 \\
6.2\end{array}$ & $\begin{array}{l}\text { Aminicola } \\
\text { Most other species }\end{array}$ & $\begin{array}{l}\text { Pennak (1978) } \\
\text { Pennak (1978) }\end{array}$ \\
\hline
\end{tabular}


Table 4 (Concluded).

\begin{tabular}{lcll}
\hline Group & $\begin{array}{c}\text { Approximate } \\
\text { Lower } \mathrm{pH} \\
\text { Limit }\end{array}$ & $\begin{array}{c}\text { Examples of Organisms } \\
\text { Occurring at Lower pH Limit }\end{array}$ & Reference \\
\hline Fish & 3.5 & Tribolodon hakonensis & $\begin{array}{c}\text { Mashiko et al. } \\
\text { (1973) } \\
\text { Rahel and } \\
\text { Magnuson (1983) } \\
\text { Rahel and } \\
\text { Magnuson (1983) }\end{array}$ \\
\hline
\end{tabular}

Source: Magnuson (1983) 


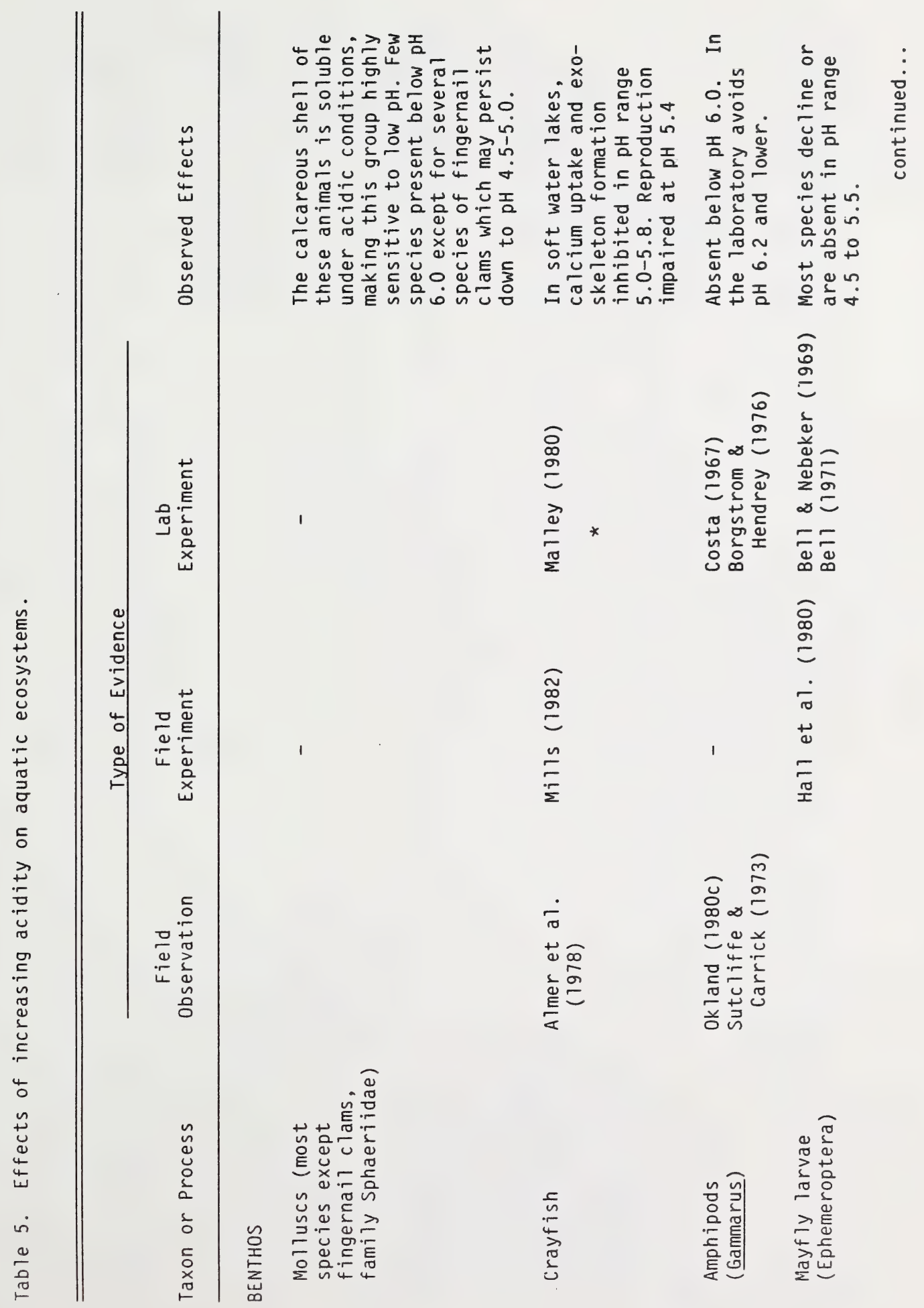




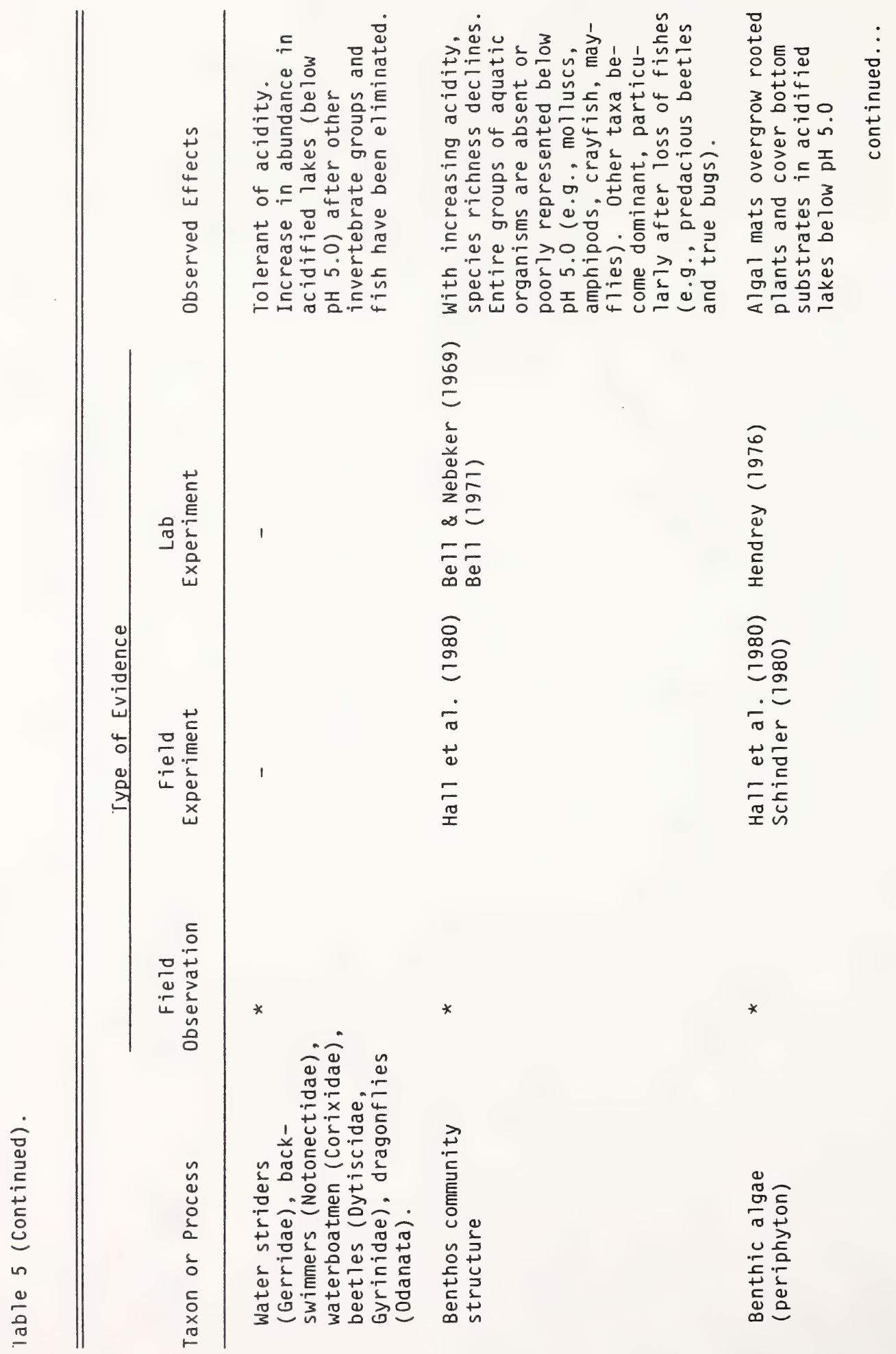




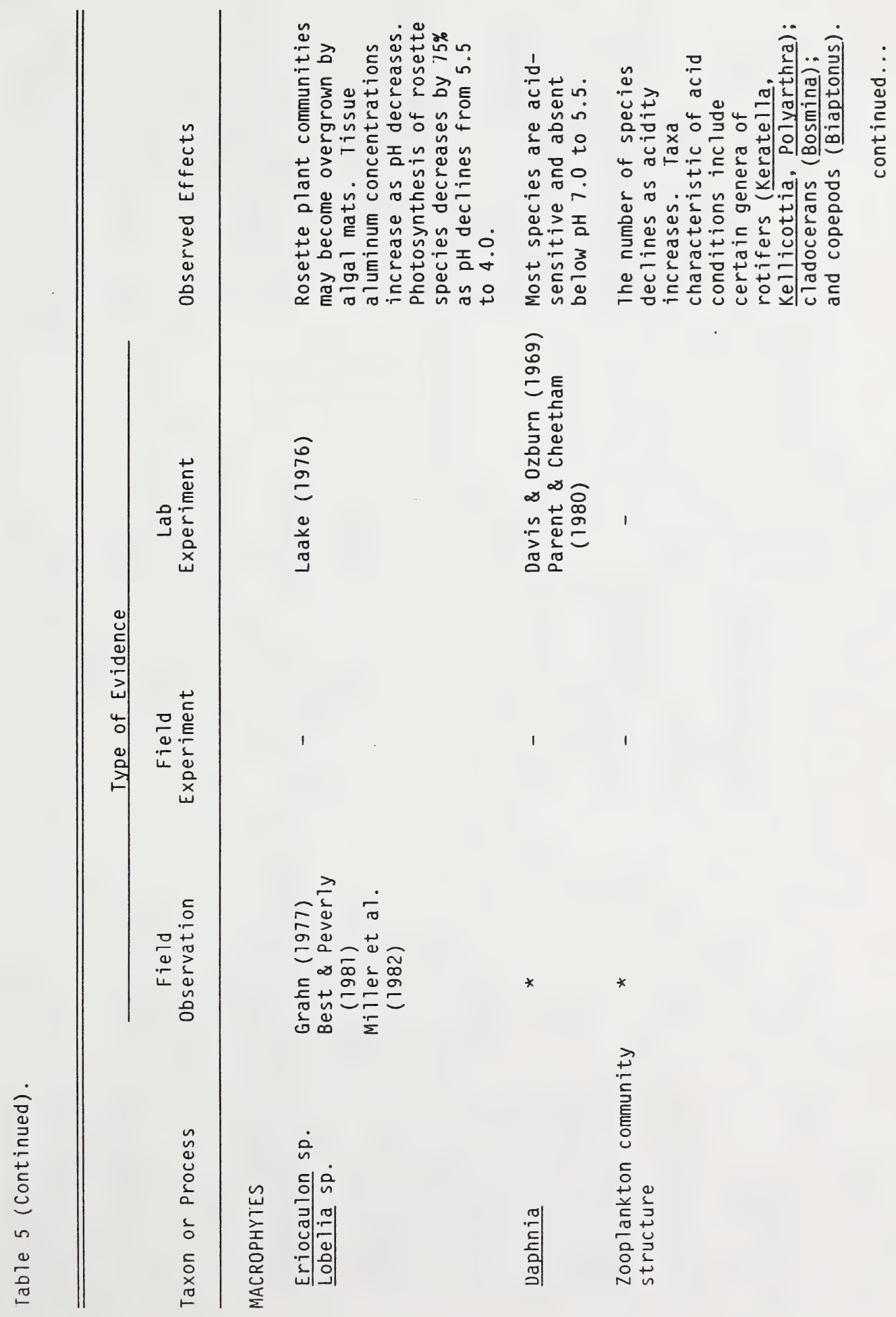




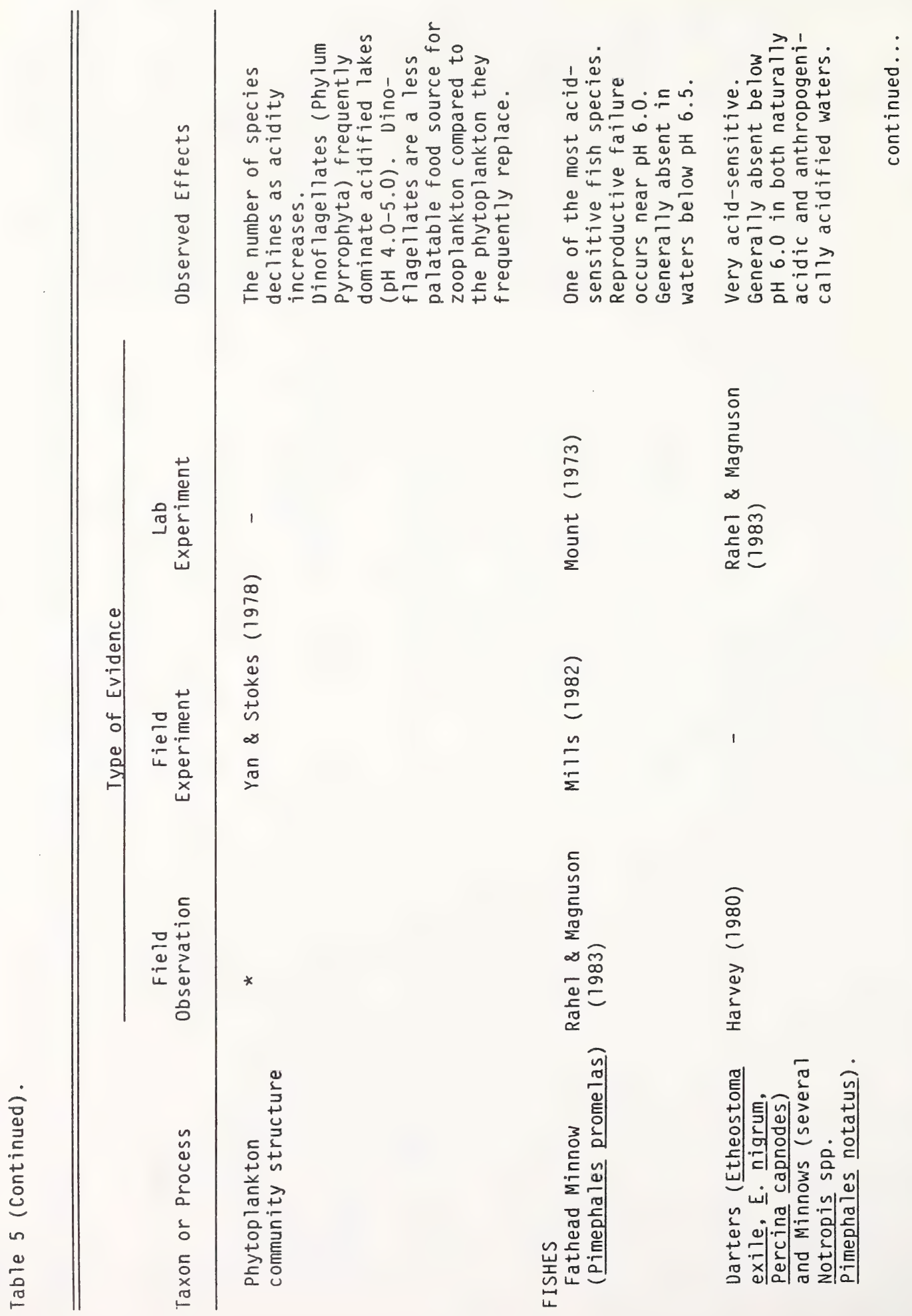




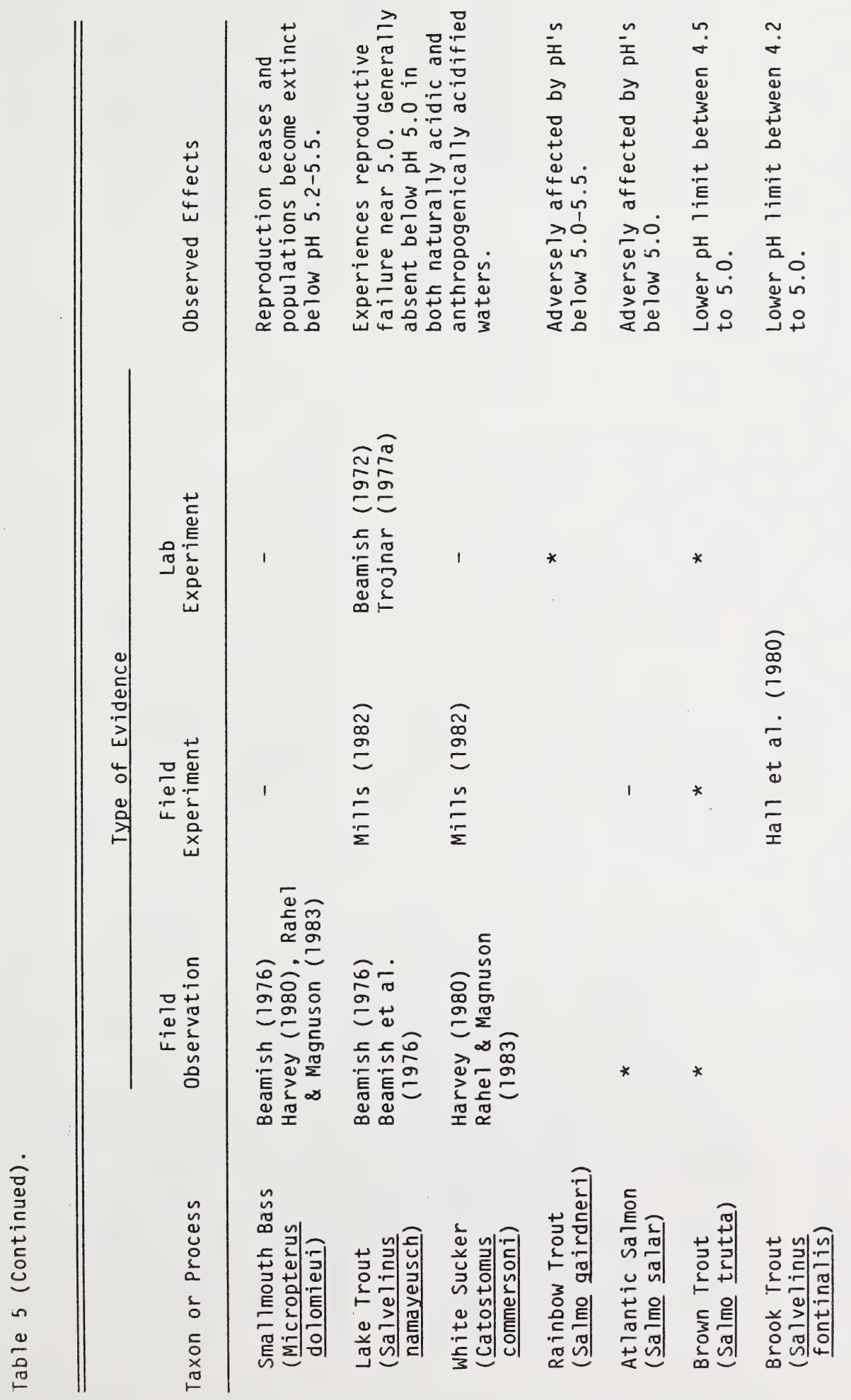




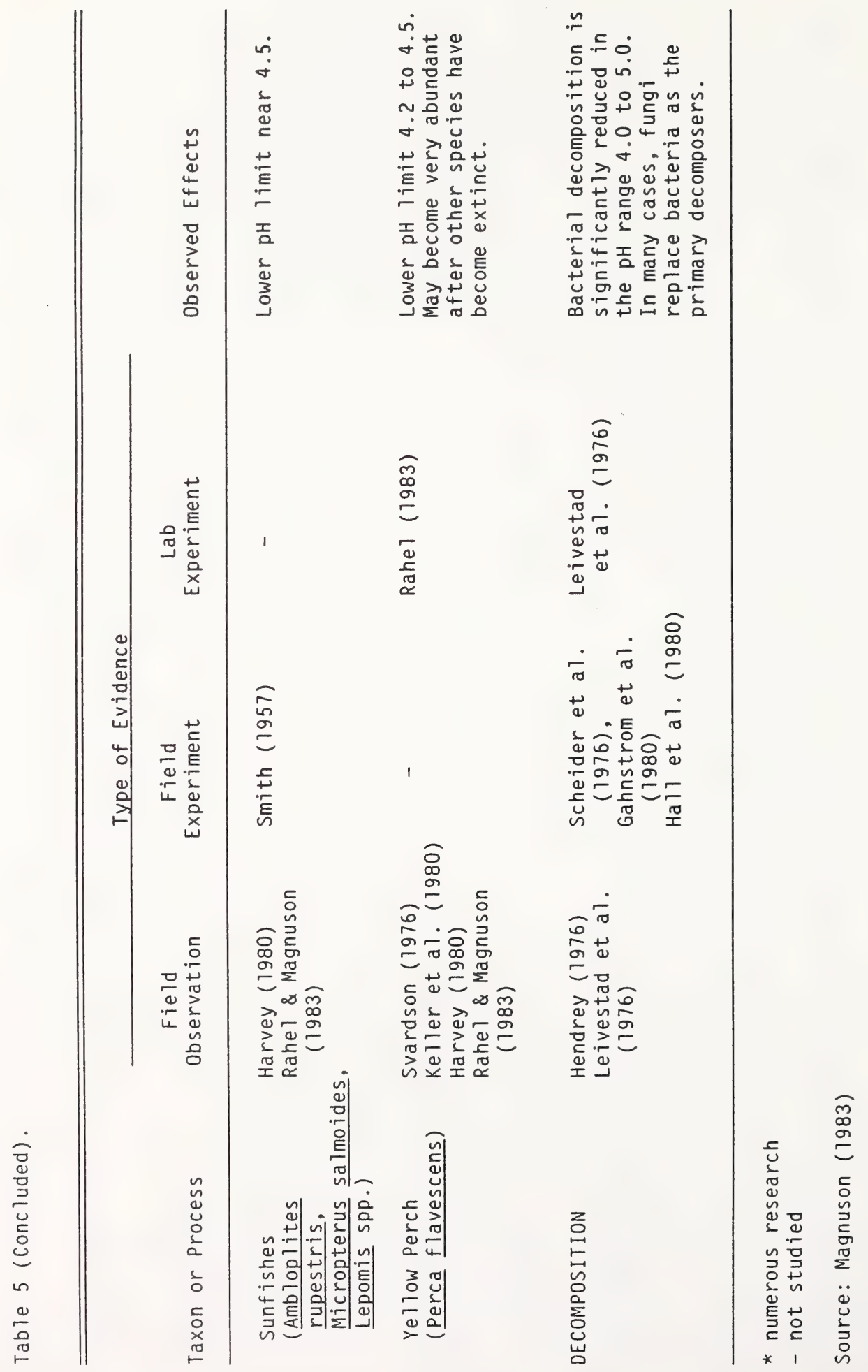


In areas where both acidified ( $\mathrm{pH}<5.6)$ and non-acidified ( $\mathrm{pH} 5.6$ to 7.5) lakes occur, dominant macrophyte species are the same (Peverly 1983).

In six Swedish lakes receiving acid deposition, shifts from isoetid dominated species to Sphagnum-dominated macrophyte communities have been observed (Grahn 1977). This changing trend in dominance was observed over a period of at least 15 years. However, in 50 oligotrophic soft water lakes surveyed in North America and receiving acid deposition, this trend of dominance by Sphagnum species was not observed. Therefore, it has been suggested that this may not be a general property of acidified lakes (Peverly 1983).

In soft water, oligotrophic lakes, standing crops of macrophytes vary widely ( 5 to $500 \mathrm{~g}$ dry $w \mathrm{~m}^{-3}$ ) and it does not appear that acidification produces a consistent change in standing crop (Sand-Jensen and Sondergrad 1979). However, physiological effects may occur. In Lobelia dortmanna, a soft water lake species, $75 \%$ reduction in oxygen production was observed at $\mathrm{pH} 4.0$ versus $\mathrm{pH} 4.3$ to 5.5 in one flow-through laboratory experiment (Laake 1976).

The only known effect of acidification on macrophytes in the field is that of changes in metal concentration in the tissues. Aluminum, iron, lead, and copper increase while cadmium, zinc, and manganese are lower compared to tissue concentrations in plants from non-acidic lakes (Best and Peverly 1981; Miller et al. 1982; and Troutman and Peters 1982). In acidified lakes, mean aluminum concentration in plant tissue (dry weight basis) averaged 3.0 to $5.0 \mathrm{~g} \mathrm{~kg}^{-1}$ (about ten times nigher than normal) while manganese concentration averaged 0.02 to $4.0 \mathrm{~g} \mathrm{~kg}^{-1}$ (about one-fifth of normal).

\section{4}

\section{PLANKTON}

The term "plankton" refers to organisms that live suspended in the water column. They are subject to distribution by water movement because of their limited powers of movement. They are small to microscopic in size (Wetzel 1975). The plankton community is made up of animals (zooplankton), plants (phytoplankton), and microbes.

Data on effects of acidification on plankton communities are based almost entirely on field observations (Baker 1983a). Results of the data summarized by Baker (1983a) are given below.

It has been observed that aquatic acidification results in a marked shift in the structure of the plankton community (Haines 1981). For both phytoplankton and zooplankton, the species diversity decreases with increasing acidity. The greatest change in zooplankton species composition occurs in the $\mathrm{pH}$ range 4.6 to 5.3 (Almer et a1. 1974; Dillon et a1. 1978; Overrein et a1. 1980; and Malley et al. 1982). For phytoplankton it is in the range of 5.0 to 6.0 (Almer et al. 1974; Kwiatkowski and Roff 1976). In lakes acidified by anthropogenic inputs (the lake pH 4.0 to 5.0 ) the biomass and/or numbers of zooplankton also decrease considerably (Yan and Strus 1980; Confer et al. 1983); in acidic lakes, zooplankton communities represent simplification of communities found in circumneutral lakes of the same region.

Changes in phytoplankton community structure with acidification are complex and difficult to interpret because they can be due to many factors such as higher metal content, predation, and nutrient availability. Yet, comparison of plankton community structure between acidic and non-acidic lakes indicates marked differences (Baker 1983a). 
Generally, in lakes undergoing increasing acidity due to acid deposition, the total number of species decreases by 30 to $70 \%$, resulting in fewer dominant species.

When experimentally acidified lakes are compared to both acidic and non-acidic lakes within the same region in terms of primary productivity, no consistent difference in water column primary productivity is observed with increased acidity (Baker 1983a).

\subsection{FISHES}

Decline of Atlantic salmon stocks in southern Norway rivers in the 1920's (Jensen and Snekvik 1972) was one of the first indicators that acid deposition was having an impact on natural ecosystems. Since then, adverse effects on fish populations have been reported in anthropogenically acidified lakes of North America and parts of Europe (Haines 1981). Effects of acid deposition on fish include mortality, reproductive failure, reduced growth rate, skeletal deformities, and increased uptake of heavy metals (Haines 1981). Baker (1983b) 1isted the seven types of available data on effects of acidification on fish. They are as follows:

1. historical records of fish population decline in surface waters with historical data of increasing acidity;

2. historical records of fish population decline in currently acidic surface waters but with no historical data on levels of acidity;

3. correlation of the existing levels of acidity with the existing fish status in surface water and regional surface water survey data;

4. data on fish stocking efforts related to acidity of surface waters;

5. biological responses to experimental acidification of aquatic ecosystems;

6. results of in situ exposures of fish to acidic waters; and

7. laboratory data on physical and physiological responses of fish to low $\mathrm{pH}$, elevated aluminum concentrations, and other water quality conditions associated with acidification.

A functional relationship between surface waters acidified by atmospheric deposition and fish response needs to be viewed with care and caution. Loss of fish populations from acidified surface waters is not a simple process; biological and chemical changes within an aquatic ecosystem caused by acid deposition and land use practices can affect fish responses in various ways (Drablos and Sevaldrud 1980; Drablos et a1. 1980; and Baker 1983b). Tolerance of fish to acidic conditions appears to vary markedly among species, among different populations of the same species, and among individuals within the same population (Baker 1983b). The survival of a fish species during a sensitive life history stage appears to be closely related to the timing and duration of acidifying episodes. During an episodic event such as spring snowmelt, the water chemistry within an aquatic ecosystem undergoes substantial chemical changes, for example, a rapid and sharp increase in toxic metal and hydrogen ion concentration (Schofield 1976a,b, 1978; Driscoll 1980; and Haines 1981). Elevated levels of hydrogen ions in these aqueous systems can disrupt the osmoregulatory balance of fish (Leivestad et a1. 1976). In addition, elevated levels of toxic metals such as aluminum could be toxic to fish (Baker et a1. 1979; Schofield and Trojnar 1980). These problems are 
further intensified by the fact that many indigenous fish species spawn in tributaries in the spring. Fish fry are susceptible to adverse environmental conditions, and they often hatch during or soon after spring snowmelt when levels of hydrogen ions and aluminum are high enough to make water quality poor (Driscoll 1980).

The adverse effects of acid deposition on fish populations have been well documented for five geographical areas: southern Norway, southern Sweden, the LaCloche Mountain region of Ontario, Nova Scotia, Quebec, and the Adirondack region of New York. This documentation is based mostly on field observations and, in some cases, fails to establish cause-and-effect responses due to the unavailability of historical data. These observations are based on the correlation of acidity of the surface water with the absence or decline of fish species. Historical data are available only in a few cases that provide concurrent documentation of the fish population decline and increase in water acidity. For example, for 40 of the 214 high elevation lakes in the Adirondack region of New York State, historic records were available from the 1930's (Schofield 1976a,b). In 1975, 19 of these 40 lakes had pH levels below 5.0 and also had no fish. In the 1930's only three lakes had pH values below 5.0 and had no fish; another lake with a pH of 6.0 to 6.5 also had no fish. Findings on the fish population status in the five documented areas are summarised below.

The Atlantic salmon decline has been attributed to the low pH levels in a few southern Norway rivers (Jensen and Snekvik 1972; Leivestad et a1. 1976). This decline in the Atlantic salmon population has continued since the 1920's and they are now almost extinct. That region of Southern Norway is subject to acid deposition and $\mathrm{pH}$ values in those rivers are now generally between 4.5 to 5.5 . No such trend was observed in 68 northern Norway rivers that are not being acidified (Jensen and Snekvik 1972; 0verrein et a1. 1980). A survey begun in 1971 of more than 2000 lakes in southern Norway concluded that about 700 of them had lost their fish populations since 1940 due to a gradual decline in the $\mathrm{pH}$ of the lake waters (Wright and Snekvik 1978). In about $80-85 \%$ of the lakes, $\mathrm{pH}$ was below 5.5 .

In Sweden, extensive surveys of fish population status and acidity of surface waters are not yet complete (Baker 1983b). However, based on historical data of fish populations, Almer et al. (1978) suggested that about 100 lakes in southern Sweden have lost their fish populations due to present day low pH levels in lakes. Apparently, as a result of these low pH levels, $43 \%$ of the minnow populations (Phoxinus phoxinus), $32 \%$ of the roach (Rutilus rutilus), 19\% of the char (Salvelinus alpinus), and $14 \%$ of the

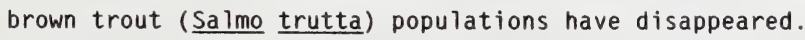

The reliable evidence that acidification of surface waters causes declines in fish populations is derived from field observations of lakes in the Lacloche Mountain regions of Ontario. These lakes are located approximately $65 \mathrm{~km}$ from the Sudbury tall stack smelters (Beamish 1974,1976). Of 68 lakes surveyed in the LaCloche Mountains, 24 percent had no fish present, and 56 percent are known or suspected to have had reductions in fish species composition (Harvey 1975). Based on historical fisheries information, several fish species appeared to have disappeared, including lake trout (Salvelinus namaycush) from 17 lakes, walleye (Stizostadion v. vitreum) from four lakes, and yellow perch (Perca flavescens) and rock bass (Ambloplites rupestris) from two lakes each (Harvey and Lee 1982). 
In Nova Scotia, records of catch of Atlantic Salmon in rivers date back to the early 1900's (Baker 1983b). Historical catch records of ten rivers with current pH $<5.0$ show that nine have had significant declines in catch success from 1936 to 1980 (Farmer et a 1. 1981; Watt et a1. 1983). Decrease in salmon catch over time is correlated with change in $\mathrm{pH}$ to the present day $\mathrm{pH}$ values of 5.0 or less. In 1981, seven rivers in western Nova Scotia were believed to be unsuitable for Atlantic salmon reproduction due to a mean annual pH of less than 4.7, and eight more rivers were threatened (Haines 1981). However, Farmer et a1. (1981) suggested that many of these rivers, especially those with $\mathrm{pH}<4.7$, have a high organic content. Most of these river basins are covered with mixed forest vegetation and peat bogs (Watt et a1. 1983), and during the 19 th and early 20 th centuries, agricultural, forestry, and mining operations were carried out in some of them (Watt et a1. 1983). Therefore, input of organic acids from natural sources (peat bogs) and of both organic and inorganic acids from land use practices appears possible in these rivers. While the cause may be a combination of natural acidification and anthropogenic input of acidifying substances in these river waters, the decline in salmon populations cannot be refuted. The fishing records show that in 1936 salmon catches ranged between 50 to 300 in the various rivers, and from 1970 to 1980 they ranged between zero to 20 (watt et a1. 1983). In contrast to these acidified rivers, salmon catches in Nova Scotian rivers with satisfactory water quality appear to have remained fairly constant (Farmer et al. 1981).

To establish the impact of acidity on fish populations, Frenette et al. (1986) studied 37 Quebec lakes in four regions; the Reserve des Laurentides; Portneuf; the Charlevoix; and Temiscamingue regions. It was observed that density of brook char (Salvelinus fontinalis), that is, catch per net per 12 hours, decreased with increasing acidity. In addition, three lakes with $\mathrm{pH} 4.6$ to 5.1 and low calcium levels (45 meq $\mathrm{L}^{-1}$ ) supported no fish; this was apparently due to reproductive failure. However, the growth of brook char in acidic lakes was faster than that of char from other lakes. The better growth was attributed to an increase in food availability following a decrease in fish density. It was also observed that brook char populations inhibiting acidic lakes were in better condition than those in less acidic lakes. This difference was pronounced in cases where $\mathrm{pH}$ was lower than 5.0. The changes in fish condition were once again attributed to an increase in food availability following a decrease in density. It was observed that acidic lakes supported fewer species in association than did non-acidic lakes. The non-acidic lakes supported three to nine species. The acid sensitive Cyprinidae and specifically Johnny darters (Etheostoma nigrum) were abundant in lakes with a pH level of 5.9 to 7.0 but were absent in lakes with a pH level of less than 5.2. Other acid sensitive species such as the white sucker (Catostomus commersoni) and the northern pike (Esox lucius) were poorly represented in acid lakes. The only fish that appeared to be tolerant to a wide pH range was the yellow perch (Perca flavescens), but their condition was poor in acidic lakes as compared with non-acidic lakes.

In Adirondack lakes and streams, fish population decline has been observed for the past 40 to 50 years. Loss of fish populations, especially brook trout, has been reported for about 180 lakes out of a total of 2877 lakes (Pfeiffer and Festa 1980). For some of these lakes, Schofield (1976a,b, 1982) has attributed fewer fish species to $\mathrm{pH}$ levels below 5.4. Although there appears to be a correlation between fish loss and 
pH, several factors may confound this relationship, e.g., increase in toxic metal concentration and availability of nutrients. For many individual Adirondack lakes, historical data are not available. Therefore, a cause-effect relationship between pH and fish population loss is difficult to make. It is possible that acidification has caused the disappearance of fish from some surface waters but exactly how many lakes and streams have been impacted by it, is difficult to assess (Baker 1983b). In contrast to Adirondack lakes, in some regions of Ontario and Maine with low alkalinity waters receiving acid deposition, acidification of surface waters appears not to have had detrimental effects on fish populations (Schofield 1982).

Fish kills are generally observed during episodic events. Mortalities of adult and young fish are typically associated with rapid decreases in $\mathrm{pH}$ 's (generally to $\mathrm{pH}$ levels below 4.5 to 5.0 ) during snowmelt (Driscoll 1980). Many lakes with acidic waters lack young fish, implying that one of the causes of fish extinction may be failure to reproduce or death of fry in acidified waters. Liming of acidic waters in Sweden has resulted in the recurrence of young fish (Haines 1981).

Direct cause-effect relationships between acidification and adverse effects on fish have been established in some laboratory and field experiments. In the Experimental Lakes Area of northwestern Ontario, addition of acid to Lake 223 produced $\mathrm{pH}$ declines from 6.5 to 5.9 in 1976, and to $\mathrm{pH} 5.0$ in 1983 (Schindler et al. 1985). The pH decline produced a number of dramatic changes in the lake's food web. Among them were cessation of fish reproduction and/or extinction of several fish species. Schindler et al. (1985) pointed out that these dramatic changes were caused by the increased concentration of hydrogen ion alone, and not by the secondary effect of aluminum toxicity. In laboratory experiments, the $\mathrm{pH}$ range of 3.5 to 4.4 was found to have adverse effects on fish survival (Baker 1983b). For example, in the case of brook trout and rainbow trout, 50\% of the fish kill occurred in two days at a pH 3.5. However, it is important to note that serious gaps exist in the understanding of how to quantitatively relate laboratory results to the field situation. Also, in the field, the acidification process results in elevated concentrations of aluminum and other toxic metals in water. As stated earlier, this increase in the concentration of toxic metals has been implicated in fish kills resulting from mucus clogging of gills (Schofield and Trojnar 1980).

\section{6}

\section{OTHER BIOTA}

Research on the effects of surface water acidification on amphibians is at an early stage of development. Several studies have suggested that habitat acidity can reduce the population size or restrict the distribution of amphibians. Gosner and Black (1957) reported that distributions of anurans in the New Jersey Pine barrens were limited by water acidity ( $\mathrm{pH} \mathrm{3.6-5.2)} \mathrm{produced} \mathrm{by} \mathrm{humic} \mathrm{substances} \mathrm{derived} \mathrm{from} \mathrm{sphagnum} \mathrm{peat.}$ Hagstrom (1980) reported the elimination of the common frog (Rana temporaria) from a lake with a pH range of 4.0 to 4.5 . He suggested that acid precipitation and natural acidity due to organic acids were the contributory factors. Saber and Dunson (1978) showed that amphibian species richness was lower in acidic bog waters compared with surrounding less acidic bog bodies. Dale et al. (1985) surveyed 159 field sites consisting of ditches, bogs, marshes, ponds, and lakes in south and central Nova scotia for the presence of the adults, eggs, or larvae of 11 amphibian species. Discriminant function analysis using 
$\mathrm{pH}$, alkalinity, colour, conductivity, cations $\left(\mathrm{Na}^{+}, \mathrm{K}^{+}, \mathrm{Ca}^{2+}, \mathrm{Mg}^{2+}\right)$, and anions ( $\mathrm{SO}_{4}{ }^{2-}$ and $\mathrm{Cl}^{-}$) predicted neither the presence or absence of any of the 11 amphibian species. Some species (Rana sylvatica and Ambystoma maculatum) were observed breeding successfully in acidic bogs ( $\mathrm{pH} 4.1$ ). In some cases (e.g., Rana clamitans) adults and larvae were observed at pH's as low as 3.5 to 3.9. The species least sensitive to acidity in the waters of Nova Scotia was found to be Rana sylvatica. Dale et al. (1985) pointed out that there is considerable variation in acid tolerance among the various species of Nova Scotia amphibians.

In general, it appears that effects of surface water acidification on aquatic biota become apparent as alkalinities decline to $65 \mu \mathrm{g} / \mathrm{L}$ and $\mathrm{pH}$ 's decline to about 6.0 (Table 5). Baker (1983a,b) suggested that pH declines below this value would result in escalating biological changes, e.g., loss of benthic community species and fish species. The effects also become apparent during episodic events when the pH of water may drop from as high as 7.0 down to 4.3. Although acid deposition can have detrimental effects on aquatic biota, it is only one of many factors working synergistically in the ecosystem. Others include natural acidic waters, elevated levels of toxic metals, availability of nutrients, and land use practices.

\subsection{FISHES OF NORTHERN ALBERTA}

Lakes, streams, and rivers located on or near the Precambrian Shield of northeastern Alberta support fish that have elsewhere been found to be sensitive to surface water acidification. Examples include brook trout, brown trout, white sucker, northern pike, lake trout, walleye, and yellow perch. A list of the fish species found in northeastern Alberta is given in Table 6 .

It could be hypothesized that a potential exists for acid deposition to adversely affect the fish populations in northern Alberta. Once the inventory of northern Alberta freshwater systems and their sensitivity ratings which is currently being compiled by the Water Quality Control Branch of Alberta Environment (David Trew, Alberta Environment, personal communication 1987) is completed, this potential can be more knowledgeably addressed. 
Table 6. Fish species common to northeastern Alberta.

Arctic Grayling (Thymallus arcticus)

Cisco (Coregonus artedi $i$ )

Shortjaw Cisco (Coregonus zenithicus)

Lake Whitefish (Coregonus clupeaformis)

Lake Trout (Salvelinus namaycush)

Brook Trout (Salvelinus fontinalis)

Brown Trout (Salmo trutta)*

Northern Pike (Esox lucius)

Goldeye (Hiodon alosoides)

Longnose Dace (Rhinichthys cataractae)

Flathead Chub (Platygobio gracilis)

Lake Chub (Couesius plumbeus)

Pearl Dace (Semotilus margarita)

Northern Redbelly Dace (Chrosomus cos)

Fathead minnow (Pimephales promelas)

Emerald Shiner (Notropis atherinoides)

Spottail Shiner (Notropis hudsonius)

Longnose Sucker (Catostomus catostomus)

White Sucker (Catostomus commersoni)

Burbot (Lota lota)

Trout-Perch (Percopsis omiscomaycus)

Brook Stickleback (Culaea inconstans)

Ninespine Stickleback (Pungitius pungitius)

Iowa Darter (Etheostoma exile)

Yellow Perch (Perca flavescens)

Walleye (Stizostedion vitreum vitreum)

Slimy Sculpin (Cottus cognatus)

Spoonhead Sculpin (Cottus ricei)

* Northern Alberta

Source: Paetz and Nelson (1970) 
9.

Three types of models have been developed to evaluate the acidification of freshwaters by acid deposition. The first type involves an empirical approach that relates changes in one variable, such as the acidity of precipitation or the deposition of $\mathrm{SO}_{4}{ }^{2-}$, to changes in other variables such as the acidity of the receiving water body or its $\mathrm{SO}_{4}{ }^{2-}$ concentration (Almer et a1. 1974; Henriksen 1979, 1980; and Thompson 1982). These empirical models, especially those of Henriksen, have proven useful in providing an initial understanding of the relationship between acid deposition and freshwater composition as a function of $\mathrm{SO}_{4}{ }^{2-}$ and hydrogen ion deposition (Gibson et al. 1983; Scruton 1983). Henriksen's model (1979), which is based on the concepts of electrical neutrality, is limited because it does not take into account biogeochemical processes or the temporal variation in the response of freshwater to acid deposition.

The second type of modelling includes static and dynamic mechanistic models. These are more site specific and data intensive than the empirical models. They are based on numerous assumptions and therefore require an effort to verify and use (Christophersen et al. 1982; Booty and Kramer 1984; Christophersen et al. 1984a,b; Gherini et al. 1984; and Seip and Rustad 1984).

Conceptual models are the third category. They incorporate a few key processes that determine how aquatic ecosystems respond to acid deposition with respect to time (Galloway et al. 1983; Turk and Adams 1983).

\section{1}

EMPIRICAL MODELS - THE HENRIKSEN MODELS

Acidification of surface waters is generally measured as $\mathrm{pH}$ or as loss of alkalinity. Where pH measurements are involved, acidification has been estimated by comparing the present data with historical data. Such is not the case with the alkalinity measurements. Earlier measurements of alkalinity for most waters in areas of concern were not made and therefore allow no basis of comparison with the present data. Henriksen $(1979,1980)$ developed models which use contemporary water chemistry data to estimate the historic acidification of surface waters due to acid deposition.

In 1979, Henriksen developed a simplistic approach to determine acidification based on the relationship between $\mathrm{pH}$ and non-marine calcium. The "acidification indicator" model is based on the premise that pre-acidification alkalinity and $\mathrm{pH}$ can be estimated from recent calcium values. That is, the process of acidification reduces alkalinity without causing a significant change in the calcium ion level. Henriksen (1979) reasoned that, because bicarbonate alkalinity in pristine lakes equals the sum of non-marine calcium and magnesium and because the ratio of non-marine calcium to nonmarine magnesium is constant in these lakes, calcium alone can be used to represent cations and associated equivalence of alkalinity. Therefore, plots of pH against calcium concentration should differentiate between acidified and non-acidified lakes. He found that on a plot of lake pH against lake non-marine calcium concentration, an empirical curve can be drawn separating lakes that receive precipitation either more or less acidic than $\mathrm{pH} 4.6$ (Figure 4). Henriksen's relationship between $\mathrm{pH}$ and non-marine calcium has proved valid for lakes in Norway, Sweden, the United States, and Canada, and has been presented as a first order approach in the identification of acidified and acidifying lakes. The purpose of the "acidification indicator" model was to serve as an early 


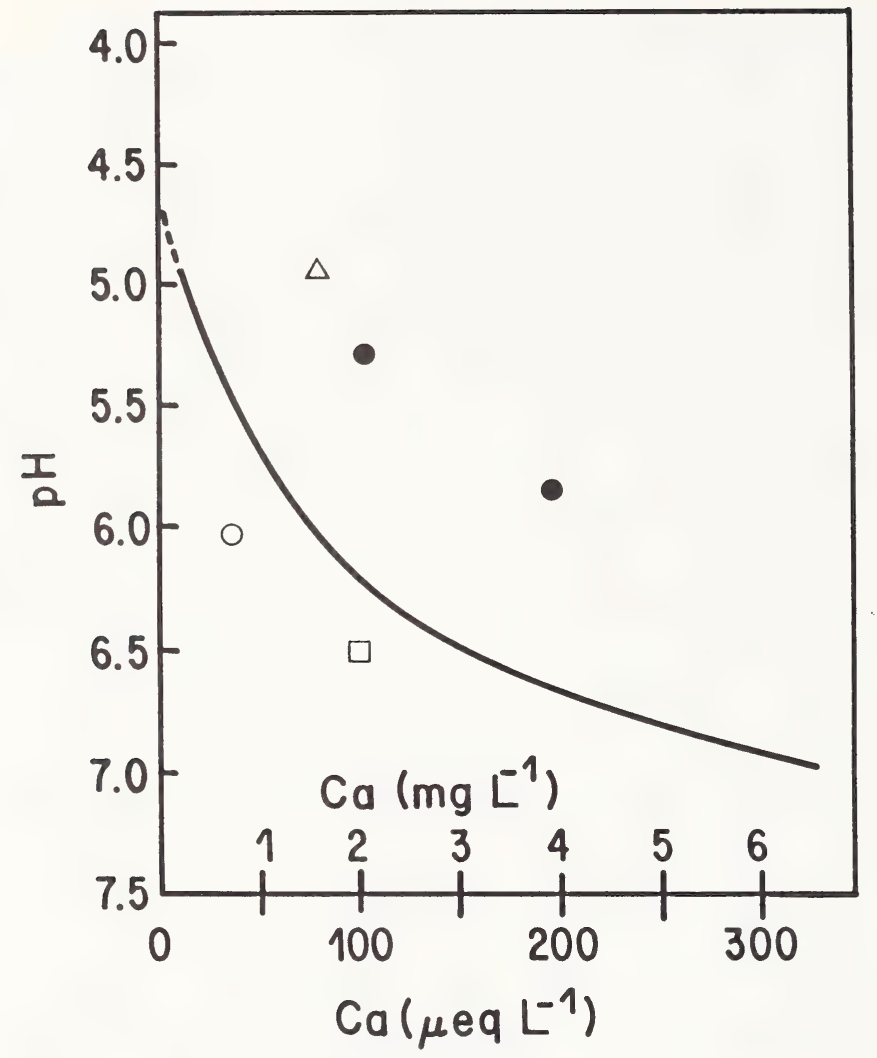

Figure 4. "Acidification Indicator" (after Henriksen 1979). 
warning by identifying waters that have lost alkalinity and are perhaps prone to further effects and biological damage.

In 1980 Henriksen developed another model or "predictor" nomograph to look at various stages of acidification. The model hypothesizes that the acidification of freshwater by acid precipitation is similar to the titration of bicarbonate solution (geochemical origin) with strong mineral acids (atmospheric origin), specifically sulphuric acid. The model is based on electroneutrality conditions, that is, inorganic cations equal inorganic anions. The model assumes no increase in weathering of base cations and considers atmospheric deposition to be the only source of $\mathrm{SO}_{4}{ }^{2-}$. The nomograph is a plot of the sum of non-marine calcium and magnesium against non-marine sulphate, such that the ordinate represents geological inputs and the abscissa represents anthropogenic inputs (Figure 5). The lake $\mathrm{SO}_{4}{ }^{2-}$ concentrations have been correlated with the $\mathrm{pH}$ and $\mathrm{SO}_{4}{ }^{2-}$ concentration in rain by a regression analysis of data from 719 Norwegian lakes. The graph (Figure 5) has been divided into three sections to represent three stages of acidification. The first stage is representative of "bicarbonate lakes" and it is characterized by small decreases in alkalinity and maintenance of the bicarbonate buffered system. The second stage is representative of "transition lakes" and it is characterized by the loss of the bicarbonate buffering system, severe fluctuations in $\mathrm{pH}$, and episodic effects on biota. The third stage is representative of "acidified lakes" and it is characterized by chronically low pH's, elevated trace metal concentrations, such as increased aluminum concentrations, and severe perturbation of resident biota. The nomograph is used to predict acidification status by plotting precipitation $\mathrm{pH}$ or non-marine lake $\mathrm{SO}_{4}{ }^{2-}$ with non-marine sum of calcium and magnesium or calcium alone. This simple model has been successfully applied to lakes in the Adirondacks, Scandinavia, Scotland, and Canada (Wright et al. 1980). Henriksen concluded that the nomograph can successfully predict lake $\mathrm{pH}$ changes in response to changes in the $\mathrm{pH}$ of precipitation and that, if the titration process is reversible, the nomograph can be used to indicate the amount of decrease in precipitation acidity necessary to restore "acid" lakes to "bicarbonate" lakes.

The use of Henriksen's model to predict acidification status has been criticized by many investigators. The main reason is that Henriksen's model assumes that acidification of surface waters is due only to atmospheric input of acidic substances, particularly sulphuric acid. It does not take into account the terrestrial contribution of weathered material.

The first specific criticism concerns the method used to estimate pre-acidification alkalinities. A basic premise of Henriksen's model is that equivalence of calcium and magnesium is proportional to the equivalence of alkalinity under carbonic acid weathering, and that these two ions remain conservative under deposition of mineral acids, therefore enabling one to predict pre-acidification alkalinities based on cation content. The use of calcium or the sum of calcium and magnesium to estimate preacidification alkalinity has been criticized; there is evidence that mineral acid rain increases the export of calcium and magnesium from some watersheds and that this may be increasing the concentrations of these ions in some waters, thus resulting in the overestimation of acidification by acid rain (Glass et al. 1981; Kramer and Tessier 1982; and Krug and Frink 1983b). Recent usage of the Henriksen model takes into account the 


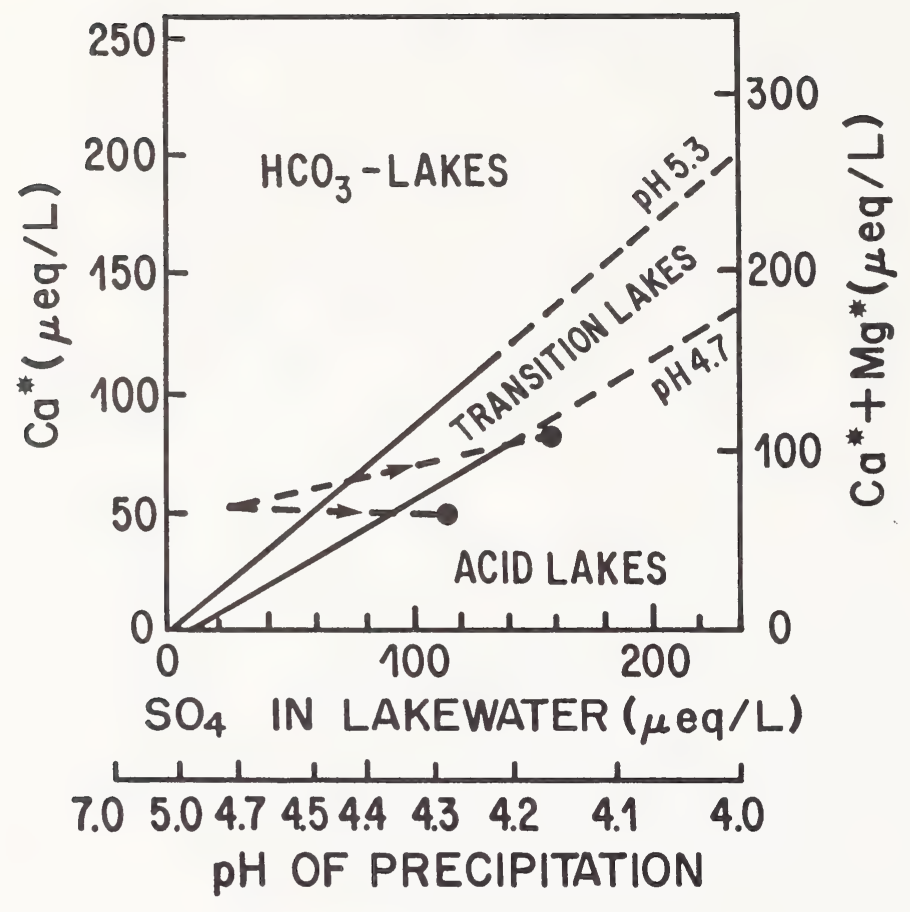

Figure 5. "Predictor" Nomograph (after Henriksen 1980). 
fact that concentrations of calcium and magnesium may be increased by acid deposition and acknowledges that this effect may differ from lake to lake (Wright and Henriksen 1983). Kramer and Tessier (1982) discussed several shortcomings in the model and suggested that $\mathrm{pH}$ should be plotted against $\log \Sigma z_{i}\left(M_{j}\right)$, where $M$ represents the $\mathrm{Ca}^{2+}, \mathrm{Mg}^{2+}, \mathrm{Na}^{+}$, and $\mathrm{K}^{+}$ concentrations and $z$ their respective charges. This approach appears to be especially important when $\mathrm{Na}^{+}, \mathrm{K}^{+}$, and $\mathrm{Mg}^{2+}$ contribute significantly to the total ion concentration (Elzerman 1983). Kramer and Tessier (1982) suggest that the theoretical relationship between $\mathrm{pH}$ and the sum of cations can be calculated from equations representing carbonic acid weathering reactions, holding $\mathrm{pCO}_{2}$ constant. Lakes that deviate from the theoretical line would then represent either an input of hydrogen ion or an additional neutralizing substance.

A second criticism of the Henriksen model is based on the treatment of freshwaters as inorganic solutions. Many freshwaters contain dissolved organic matter, much of which is acidic. This humic material of terrestrial origin has a high capacity to complex ions (e.g., $\mathrm{Ca}^{2+}$ and $\mathrm{Mg}^{2+}$ ) and to act as a buffer against acid or base additions (Krug et al. 1985). The weak organic acids could disturb the basic cation-alkalinity-pH relationship making it difficult to isolate the roles of mineral acids and organic acids in the acidification process. Henriksen (1980) pointed out that lakes with high concentrations of organic acids may not meet several of the assumptions implicit in developing his relationships. Therefore, it is unreasonable to assume that $\mathrm{Ca}^{2+}$ or $\mathrm{Mg}^{2+}$ are naturally charge balanced by $\mathrm{HCO}_{3}$ or that alkalinity or anion deficiency represents $\mathrm{HCO}_{3}$, especially with highly coloured humic waters. In addition, ionic calcium and magnesium may be overestimated in coloured lakes because organically bound cations will be measured. Thus, the Henriksen model could overestimate acidification by acid precipitation for coloured lakes (Henriksen 1979,1980).

The third criticism is related to the use of non-marine sulphate in water as a surrogate for acidification by inputs of $\mathrm{H}_{2} \mathrm{SO}_{4}$ (Everett et al. 1982, cited by Krug et al. 1985). Everett et a1. (1982) reported that this approach overestimates acidification in Adirondack waters. In precipitation water, $\mathrm{pH}$ and $\mathrm{SO}_{4}{ }^{2-}$ have an inverse relationship (that is, the higher the $\mathrm{SO}_{4}{ }^{2-}$ concentration the lower the $\mathrm{pH}$ ), whereas in surface waters they are directly related (that is, the higher the $\mathrm{SO}_{4}{ }^{2-}$, the higher the $\mathrm{pH}$ ). Data from Swedish and Nova Scotian lakes apparently show that $\mathrm{pH}$ and alkalinity are positively correlated with the concentration of $\mathrm{SO}_{4}{ }^{2-}$ at the $p=0.02$ and $p=0.001$ levels, respectively (Everett et al. 1982, cited by Krug et al. 1985). The use of $\mathrm{SO}_{4}{ }^{2-}$ as a surrogate for acidification by atmospheric inputs of $\mathrm{H}_{2} \mathrm{SO}_{4}$ may, therefore, overestimate acidification in surface waters. Predictions of acidification by the Henriksen model now incorporate estimates of background $\mathrm{SO}_{4}{ }^{2-}$. However, there are great uncertainties in such background estimates, particularly for dilute waters which are most sensitive to acidification.

The Henriksen models can be applied only to areas receiving sulphuric acid precipitation and where $\mathrm{Ca}^{2+}$ and $\mathrm{Mg}^{2+}$ ions are dominant cations in surface waters. It is not applicable in areas where $\mathrm{SO}_{4}{ }^{2-}$ is not the major anion in the precipitation or surface water and where cations other than $\mathrm{Ca}^{2+}$ and $\mathrm{Mg}^{2+}$ may be dominant. In such a case the model must be modified. 
Gibson et a1. (1983) studied lakes in the Rocky Mountain National Park, located in north central Colorado, for the effect of acid deposition on the lake chemistry. In their study area, $\mathrm{Na}^{+}$and $\mathrm{Mg}^{2+}$ were the major cations and $\mathrm{NO}_{3}{ }^{-}$was the major anion. They therefore modified the Henriksen nomograph to use it as a tool to evaluate the current and future effects of acid rain in the Rocky Mountains. They replaced the non-marine sum of $\mathrm{Ca}^{2+}$ and $\mathrm{Mg}^{2+}$ used by Henriksen as the y-axis in the nomograph with the sum of nonmarine base cations $\left(\mathrm{Ca}^{2+}, \mathrm{Mg}^{2+}, \mathrm{Na}^{+}\right.$, and $\left.\mathrm{K}^{+}\right)$, and replaced the non-marine $\mathrm{SO}_{4}{ }^{2-}$ used by Henriksen as the $x$-axis with the sum of non-marine anions $\left(\mathrm{SO}_{4}{ }^{2-}\right.$ and $\mathrm{NO}_{3}{ }^{-}$). The background concentration of $\mathrm{SO}_{4}{ }^{2-}(20 \mu \mathrm{eq} / \mathrm{L})$ was subtracted from the non-marine sulphate value. Plotting this information on the nomograph, they observed that most of the lakes in the park could be classified as "bicarbonate" lakes while a few approached the "transition" stage. A maximum loss of $10 \mu \mathrm{eq} / \mathrm{L}$ of alkalinity was observed for some of the lakes in the park.

Church and Galloway (1984) found that both of the original Henriksen models were not applicable to the Adirondack lakes. The reason was that the chemical composition of precipitation in the Adirondacks is quite different from that in the area of Scandinavia from which Henriksen developed the acidification indicator and predictor nomograph. The ratio of $\mathrm{H}^{+}$to $\mathrm{SO}_{4}{ }^{2-}$ indicated that the contribution of $\mathrm{H}_{2} \mathrm{SO}_{4}$ to acidity of precipitation in the Adirondacks is less than in the area for which the Henriksen's models were developed. In the Adirondacks, other acids, particularly $\mathrm{HNO}_{3}, \mathrm{play}$ a greater role in the overall acidity of the precipitation. This causes relationships between precipitation $\mathrm{pH}$ and lake chemistry in the two regions to be different (Church and Galloway 1984).

\subsubsection{Thompson Model}

Thompson (1982) has proposed a cation denudation model of acidification, which can be expressed as a rate model or a concentration model. The rate model depicts the export of cations in runoff from a watershed. This model is very similar to the Henriksen model, except that the sum of cations replaces the sum of calcium and magnesium, and $\mathrm{pH}$ is predicted theoretically rather than empirically. The model allows prediction of $\mathrm{pH}$ based upon the relationship between bicarbonate ion and hydrogen ion in the carbonic acid system. Sulphate is assumed to originate from atmospheric deposition (all ions were corrected for marine aerosols), and no correction for background sulphate is applied.

Thompson's model has been criticized by Marcus et al. (1983) for ignoring several important considerations necessary to relate the cation denudation rate (CDR) to changes in acid loading. They suggested that: (1) CDR models should include parameters for watershed soils and geology; (2) they should consider the relationship between chemical weathering and precipitation volume; (3) they should consider changes in precipitation volume because it influences apparent COR by altering proportional contributions from groundwater and from precipitation; (4) they should incorporate biological influence; and, (5) they should consider the influences of atmospheric deposition of cations on apparent CDRs. 
In southern Norway simple hydrochemical reservoir models based on the mobile anion concept have been developed for two catchments (in Birkenes and Storgama) with acidified stormwater (Christophersen et al. 1984a,b). The purpose of the model was to attempt to explain the acidification of streamwaters in these two areas by the observed variations in a small number of physically realistic processes. Key processes used in the model were water-routing, sulphate adsorption-desorption, ion-exchange reactions, weathering, and a gibbsite equilibrium condition.

The entire process was based on the hypothesis that soil acidification had occurred and that acid precipitation was at least partly responsible. Using primarily input-output measurements of water and major ions, the models reproduced principal characteristics of the observed runoff concentrations, but they were not necessarily physically and chemically accurate descriptions of the catchments. The authors claimed that the approach is an iterative one, constituting a set of hypotheses which can later be tested by new measurements and experiments, which in turn may be used to develop improved models.

In Scandinavian catchments it was found that the concentrations of nitrate $\left(\mathrm{NO}_{3}{ }^{-}\right)$, ammonium $\left(\mathrm{NH}_{4}{ }^{+}\right)$, and potassium $\left(\mathrm{K}^{+}\right)$were negligible, although nitrate could be significant in some areas during snowmelt. In the catchments under study the amounts of cations $\left(\mathrm{Na}^{+}\right)$and anions $\left(\mathrm{Cl}^{-}\right)$were found to be nearly the same in both precipitation and runoff. It was therefore decided to ignore these ions. Organic anions were disregarded, as well as the negligible concentrations of bicarbonate $\left(\mathrm{HCO}_{3}{ }^{-}\right)$. With these simplifying conditions sulphate was left as the major anion, while the principal cations were $\mathrm{H}^{+}, \mathrm{Ca}^{2+}, \mathrm{Mg}^{2+}$, and $\mathrm{Al}^{3+}$. The importance of sulphate anions for the transport of cations through soils (i.e., the mobile anion concept) had been stressed a number of years earlier by Cronan et al. (1978) and Seip (1980a,b).

\subsubsection{The Hydrological Sub-Model}

Most of the sulphur entering the catchment and all sulphur leaving occur in the form of aqueous sulphate, so a model for sulphate rested critically on an adequate hydrological sub-model.

The basic sub-model used was a slightly modified version of the simple two-reservoir model (Figure 6) developed by Lundquist (1977, cited by Christophersen et al. 1984b). Physically, the upper reservoir was considered as water draining down the hillsides as piped flow or as fast throughflow entering the brooks directly. This water was thought of as being mainly in contact with or most recently in contact with the upper soil horizons, i.e., the humus and upper mineral layers. Drainage half-time for this reservoir was set at 0.99 days.

The lower reservoir in the model provided the base-flow, which presumably came largely from deeper soil layers. For this reservoir, drainage half-time was taken as 15.4 days.

Water enters the model as precipitation in the upper reservoir. After reaching the threshold value, it flows out at a rate proportional to the amount above threshold. This discharge flows wholly into the lower reservoir if the level in the latter is below its threshold. If the level is above threshold an arbitrary portion enters the lower 


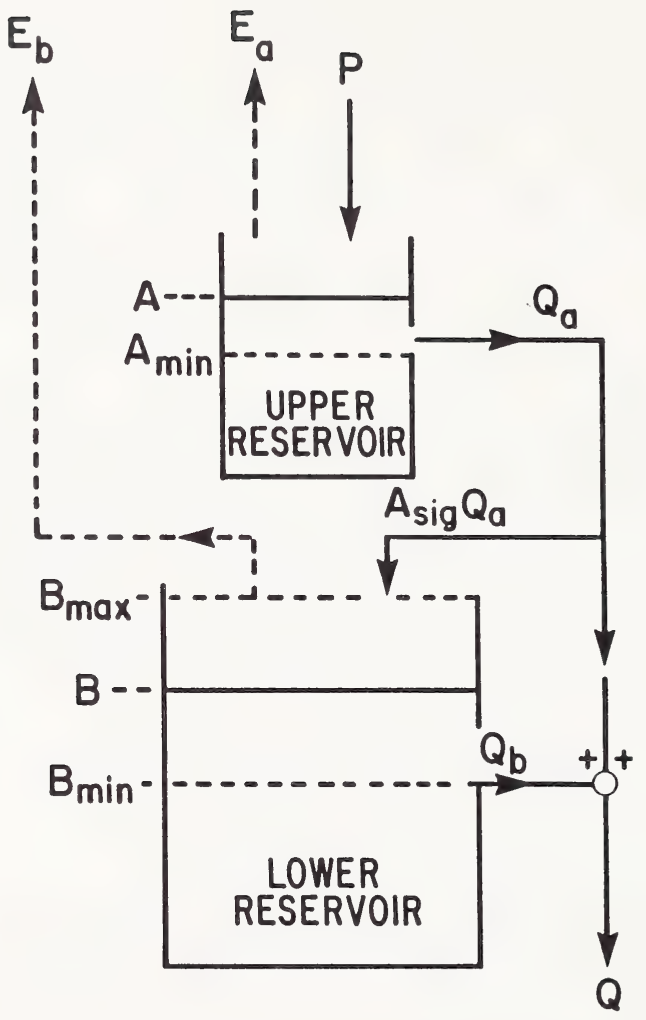

Figure 6. Hydrologic Submodel (after Christophersen et al. 1984b); in the submode1, $E$ = evapotranspiration, $P=$ precipitation, and $Q=$ water flux. 
reservoir, and the rest leaves as runoff. Finally, if the lower reservoir is filled, overflow occurs. Drainage from the lower reservoir is also governed by the amount of water above the minimum level.

Water is also lost by evapotranspiration. Data inputs to the model are daily precipitation volume and daily mean temperature, and runoff is simulated.

\subsubsection{The Chemical Model}

The chemical model was built on the simple hydrological sub-model. The concentration of sulphate was assumed to determine the sum of concentrations of the four cations $\left(\mathrm{H}^{+}, \mathrm{Ca}^{2+}, \mathrm{Mg}^{2+}, \mathrm{Al}^{3+}\right)$. This chemical model is divided into two sub-models: the sulphate model and the model for cation concentrations.

9.2.2.1 The sulphate sub-model (Christophersen et al. 1982). This sub-model attempted to quantify the accumulation and depletion of sulphate by comparing observed and simulated concentrations. There were good measurements of sulphate entering and leaving the catchment but few measurements of the amounts of sulphate and other sulphur compounds within the catchment, and no direct measurements of the various processes in which sulphur was involved. Processes such as biological activity and mineralization of sulphur compounds were not considered quantitatively but were included indirectly in the model.

Stormflow came almost entirely from the upper reservoir and thus the high $\mathrm{SO}_{4}$ concentrations were due to the release of $\mathrm{SO}_{4}$ in the upper zone. During the baseflow period, streamwater sulphate decreased. Because this baseflow came entirely from the lower reservoir, there must have been a process occurring in the lower zone by which sulphate concentrations were regulated to an "equilibrium" level. At one of the sites (Birkenes), sulphate was the major anion in both precipitation and runoff, and presumably also in the soil solution. Most of the sulphate was of anthropogenic origin. About $10 \%$ of the total sulphate input was ascribed to seawater salts. The investigators estimated that over $80 \%$ of the present day sulphur input to Birkenes came from the emission and long-range transport of anthropogenic sulphur.

Precipitation at Birkenes was acidic, with sulphate as the major anion. The chemical composition of precipitation was depicted as a mixture of long-range transported components $\left(\mathrm{H}^{+}, \mathrm{SO}_{4}{ }^{2-}, \mathrm{NO}_{3}{ }^{-}, \mathrm{NH}_{4}{ }^{+}\right)$, marine salts from sea spray $\left(\mathrm{Na}^{+}, \mathrm{Mg}^{2+}, \mathrm{Cl}^{-}, \mathrm{SO}_{4}{ }^{2-}\right)$, and components from several sources $\left(\mathrm{Ca}^{2+}, \mathrm{K}^{+}\right)$. About $10 \%$ of the sulphate in the precipitation was of a marine origin.

9.2.2.2 The cation sub-model. The sulphate sub-model stipulated the total concentration of anions in the water in each reservoir. This formed the point of departure for the cation model. The basic assumption was that the four cations $\mathrm{H}^{+}, \mathrm{Ca}^{2+}, \mathrm{Mg}^{2+}$, and $\mathrm{Al}^{3+}$ exactly balance the anion sulphate in each reservoir at all times. It was also assumed that each reservoir was ideally mixed, i.e., the concentrations of the species were uniform throughout the reservoirs.

There were additional simplifying assumptions for this mode1. The cations $\mathrm{Ca}^{2+}$ and $\mathrm{Mg}^{2+}$ behave similarly in many respects. Both are released to solution by chemical weathering of primary minerals. Thus, $\mathrm{Ca}^{2+}$ and $\mathrm{Mg}^{2+}$ were lumped together into a new 
parameter, $\mathrm{M}^{2+}$, which represented the sum of these two divalent cations. The cation model in the upper reservoir was expressed by three equations (refer to Christophersen et a1. 1984).

Because the cation sub-model is based on the sulphate sub-model, which in turn relies on the hydrological model, it is sometimes difficult to determine where in the chain lies the cause of discrepancies between the observed and the simulated cation concentrations. In many cases, it is clear that the hydrological sub-model is the weakest link.

Seip and Rustad (1984), using a simple two-reservoir model (Christophersen et a1. 1982), estimated that a doubling of the sulphate concentration in runoff (by a doubling of the sulphur deposition) may in some cases give pH decreases in surface waters of 0.7 to 1.0 unit or even more. This, for example, might be a pH drop from 6 to about 5 , assuming no changes in soil properties such as base saturation. This contradicts observations by Rosenqvist (1980) that the shift would be about $0.2 \mathrm{pH}$ units or less. The Christopherson et al. (1982) model is suitable for catchments where the bicarbonate concentration in the stream is low. Seip and Rustad (1984) extended the Christophersen model to streams where bicarbonate is significant and by simple calculations they studied the effects of changed sulphate deposition on a system with significant bicarbonate concentrations in the base flow.

Krug et al. (1985) have developed a model to describe precipitation-soil interactions on the basis of ion-exchange and solution electroneutrality. The model attempts to describe chemically the part of the terrestrial hydrologic cycle that results in acid runoff and to identify the source of acidity by identification of anions in solution.

\subsubsection{Chemical Equilibrium Model}

Arp (1983) developed a model to quantify the extent of soil and lake acidification for chemically and biologically active soils under the threat of acid precipitation. The model attempts to predict the acid $\left(\mathrm{H}^{+}, \mathrm{Al}^{3+}\right.$, and $\left.\mathrm{Fe}^{3+}\right)$ and base $\left(\mathrm{Na}^{+}, \mathrm{K}^{+}, \mathrm{Mg}^{2+}, \mathrm{and}^{+}\right.$ $\mathrm{Ca}^{2+}$ ) cation losses from the soil calculated from the rate and amount of acid cation retention when the rate of acid cation input is constant. The model assumes that the total amount of acidity retained by the soil is limited and qualitatively follows a Freundich-type "absorption" isotherm. The model requires input information on: the total amounts of acid and base cations received by the soil via precipitation and weathering; and, the exchangeable base cation content and total number of cation exchange sites of the soil prior to the onset of acid precipitation.

Reuss and Johnson (1985) used the chemical equilibrium models to investigate the mechanism whereby acid deposition can cause acidification of surface waters via equilibrium processes in soil solution. In acid soils, the introduction of mobile anions appears to cause sufficient increases in soil solution ionic strength to decrease the alkalinity of the soil solutions. Within certain critical ranges, this effect causes a switch from positive to negative alkalinity in the solution, producing large pH effects when the solutions leave the $\mathrm{CO}_{2}$-rich soil environment and begin to equilibrate with ambient atmospheric $\mathrm{CO}_{2}$-levels. Such effects are observed in waters with low ionic strength, low but positive alkalinities, and in which the alkalinity was originally 
produced in soil solution. The mechanism does not require soil acidification, but does require a certain combination of soil $\mathrm{CO}_{2}$ pressure and soil characteristics that will produce a positive, low alkalinity soil solution. The effects are reversible if no anion adsorption-desorption occurs. The mechanism is proposed by the authors as a testable hypothesis.

\subsubsection{Computer Model}

Booty and Kramer (1984) have developed a computer model applicable to a small $\left(1 \mathrm{~km}^{2}\right.$ ) non-calcareous basin. The model is calibrated for simulating the movement of water and $\mathrm{H}$ ions through a forested watershed. The watershed is divided into homogenous sub-basins and each sub-basin is defined by its surface area, vegetation and forest type, and soil characteristics. The model operates on a daily time step with meteorological and $\mathrm{pH}$ of precipitation inputs. Controls are used in the model to regulate the influence of the various hydrological processes during the spring, summer, autumn, and winter periods. The model incorporates the acid neutralizing capacity for various horizons. Basin outflow is affected by changes in field capacity in the short and long term (weeks and months) and changes in the hydraulic conductivity of the saturated zone in the long term. The acid neutralizing capacity and depth of the soil appear to affect the $\mathrm{pH}$ of water on the long term. Reasonable changes in snow leaching, canopy enrichment, acid neutralizing capacity, soil depth, and total soil thickness do not seem to have an effect on $\mathrm{pH}$ in the short term. Booty and Kramer (1984) applied the model to the Batchawana Lake basin in Ontario and estimated long-term and short-term acidification of soil waters.

\subsubsection{ILWAS Mode 1}

For the Integrated Lake-Watershed Acidification Study (ILWAS) in the Adirondack Mountains, New York, Gherini et al. (1984) and Goldstein et al.(1984b) developed a mathematical model to predict changes in surface water acidity given changes in the acidity of precipitation and dry deposition. The model was developed specifically to predict surface water hydrogen ion and aluminum concentrations because of their importance to fish. The model was divided into two modules: hydrological and chemical. The model incorporated the major flowpaths followed by precipitation and the major biogeochemical processes that altered the chemical characteristics of water as it moved along these flowpaths. The model routed precipitation through the forest canopy, soil horizons, streams, and lakes using mass-balance concepts and equations which related flow to hydraulic gradients. The physical and chemical processes which change the acid-base status of the water were simulated by rate and equilibrium expressions. Mass balance transfers between gas-liquid and solid phases were included in the model. The aqueous constituents simulated were the major cations $\left(\mathrm{Ca}^{2+}, \mathrm{Mg}^{2+}, \mathrm{Na}^{+}, \mathrm{K}^{+}, \mathrm{NH}_{4}^{+}\right)$and anions $\left(\mathrm{SO}_{4}{ }^{2-}, \mathrm{NO}_{3}{ }^{-}, \mathrm{Cl}^{-}, \mathrm{F}^{-}\right)$, aluminum and its complexes, organic acid analogues, and dissolved inorganic carbon. Concentrations of free hydrogen ion or $\mathrm{pH}$ were derived from the solution alkalinity and the total concentrations of inorganic carbon, organic acid, and monomeric aluminum.

The model was used to predict changes in the acidity of Woods Lake (pH 4.5 to 5.0) and Panther Lake ( $\mathrm{pH} 6$ to 7 ) given reductions in the total atmospheric sulphur 
loads. A halving of the sulphur load had little effect on the pH of Panther Lake even after 12 years; in Woods Lake, the change was large.

The model showed that movement of water through shallow or deep soil largely determines the extent to which incident precipitation is neutralized as reported by chen et al. (1984) and Schofield (1984). Analysis of the two lake basins using the simulated model and field data showed the watersheds to be net suppliers of base to the throughflowing water, and that the watershed internally provided two-thirds the amount of the atmospheric acidity.

The ILWAS model can be criticized for treating the role of internally generated organic acids simplistically. However, it is important to note that Schofield (1984) observed that organic acids were not important in determining the pH of lakes studied in the ILWAS project.

\subsection{CONCEPTUAL MODELS}

Galloway et al. (1983) published a simple conceptual model that incorporated a few key soil processes to determine how aquatic ecosystems respond to acid deposition with respect to time. The model was based on the assumption that if the rate of acid deposition changes, a variety of constituents, such as $\mathrm{SO}_{4}{ }^{2-}$, base cations, and alkalinity in both the terrestrial and aquatic ecosystems will respond. The article addressed the complex temporal relationships between changes in sulphur deposition and changes in surface water chemistry with the use of a conceptual model. The model includes: (1) the stages of acidification of aquatic systems; (2) the stages of recovery; (3) the time lags in acidification and recovery; and, (4) the processes that control the time lags.

The model is applicable to those lakes where terrestrial processes bring about lake water acidification. It is not applicable to situations where acidification results from the dilution of more alkaline water by less alkaline water or where more acidic water, unaltered by terrestrial processes, replaces less acidic water volume by volume. The net biomass in the terrestrial system is assumed to be constant. Only sulphate is included in the model because $\mathrm{SO}_{4}{ }^{2-}$ more than $\mathrm{NO}_{3}{ }^{-}$is considered to promote long-term acidification of aquatic systems.

The model has seven stages. The effect of each stage on the water composition of a lake is shown in Figure 7. Stage 1 represents the pre-acid deposition status of an aquatic ecosystem. Stages 1 to 4 represent the acid deposition status of an aquatic ecosystem and Stages 4 to 7 represent the post-acid deposition status of an aquatic ecosystem.

In Stage 1, the concentrations of $\mathrm{SO}_{4}{ }^{2-}$, alkalinity, and base cations remain constant over time because the systems are not receiving acid deposition. The lake chemistry is dominated by base cations and $\mathrm{HCO}_{3}{ }^{-}$formed by soil solution neutralization during the weathering. This stage represents a steady state and lasts as long as sulphur deposition does not increase substantially. However, the important point to remember is that ecosystems are dynamic and always changing, and a steady state is only a short-term phenomenon. Low alkalinity lakes in the Rocky Mountains and Sierra Nevada Mountains fall into this category. 


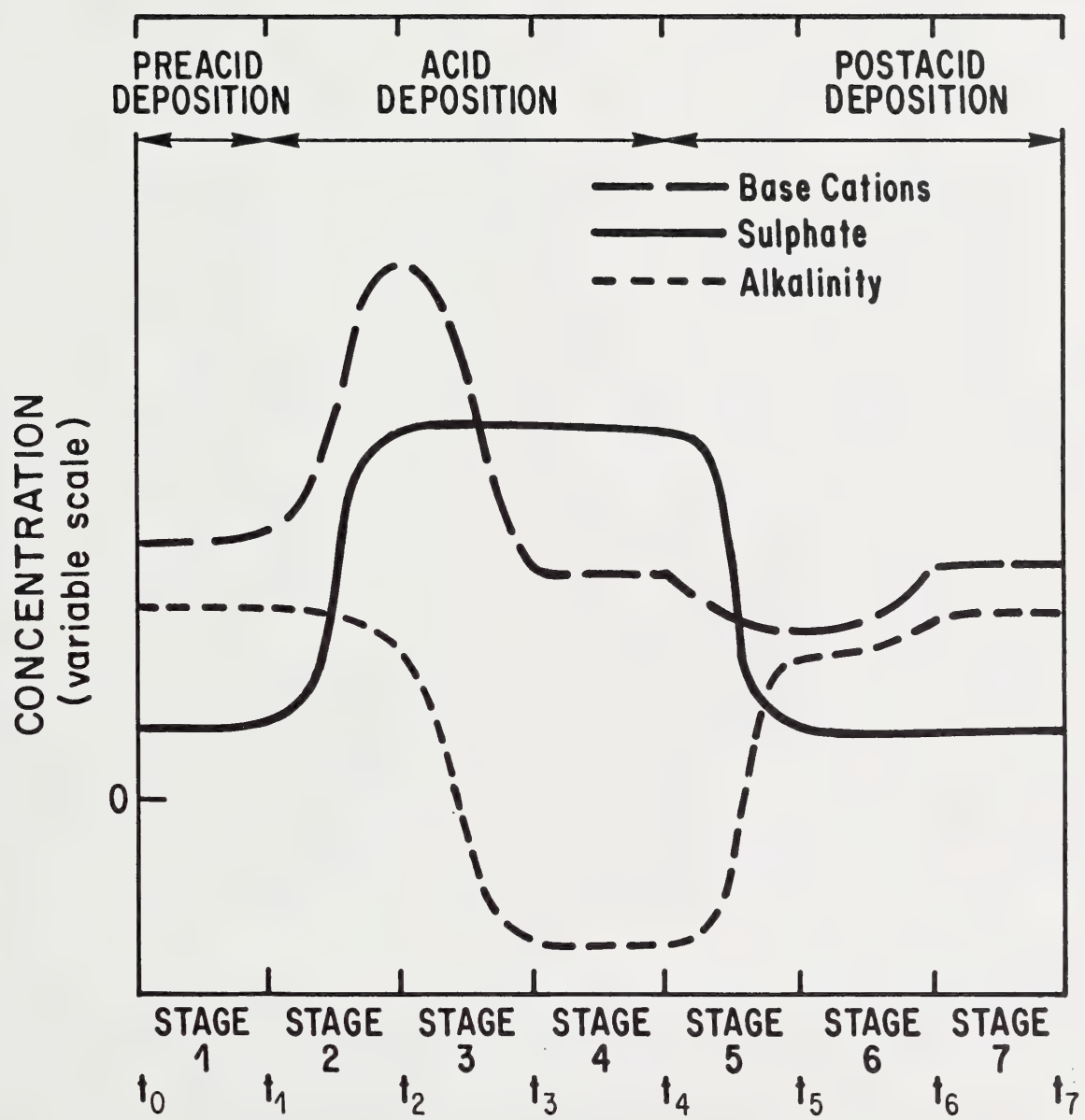

Figure 7. Changes in the concentrations $(\mu \mathrm{eq} / \mathrm{L})$ of sulphate, base cations, and alkalinity during the seven stages of acidification (after Galloway et al.1983). 
In Stage 2, aquatic ecosystems receive acid deposition, and the increased sulphur deposition accumulates in the terrestrial system because the soil is unsaturated with sulphur. This gradually increases base cation concentrations in the aquatic system and alkalinity gradually decreases. The length of this stage depends on the sulphate adsorption capacity of the soil (SAC), the cation exchange capacity of the soil (CEC), and on the sulphur deposition loading. Regions containing such systems are Shenandoah National Park, VA; Camp branch TN; Cowestra Experimental Forest NC; and Walker Branch watershed, TN (Galloway et al. 1983).

In Stage 3, the soil becomes saturated with $\mathrm{SO}_{4}{ }^{2-}$. This allows an amount of $\mathrm{SO}_{4}{ }^{2-}$ equivalent to the sulphur deposition from the atmosphere to be discharged to the aquatic system. This in turn causes the alkalinity and base cations to decrease in the aquatic system. The length of this stage depends on the rates of desorption and primary chemical weathering, the size of the soil reservoir associated with the hydrologic pathway, and the cationic composition of the precipitation. Ecosystems in the northeastern United States and southeastern Canada are probably in Stage 3.

Stage 4 represents a steady-state period of lake acidification. In this stage, the soil is still saturated with sulphur, alkalinity is lower than in Stage 3 but remains constant, and base cation concentrations are constant. This stage lasts as long as sulphur deposition remains constant. The lack of reliable temporal data for alkalinity makes it difficult to determine which regions have reached a new steady state. Possible sites are the sudbury and Wawa regions in Ontario, because they have received heavy loadings of $\mathrm{SO}_{4}{ }^{2-}$ for a long period of time.

Stage 5 begins with decreases in the deposition of $\mathrm{SO}_{4}{ }^{2-}$ due to decreases in sulphur emissions. Soil adsorption of base cations from primary weathering increases and, therefore, base cation concentration in the aquatic system decreases. The alkalinity begins to increase. The length of Stage 5 may range from years to decades. Decreases in $\mathrm{SO}_{4}{ }^{2-}$ deposition result in the gradual decreases in the $50 i 1$ of $\mathrm{SO}_{4}{ }^{2-}$ accumulated during Stages 2 to 4 , depending upon the reversibility of adsorbed $\mathrm{SO}_{4}{ }^{2-}$ and the amount of soil associated with hydrologic pathways. Thus, it may take several years before lake alkalinity increases.

Stage 6 represents recovery of the percent base saturation of the terrestrial system. During this stage the percent base saturation of the soil increases. Therefore, fewer base cations are adsorbed by the soil through primary weathering, causing a recovery of base cations in the surface waters. The recovery length of this stage appears to depend on the hydrologic pathway through the terrestrial system and on soil characteristics. Generally, lakes should de-acidify in the same order at which they acidified.

Stage 7 represents the stable period of lake recovery. The aquatic ecosystem is now in a steady state with the lower levels of $\mathrm{SO}_{4}{ }^{2-}$ deposition.

Because, in reality, sulphur deposition has not yet decreased significantly, the characteristics of an aquatic ecosystem during the post-acid deposition period stages 5 to 7 are based on theoretical generalizations and speculations.

Based on Galloway et al.'s (1983) conceptual model, Cosby et al. (1985) have published a simple quantitative model called MAGIC (Model of Acidification of Groundwater in Catchments). The model assumes that surface water acidification is determined by 
physical and chemical processes in catchment soils, and estimates patterns and absolute time scales of surface water acidification.

Galloway et al.'s (1984) conceptual model and Cosby et al.'s MAGIC model are applicable only to those areas which receive atmospheric deposition with $\mathrm{SO}_{4}{ }^{2-}$ as the dominant anion. They are not applicable to situations where $\mathrm{NO}_{3}{ }^{-}$is the major anion.

Turk and Adams (1983) developed a conceptual model to assess sensitivity to acidification of lakes in the flat Tops Wilderness area, Colorado. The model is not defined clearly. It predicts chemical quality of surface water from the present day alkalinity and the presumed volume of added acid. The model does not take into account reactions of the added acid with the environment, other than those involving the aqueous component of the pre-existing, steady state watershed.

In summary, it appears that most of the above-mentioned models have several weaknesses and that they are applicable to areas where $\mathrm{SO}_{4}{ }^{2-}$ is the major anion in acid deposition. Also, these models do not take into consideration the role of organic and other weak acids in the natural acidification process. An exception to this observation may be the ILWAS model which may have a universal application. 
10. SURFACE WATER ACIDIFICATION STUDIES IN ALBERTA

Only one study appears to have been carried out in the Province of Alberta on the effects of acidic atmospheric deposition on surface water chemistry.

Hesslein (1979) surveyed 20 lakes in the Alberta $0 i 1$ Sands Environmental Research Program (AOSERP) study area near Fort McMurray in order to determine their susceptibility to $\mathrm{pH}$ change resulting from atmospheric acid additions. The lakes were sampled for only a short period of time; October 6 - 10, 1976. Most lakes in the region were found to have high $\mathrm{pH}$ values and high alkalinity. However, they could be divided into two groups, one having $\mathrm{pH}$ and alkalinity in the range of $6.18-7.49 \mathrm{pH}$ units and $342-811 \mu \mathrm{eq} / \mathrm{L}$, respectively, and the other in the range of $7.89-8.32 \mathrm{pH}$ units and $965-3090 \mu \mathrm{eq} / \mathrm{L}$, respectively. The first group of lakes is located at the northwest corner of the study area, whereas, the second group of lakes is located in the more alkaline region along the Athabasca River. Hesslein (1979) suggested that the first group of lakes might be susceptible to serious $\mathrm{pH}$ alterations if the $\mathrm{pH}$ of rain averages below 4.0. However, this is unlikely to happen for two reasons. The first is that sulphur emissions in Alberta are controlled by provincial legislation, allowing less than one percent of the total oxides of sulphur to be emitted into the atmosphere. The second reason is that the sudbury, Ontario area, with much greater emissions of sulphur dioxide than Alberta, has rains averaging 4.0 to 4.5 in pH (Hesslein 1979).

In Alberta, streams and rivers have been routinely sampled by Environment Canada and Alberta Environment since 1969. Very few lakes, particularly the ones at high altitudes, have been sampled by the two agencies. In general, most Alberta rivers and streams have high pH's, above 7.5, and high alkalinity, above 1000 req/L values (Environment Canada 1982).

Most of Alberta, except the northeast corner of the province, is underlain by carbonate rich minerals (limestone, dolomite, slightly calcareous rocks) with medium to high buffering capacity. The northeast corner of the province is in the Precambrian Canadian Shield and is underlain by granitic gneisses and quartz sandstone with low buffering capacity. Shewchuck (1986) conducted regional surveys of rain, snow, and lake water chemistry in several locations of western Canada located on and near the Precambrian shield. The areas included part of Saskatchewan (east to northwest section), part of Manitoba, The Northwest Territories, and a northeastern section of Alberta. Snow and rain in the Shield region had average $\mathrm{pH}$ values of 5.0 and 6.4 , respectively, indicating that the area was not receiving significant amounts of acid deposition. The total amount of sulphate deposition for a seven month period in 1983 amounted to $2 \mathrm{~kg} \mathrm{ha}^{-1}$. The average $\mathrm{pH}$ of lakes on the Precambrian shield averaged $7.3 ; \mathrm{the} \mathrm{pH}$ of lakes on the fringe or off the Precambrian Shield averaged 8.1. Sulphate, alkalinity (as $\mathrm{CaCO}_{3}$ ), and calcium ion concentrations in the Precambrian Shield lakes averaged $2.7,13$, and $4.3 \mathrm{mg} / \mathrm{L}$, whereas, in the fringe or off-shield lakes they averaged 15,200 , and $55 \mathrm{mg} / \mathrm{L}$, respectively. Although Precambrian Shield lakes are highly sensitive to acid deposition due to lack of buffering capacity, there is little evidence to suggest that at present they are undergoing significant acidification. Acidification studies conducted on lakes located in the Precambrian Shield of Nova Scotia, Ontario, and Quebec, however, suggest that these lakes have become acidic over the last few decades. Acid deposition is reported to be the cause of the lake acidification. Although the mechanism 
of their acidification is a subject of much discussion, it appears that lakes located in this sensitive shield area are. susceptible to acidification. Therefore, one can make a cautious prediction that lakes located in the northeast corner of Alberta may also be susceptible to acidification.

Three reports coordinated by Alberta Environment and Western Canada LRTAP concerning the acidification potential for northern Alberta are nearing completion. They include: an inventory of freshwater systems and their sensitivity ratings; a mapping of the northern soils and hydrogeology; and, a statement of target loading for northern Alberta (David Trew, Alberta Environment, personal communication 1987). When completed, they will provide a valuable tool for examining future scenarios of, and possible mitigative measures for, aquatic acidification in northern Alberta, particularly in the context of oil sands production and development. 


\section{RECOMMENDATIONS FOR FURTHER STUDIES}

Alberta contains many lakes and streams in remote, sensitive regions not yet investigated for the effects of acid deposition on surface water quality. These areas are pristine and are not affected by changed land use practices. Therefore, lakes in these regions offer a unique opportunity to study mechanisms of surface water acidification in terms of the relative contribution of atmospheric deposition and internal watershed processes.

Based on the literature review, the following recommendations regarding surface water acidification studies in Alberta are provided:

1. Lakes and streams located in the northeast part of the province should be investigated for surface water acidification. This area is located in the Precambrian Canadian Shield and this physiographic region has been shown to be sensitive to acid deposition in Ontario, Quebec, and Nova Scotia.

2. Investigation should focus on clearwater seepage and drainage lakes, and lakes with low watershed-to-lake ratios.

3. Study lakes should have low dissolved organic carbon value (less than $3 \mathrm{mg} / \mathrm{L}$ ) and low colour values. (less than 15).

4. The ILWAS approach should be used in the study; the chemical composition of the precipitation and the major flowpaths followed by the precipitation water before reaching a lake should be determined. The ILWAS approach should be used on carefully selected systems, with a significant commitment of effort to the study.

5. Water samples should be analysed for major cations, including $\mathrm{NH}_{4}^{+}$, aluminum and its organic and inorganic forms, major anions, pH, alkalinity, colour, dissolved organic carbon, and organic acids.

\subsection{RESEARCH DEFICIENCIES}

During the course of the literature review, two research deficiencies were identified in the studies of surface water acidification. The first concerns the effects of sulphur dust on surface water quality. The second lack of knowledge deals with the effects of agriculturally applied ammonium, nitrate, and sulphate fertilizers on surface water quality. Studies related to these effects can be carried in Alberta, particularly those dealing with sulphur dust. For example, at Whitecourt, Alberta, it has been observed that substantial quantities of sulphur dust accumulate on the terrestrial ecosystem through atmospheric deposition (A.H. Legge, private communication 1986). oxidation of this accumulated sulphur dust could potentially alter the acid-base status of surface waters and thus alter the $\mathrm{pH}$ of lakes and streams. 
12. RERERENCES CITED

Alfheim, I., M. Stobet, N. Gjos, A. Bjorseth, and S. Wilhelmsen. 1980. An analysis of organic micropollutants in aerosols. In: Ecological Impact of Acid Precipitation, Proceedings of an International Conference, eds. D. Drablos and A. Tollan. 1980 March 11-14; Sandefjord, Norway; SNSF Project. 0s10, Norway; pp. 100-101.

Allen H.L. 1972. Phytoplankton photosynthesis, micronutrient interactions, and inorganic carbon availability in a soft-water Vermont lake. In: Nutrients and Eutrophication, the Limiting-Nutrient Controversy, ed. G.E. Likens. Special Symposium, Vol. 1. American Society of Limnology and Oceanography. Lawrence, Kansas. pp. 68-83. (Original not seen; information taken from Marcus et. al. 1983.)

Almer, B., W. Dickson, C. Ekstrom, and E. Hornstrom. 1978. Sulfur pollution and the aquatic ecosystem. In: Sulfur in the Environment. Part II, ed. J. Nriagu. New York: John Wiley and Sons, pp. 273-311.

Almer, B., W. Dickson, C. Ekstorm, E. Hornstorm, and U. Miller. 1974. Effects of acidification on Swedish lakes. Ambio 3: 30-36.

Arp, P.A. 1983. Modelling the effects of acid precipitation on soil leachates: a simple approach. Ecological Modelling 19: 105-117.

Baker, J.P. 1983a. 5.5 Plankton. In: Chapter E-5. Effects on Aquatic Biology. The Acidic Deposition Phenomenon and Its Effects. Critical Assessment Review Papers. Volume II - Effects Sciences. Public Review Draft, eds. A.P. Altshuller and R.A. Linthurst. US Environmental Protection Agency Report 600/8-83-016B. pp. $5-45$ to $5-76$.

Baker, J.P. 1983b. 5.6 Fishes. In: Chapter E-5. Effects on Aquatic Biology. The Acidic Deposition Phenomenon and Its Effects. Critical Assessment Review Papers. Volume II - Effects Sciences. Public Review Draft, eds. A.P. Altshuller and R.A. Linthurst. US Environmental Protection Agency Report 600/8-83-016B. pp. $5-76$ to $5-137$.

Baker, J.P., C.L. Schofield, and C.T. Driscoll. 1979. Aluminum toxicity to fish as related to acid precipitation and Adirondack surface water quality. Fisheries Abstracts, 35th Annual Fish and Wildlife Conference, Providence, RI.

Barnard, T.E. and J.J. Bisogni, Jr. 1985. Errors in gran function analysis of titration data for dilute acidified water. Water Research 19: 393-399.

Battarbee, R.W. and D.F. Charles. 1986. Diatom-based PH reconstruction studies of acid lakes in Europe and North America: A synthesis. Water, Air, and Soil Pollution 30: $347-354$.

Beamish, R.J. 1976. Acidification of lakes in Canada by acid precipitation and the resulting effects on fish. Water, Air, and Soil Pollution 6: 501-514.

Beamish, R.J. 1974. Loss of fish populations from unexploited remote lakes in ontario, Canada as a consequence of atmospheric fallout of acid. Water Research 8: $85-95$.

Beamish, R.J. 1972. Lethal pH for the white sucker Catostomus commersoni (Lacepede). Transactions of the American Fisheries Society 101: 355-358. 
Beamish, R.J. and H.H. Harvey. 1972. Acidification of the LaCloche Mountain lakes, Ontario and resulting fish mortalities. Journal of the Fisheries Research Board of Canada 29: 1131-1143.

Beamish, R.J., W.L. Lockhart, J.C. Van Loon, and H.H. Harvey. 1975. Long-term acidification of a lake and resulting effects on fishes. Ambio 4: 98-102.

Be11, G.R. 1971. Effect of $10 \mathrm{w}$ pH on the survival and emergence of aquatic insects. Water Resources 5: 313-319.

Be11, G.R., G.E. Hoskins, and J.W. Bagshaw. 1969. On the structure and enzymatic degradation of the external membrane of the salmon egg. Canadian Journal of Zoology 47: $146-148$.

Be11, H.L. and A.V. Nebeker. 1969. Primary studies on the tolerance of aquatic insects to low pH. Journal of the Kansas Entomological Society 42(2): 230-237.

Best, M.O. and J.H. Peverly. 1981. Water and sediment chemistry and elemental composition of macrophytes in thirteen Adirondack lakes (abstract). In: Proceedings of International Symposium on Acidic Precipitation and Fishery Impacts in North Eastern North America, North Eastern Division American Fisheries Society. 1981 August 2-5; Cornell University, Ithaca, New York; p. 348.

Bjarnborg, B. 1983. Dilution and acidification effects during the spring flood of four Swedish mountain brooks. Hydrobiologia 101: 19-26.

Booty, W.G. and J.R. Kramer. 1984. Sensitivity analysis of a watershed acidification model. Philosophical Transactions of the Royal Society London B305: 441-449.

Borgstrom, R. and G.R. Hendrey. 1976. pH tolerance of the first larval stages of Lepidurus arcticus (Pallas) and adult Gammarus lacustris G.0. Sars. SNSF Project, Internal Report 22/76. 0s10-As, Norway. $37 \mathrm{pp}$.

Brady, N.C. 1974. The Nature and Properties of Soils. New York: McMillan Publishing. $639 \mathrm{pp}$.

Braekke, F.H. 1981. Hydrochemistry in 10w-pH-soils of South Norway. 1. Peat and soil water quality. Meddelelser fra Norsk Institutt for Skogforskning 36(11): 1-32.

Brezonik, P.L., E.S. Edgerton, and C.D. Hendry. 1980. Acid precipitation and sulfate deposition in Florida. Science 208: 1027-1029.

Brock, T.D. 1978. Thermophilic Organisms and Life at High Temperatures. New York: Springer-Verlag. $465 \mathrm{pp}$.

Cadle, S.H., J.M. Dasch, and N.E. Grossnickle. 1984. Retention and release of chemical species by a northern Michigan snowpack. Water, Air, and Soil Pollution 22: 303-319.

Canfield, D.E., Jr. 1983. Sensitivity of Florida lakes to acidic precipitation. Water Resources Research 19(3): 833-839.

Charlson, R.J. and H. Rodhe. 1982. Factors controlling the acidity of natural rainwater. Nature 295: 683-685.

Chen, C.W., S.A. Gherini, N.E. Peters, P.S. Murdoch, R.M. Newton, and R.A. Goldstein. 1984. Hydrologic analyses of acidic and alkaline lakes. Water Resources Research 20(12): 1875-1882.

Christophersen, N. and R.F. Wright. 1981. Sulfate budget and a model for sulfate concentrations in stream water at Birkenes, a small forested catchment in southernmost Norway. Water Resources Research 17: 377-389. 
Christophersen, N., H.M. Seip, and R.F. Wright. 1982. A model for streamwater chemistry at Birkenes, Norway. Water Resources Research 18(4): 977-996.

Christophersen, N., L.H. Dymbe, M. Johannssen, and H.M. Seip. 1984a. A model for sulphate in streamwater at Storgama, Southern Norway. Ecological Mode11ing 21: 35-61.

Christophersen, N., S. Rustad, and H.M. Seip. 1984b. Modelling streamwater chemistry with snowme1t. Proceedings of Transactions of Royal Society London B305: 427-439.

Church, M.R. and J.N. Galloway. 1984. Application of Henriksen's 'Acidification Indicator' and 'Predictor Nomograph' to two Adirondack lakes. Water, Air, and Soil Pollution 22: 111-120.

Clesceri, N.L. and C. Vasudevan. 1980. Acid precipitation, throughfall chemistry and canopy processes. In: Ecological Impact of Acid Precipitation, Proceedings of an International Conference, eds. D. Drablos and A. Tollan. 1980 March 11-14; Sandefjord, Norway; SNSF Project, 0s10, Norway; pp. 258-259.

Cogbill, C. and G. Likens. 1974. Acid precipitation in northeastern United States. Water Resources Research 190: 1133-1137.

Confer, J., T. Kaaret, and G. Likens. 1983. Zooplankton diversity and biomass in recently acidified lakes. Canadian Journal of Fisheries and Aquatic Sciences 40: 36-42.

Cosby, B.J., G.M. Hornberger, J.N. Galloway, and R.F. Wright. 1985. Modeling the effects of acid deposition: assessment of a lumped parameter model of soil water and streamwater chemistry. Water Resources Research 21(1): 51-63.

Costa, H.H. 1967. Responses of Gammarus pulex (L.) to modified environment II. Reactions to abnormal hydrogen ion concentrations. Crustaceana 13: 1-10.

Cowling, E.B. 1982. Acid precipitation in historical perspective. Environmental Science and Technology 16(2): 110A-123A.

Craum, G.F. and L.J. McCabe. 1975. Problems associated with metals in drinking water. Journal of American Water Works Association 67(11): 593.

Cronan, C.S. and W.A. Reiners. 1983. Canopy processing of acidic precipitation by coniferous and hardwood forests in New England. 0ecologia 59: 216-223.

Cronan, C.S., W.A. Reiners, R.C. Reynolds, and G.E. Lang. 1978. Forest floor leaching: contributions from mineral, organic and carbonic acids in New Hampshire subalpine forests. Science 200: 309-311.

Dale, J.M., B. Freedman, and J. Kerekes. 1985. Acidity and associated water chemistry of amphibian habitats in Nova Scotia. Canadian Journal of Zoology 63: 97-105.

Dannevig, A. 1959. Nedborens Innflytclse Pa Vassdragenes Surhet $0 \mathrm{~g} \mathrm{~Pa}$ Fiskebestanden (Influence of precipitation on the acidity of watercourses and on fish stocks). Jeger of Fisker 3: 116-118.

Davis, P. and G. Ozburn. 1969. The pH tolerance of Daphnia pulex (Leydig, emend., Richard). Canadian Journal of Zoology 47: 1173-1175.

Davis, R., M. Smith, J. Bailey, and S. Norton. 1978. Acidification of Maine (USA) lakes by acidic precipitation . Verhandlungen Internationale Vereinigung für Limnologie 20: 532-537.

Davis, R.B., D.S. Anderson, and F. Berge. 1985. Palaeolimnological evidence that lake acidification is accompanied by loss of organic matter. Nature 316: 436-438. 
Dickman, M. and J. Fortescue. 1984. Rates of lake acidification inferred from sediment diatoms from 8 lakes. located north of Lake Superior, Canada. Verhandlungen Internationale Vereinigung für Limnologie 22: 1354-1356.

Dickman, M., S. Dixit, J. Fortescue, R. Barlow, and J. Tarasmae. 1984. Diatoms as indicators of the rate of lake acidification. Water, Air, and Soil Pollution 21: 375-386.

Dickson, W. 1983. Characterization of acidified waters. In: Acid Precipitation - Origin and Effects, VDI-Berichte, Nr. 500, Killoquium Lindau, 1983; Dusseldorf, W. Germany; pp. 387-391.

Dickson, W. 1980. Properties of acidified waters. In: Ecological Impact of Acid Precipitation, Proceedings of International Conference, eds. D. Drablos and A. Tollan. 1980 March 11-14; Sandefjord, Norway; SNSF Project, 0s10, Norway; pp. 75-83.

Dillon, P.J., D.S. Jeffries, and W.A. Scheider. 1982. The use of calibrated lakes and watersheds for estimating atmospheric deposition near a large point source. Water, Air, and Soil Pollution 18: 241-258.

Dillon, P.J., D.S. Jeffries, W. Snyder, R. Reid, N.D. Yan, D. Evans, J. Moss, and W.A. Scheider. 1978. Acidic precipitation in south-central Ontario: recent observations. Journal of the Fisheries Research Board of Canada 35: 809-815.

Drablos, D. and A. Tollan, eds. 1980. Ecological impact of acid precipitation. Proceedings of an International Conference. 1980 March 11-14; Sandefjord, Norway. SNSF Project, 0s10, Norway; 383 pp.

Drablos, D. and I. Sevaldrud. 1980. Lake acidification, fish damage, and utilisation of outfields. A comparative survey of six highland areas, Southeastern Norway. In: Ecological Impact of Acid Precipitation, Proceedings of an International Conference, eds. D. Drablos and A. Tollan. 1980 March 11-14; Sandefjord, Norway; SNSF Project, OS10, Norway; pp. 354-355.

Drablos, D., I. Sevaldrud, and J.A. Timberlid. 1980. Historical land-use changes related to fish status development in different areas in southern Norway. In: Ecological Impact of Acid Precipitation, Proceedings of International Conference, eds. D. Drablos and A. Tollan. 1980 March 11-14; Sandefjord, Norway; SNSF Project, 0slo, Norway; pp. 367-369.

Driscol1, C.T. 1980. Aqueous speciation of aluminum in Adirondack region of New York State, U.S.A. In: Ecological Impact of Acid Precipitation, Proceedings of an International Conference, eds. D. Drablos and A. Tollan; 1980 March 11-14, Sandefjord, Norway; SNSF Project, 0s10, Norway; pp. 214-215.

Drisco11, C.T. and R.M. Newton. 1985. Chemical characteristics of Adirondack lakes. Environmental Science and Technology 19(11): 1018-1024.

Edmondson, W.T. 1944. Ecological studies of sessile rotatoria. Ecological Monographs 14: $31-66$.

Eilers, J.M., G.E. Glass, K.E. Webster, and J.A. Rogalla. 1983. Hydrologic control of lake susceptibility to acidification. Canadian Journal of Fisheries and Aquatic Sciences 40: 1896-1904.

Eisenreich, S.J. 1980. Atmospheric input of trace metals to Lake Michigan. Water, Air, and Soil Pollution 13: 287-301. 
E1-Ashry, M.T. 1984. Study shows mountain ecosystems may be especially sensitive to acid deposition. Ambio 14(3): 179-180.

Elias, R.W., T.B. Inge, and P. Von-Ward. 1984. Air pollution effects on aquatic ecosystems: summary of a symposium. US Environmental Protection Agency Report EPA-600-9-84-010. Available from US National Technical Information Service as NTIS PB84-18524. $41 \mathrm{pp}$.

Elzerman, A.W. 1983. Effects of acid deposition (rain) on a piedmont aquatic ecosystem: acid inputs, neutralization, and $\mathrm{pH}$ changes. Final Technical Completion Report B-141-SC to Bureau of Reclamation, US Department of the Interior, Washington, DC. $79 \mathrm{pp}$.

Environment Canada. Water Quality Branch, Data and Instrumentation Section. 1982. NAQUADAT. Dictionary of Parameter Codes.

Everett, A.G., W.C. Retzsch, J.R. Kramer, I.P. Montanez, and R.F. Duhamine. 1982. Hydrogeochemical characteristics of Adirondack waters influenced by terrestrial environments. In: Second National Symposium on Acid Rain, ed. M.D. Kostic, Pittsburgh Chamber of Commerce, Pittsburg, P.A. (Original not seen; information taken from Krug et al. 1985.)

Farmer, G.J., T.R. Goff, D. Ashfield, and H.S. Samat. 1981. Some effects of the acidification of Atlantic Salmon rivers in Nova Scotia. In: Acid Rain and the Atlantic Salmon. International Atlantic Salmon Foundation Special Publication 10, pp. 73-91.

Faust, S.D. and A. McIntosh. 1983. Buffer capacities of fresh water lakes sensitive to acid rain deposition. Journal of Environmental Science and Health $A 18(1)$ : 155-161.

Flora, M.D. and P.C. Rosendah1. 1982. The impact of atmospheric deposition on the water quality of Everglades National Park. Proceedings of the American Water Resources Association International Symposium on Hydrometeorology, eds. R. Herrmann and A.I. Johnson. 1982 June; pp. 55-61.

Ford, J. 1981. Interglacial perspectives on ecosystem acidification. Bulletin of Ecological Society of America 62(2): 154.

Frenette, J.J., Y. Richard, and G. Moreau. 1986. Fish responses to acidity in Quebec lakes. A review. Water, Air, and Soil Pollution 30: 461-475.

Gahnstrom, G., G. Andersson, and S. Fleischer. 1980. Decomposition and exchange processes in acidified lake sediment. In: Ecological Impact of Acid Precipitation, Proceedings of an International Conference, eds. D. Drablos and A. Tollan. 1980 March 11-14; Sandefjord, Norway; SNSF Project, 0s10, Norway; pp. 306-307.

Galloway, J.N., C.L. Schofield, G.R. Hendrey, N.E. Peters, and A.H. Johannes. 1980. Sources of acidity in three lakes acidified during snowmelt. In: Ecological Impact of Acid Precipitation, Proceedings of International Conference, eds. D. Drablos and A. Tollan. 1980 March 11-14; Sandefjord, Norway; SNSF Project, Os 10, Norway; pp. 264-265.

Galloway, J.N., E. Cowling, E. Gorham, and W. McFee. 1978. A national program for assessing the problem of atmospheric deposition (acid rain). Report, Council of Environmental Quality, Fort Collins, Colorado. 
Galloway, J.N., G.E. Likens, and M.E. Hawley. 1984. Acid precipitation: natural vs. anthropogenic components. Science 226: 829-831.

Galloway, J.N., G.E. Likens, W.C. Keene, and J.M. Miller. 1982. The composition of precipitation in remote areas of the world. Journal of Geophysical Research 87 : $8771-8786$.

Galloway, J.N., S.A. Norton, and M.R. Church. 1983. Freshwater acidification from atmospheric deposition of sulfuric acid: a conceptual model. Environmental Science and Technology 17(11): 541A-545A.

Gherini, S.A., C.W. Chen, L. Mok, R.A. Goldstein, R.J.M. Hudson, and G.F. Davis. 1984. The ILWAS Mode1: Formulation and Application in the Integrated Lake-Watershed Acidification Study, Volume 4. Summary of Major Results. Electric Power Research Institute. EA-3221. pp. 7-7 to 7-45.

Gibson, J.H., J.N. Galloway, C. Schofield, W. McFee, R. Johnson, S. McCarley, N. Dise, and D. Herzog. 1983. Rocky Mountain acidification study. US Fish and Wildiife Service, Division of Biological Services, Eastern Energy and Land Use Team. Report FWS/OBS-80/40.17. 137 pp.

Glass, G.E. 1984. Susceptibility of aquatic and terrestrial resources of Minnesota, Wisconsin, and Michigan to impacts from acid precipitation: informational requirements. US Environmental Protection Agency Report EPA 600/D-84-064. Available from National Technical Information Services as NTIS PB84-174929. pp. $21-22$.

Glass, G.E. and 0. Loucks, eds. 1980. Impacts of air pollutants on wilderness areas of Northern Minnesota. Report, EPA 600/3-80-044. Environmental Research Laboratory, Duluth, Minnesota.

Glass, G.E., T.G. Brydges, and O.E. Loucks, eds. 1981. Impact assessment of airborne acidic deposition on the aquatic environment of the United States and Canada. US-Canada Memorandum of Intent on Transboundary Air Pollution. Interim Report. $206 \mathrm{pp}$.

Glover, G.M., A.S. Kallend, A.R.W. Marsh, and A.H. Webb. 1980. Ion relationships in acid precipitation and stream chemistry. In: Effects of Acid Precipitation on Terrestrial Ecosystems, eds. T.C. Hutchinson and M. Havas. NATO Conference Series 1: Ecology, Volume 4. New York: Plenum Press, pp. 95-109.

Goldstein, R.A., C.W. Chen, and S.A. Gherini. 1984a. Integrated Lake-Watershed Acidification Study - Summary. In: The Integrated Lake-Watershed Acidification Study. Volume 4. Summary of Major Results, eds. R.A. Goldstein and S.A. Gherini. Electrical Power Research Institute EA-3221. 1-1-1-15 pp.

Goldstein, R.A., S.A. Gherini, C.W. Chen, L. Mok, and R.J. Hudson. 1984b. Integrated acidification study (ILWAS): a mechanistic ecosystem analysis. Philosophical Transactions of the Royal Society of London B 305: 409-425.

Gorham, E. 1955. On the acidity and salinity of rain. Geochimica et Cosmochimica Acta 7: $231-239$.

Gorham, E. and W.W. McFee. 1980. Effects of acid deposition upon outputs from terrestrial to aquatic ecosystems. In: Effects of Acid Precipitation on Terrestrial Ecosystems, eds. T.C. Hutchinson and M. Havas. NATO Conference Series 1: Ecology, Volume 4. New York: Plenum Press, pp. 465-480. 
Gorham, E., F.B. Martin, and J.T. Litzau. 1984a. Acid rain: ionic correlations in the eastern United States, 1980-1981. Science 225: 407-409.

Gorham, E., P.M. Vitousek, and W.A. Reiners. 1979. The regulation of chemical budgets over the course of terrestrial ecosystem succession. Annual Review of Ecological Systems 10: 53-84.

Gorham, E., S.E. Bayley, and D.W. Schindler. 1984b. Ecological effects of acid deposition upon peatlands: a neglected field in "acid rain" research. Canadian Journal of Fisheries and Aquatic Sciences 41: 1256-1268.

Gosner, K.L. and I.H. Black. 1957. The effects of acidity on the development and hatching of New Jersey frogs. Ecology 38: 256-262.

Grahn, 0. 1977. Macrophyte succession in Swedish lakes caused by deposition of airborne acid substances. Water, Air, and Soil Pollution 7: 295-305.

Grant, M.C. and W.M. Lewis, Jr. 1982. Chemical loading rates from precipitation in the Colorado Rockies. Tellus $34: 74-88$.

Griffiths, D. 1973. The structure of an acid moorland pond community. Journal of Animal Ecology 42: 263-283.

Groterud, 0. 1981. The dynamics of acidification from a new view elucidated by studies in a lake area of Norway. Verhandlungen Internationale Vereinignung für Theoretische und Angewandte Limnologie 21(1): 406-411.

Gunn, J. and W. Keller. 1980. Enhancement of the survival of rainbow trout (Salmo gairdneri) eggs and fry in an acid lake through incubation in limestone. Canadian Journal of Fisheries and Aquatic Sciences 37: 1522-1530.

Hagstrom, T. 1980. Reproductive strategy and success of amphibians in waters acidified by atmospheric pollution. Proceedings of the European Herpetological Symposium C.W.L.P. Oxford, UK pp. 55-57.

Haines, T.A. 1981. Acidic precipitation and its consequences for aquatic ecosystems: a review. Transactions of the American Fisheries Society 110: 669-707.

Haines, T.A., J. Akielaszek, and P. Rago. 1983. A regional survey of the chemistry of headwater lakes and streams in New England: vulnerability to acidification. Fish and Wildlife Service, US Department of the Interior. Air Pollution and Acid Rain Report No. 15. FWS/OBS-80/40.15. Available from National Technical Information Service as PB84-103357. 141 pp.

Ha11, R. and G. Likens. 1980. Ecological effects of experimental acidification on a stream ecosystem. In: Ecological Impact of Acid Precipitation, Proceedings of an International Conference, eds. D. Drablos and A. Tollan. 1980 March 11-14; Sandefjord, Norway; SNSF Project, 0s10, Norway; pp. 375-376.

Ha11, R.J., G.G. Likens, S.B. Fiance, and G.R. Hendrey. 1980. Experimental acidification of a stream in the Hubbard Brook Experimental Forest, New Hampshire. Ecology $61(4)$ : $976-989$.

Hansen, D.A., G.M. Hidy, and G.J. Stensland. 1981. Examination of the basis for trend interpretation of historical rain chemistry in the eastern United States. Environmental Research and Technology Incorporation. Document P-A097R.

Hanson, D.W., S.A. Norton, and J.S. Williams. 1982. Modern and paleolimnological evidence for accelerated leaching and metal accumulation in soils in New England, caused by atmospheric deposition. Water, Air, and Soil Pollution 18: 227-239. 
Hargreaves, J.W., E.J.H. Lloyd, and B.A. Whitton. 1975. Chemistry and vegetation of highly acidic streams. Freshwater Biology 5: 563-576.

Harte, J., G.P. Lockett, R.A. Schneider, H. Michaels, and C. Blanchard. 1985. Acid precipitation and surface-water vulnerability on the western slope of the high Colorado Rockies. Water, Air, and Soil Pollution 25: 313-320.

Harvey, H.H. 1980. Widespread and diverse changes in the biota of North American lakes and rivers coincident with acidification. In: Ecological Impact of Acid Precipitation, Proceedings of an International Conference, eds. D. Drablos and A. Tollan. 1980 March 11-14; Sandefjord, Norway; SNSF Project, 0s10, Norway; pp. 93-98.

Harvey, H.H. 1975. Fish populations in a large group of acid stressed lakes. Internationale Vereinigung für Theoretische und Angewandte Limnologie Verhandlungen 19: 2406-2417.

Harvey, H.H. and C. Lee. 1982. Historical fisheries changes related to surface water pH changes in Canada. In: Acid Rain/ Fisheries. American Fisheries Society, Bethesda, Maryland, pp. 45-62.

Harvey, H.H., R.C. Pierce, P.J. Dillon, J.P. Kramer, and D.M. Whelpdale. 1981. Acidification in the Canadian Environment. Canadian National Research Council Committee Report No. 18475. Ottawa. 369 pp.

Havas, M., T.C. Hutchinson, and G.E. Likens. 1984. Red herrings in acid rain research. Environmental Science and Technology 18(6): 176A-186A.

Hendrey, G. 1976. Effects of low pH on the growth of periphytic algae in artifical stream channels. SNSF Project Report IR 2576, 0s10, Norway.

Hendrey, G. and F. Vertucci. 1980. Benthic plant communities in acidic Lake Colden, New York: Sphagnum and the algal mat. In: Ecological Impact of Acid Precipitation, Proceedings of an International Conference, eds. D. Drablos and A. Tollan. 1980 March 11-14; Sandefjord, Norway; SNSF Project, 0sio, Norway; pp. 314-315.

Hendrey, G.R., J.N. Galloway, S.A. Norton, C.L. Schofield, D.A. Burns, and P.W. Schaffer. 1980a. Sensitivity of the Eastern United States to acid precipitation impacts on surface waters. In: Ecological Impact of Acid Precipitation, Proceedings of an International Conference, eds. D. Drablos and A. Tollan. 1980 March 11-14; Sandefjord, Norway; SNSF Project, 0s70, Norway; pp. 216-217.

Hendrey, G.R., J.N. Galloway, and C.L. Schofield. 1980b. Temporal and spatial trends in the chemistry of acidified lakes under ice cover. In: Ecological Impact of Acid Precipitation, Proceedings of an International Conference, eds. D. Drablos and A. Tollan. 1980 March 11-14; Sandefjord, Norway; SNSF Project, 0s10, Norway; pp. 266-267.

Henriksen, A. 1980. Acidification of freshwaters--a large scale titration. In: Ecological Impact of Acid Precipitation, Proceedings of an International Conference, eds. D. Drablos and A. Tollan. 1980 March 11-14; Sandefjord, Norway; SNSF Project, 0slo, Norway; pp. 68-74.

Henriksen, A. 1979. A simple approach for identifying and measuring acidification of freshwater. Nature 278: 542-545. 
Herczeg, A.L., W.S. Broecker, R.F. Anderson, S.L. Schiff, and D.W. Schindler. 1985. A new method for monitoring temporal trends in the acidity of fresh waters. Nature 315: 133-135.

Herrmann, R. and A.I. Johnson, eds. 1983. Acid rain. A water resource issue for the 80 's. Reprinted from Proceedings of the American Water Resources Association International Symposium on Hydrometeorology. $83 \mathrm{pp}$.

Herrmann, R. and J. Barron. 1980. Aluminum mobilization in acid stream environments. Great Smoky Mountains National Park, U.S.A. In: Ecological Impact of Acid Precipitation, Proceedings of an International Conference, eds. D. Drablos and A. Tollan. 1980 March 11-14; Sandefjord, Norway; SNSF Project, 0s10, Norway; pp. 218-219.

Hesslein, R.H. 1979. Lake acidification potential in the Alberta $0 i 1$ Sands. Environmental Research Program Study Area. Prepared for the Alberta 0 il Sands Environmental Research Program by the Freshwater Institute, Environment Canada. AOSERP Report 71. $36 \mathrm{pp}$.

Hornbeck, J.W., G.E. Likens, and J.S. Eaton. 1977. Seasonal patterns in acidity of precipitation and their implications for forest stream ecosystems. Water, Air, and Soil Pollution 7: 355-365.

Hultberg, H. 1977. Thermally stratified acid water in late winter - a key factor inducing self-accelerating processes which increase acidification. Water, Air, and Soil Pollution 7: 279-294.

Hunt, D. and C.E. Boyd. 1981. Alkalinity losses from ammonia fertilizers used in fish ponds. Transactions of the American Fisheries Society 110: 81-85.

Hutchinson, G.E., W. Gizyn, M. Havas, and V. Zobens. 1978. Effect of long-term ligmite burns on arctic ecosystems at the Smoking Hills, NWT. In: Trace Substances in Environmental Health - XII, ed. D.D. Hemphill. Columbia, Missouri: University of Missouri.

Jeffries, D.S., C.M. Cox, and P.J. Dillon. 1979. The depression of pH in lakes and streams in central Ontario during snowmelt. Journal of the Fisheries Research Board of Canada 36: 640-646. (Original not seen; information taken from Marcus et al. 1983.)

Jensen, K. and E. Snekvik. 1972. Low pH levels wipe out salmon and trout populations in southernmost Norway. Ambio 1: 223-225.

Johannes, A.H. and E.R. Altwicker. 1980. Atmospheric Inputs to Three Adirondack Lake Watersheds. In: Ecological Impact of Acid Precipitation, Proceedings of an International Conference, eds. D. Drablos and A. Tollan. 1980 March 11-14; Sandefjord, Norway; SNSF Project, 0s10, Norway; pp. 256-257.

Johannes, A.H., E.R. Altwicker, and N.L. Clesceri. 1984. Atmospheric inputs to the ILWAS lake watershed in the Integrated Lake-Watershed Acidification Study. Vol. 4. Summary of major results. Prepared by Tetra Tech Inc., Lafaette, California, pp. 2-13 to 2-14.

Johannessen, M., A. Skartveit, and R.F. Wright. 1980. Streamwater chemistry before, during, and after snowmelt. In: Ecological Impact of Acid Precipitation, Proceedings of an International Conference, eds. D. Drablos and A. Tollan. 1980 March 11-14; Sandefjord, Norway; SNSF Project, 0s 10, Norway; pp. 224-225. 
Johnson, A.H. 1979a. Acidification of headwater streams in the New Jersey pine barrens. Journal of Environmental Quality 8(3): 383-386.

Johnson, A.H. 1979b. Evidence of acidification of headwater streams in the New Jersey pinelands. Science 206: 834-836.

Johnson, D.W. 1981. The natural acidity of some unpolluted waters in southeastern Alaska and potential impact of acid rain. Water, Air, and Soil Pollution 16: 243-252.

Johnson, D.W., J.W. Hornbeck, J.M. Kelly, W.T. Swank, and D.E. Todd. 1980. Regional patterns of soil sulfate accumulation: relevance to ecosystem sulfur budgets. In: Atmospheric Sulfur Deposition: Environmental Impact and Health Effects, eds. D.S. Shriner, C.R. Richmond, and S.E. Lindberg. Ann Arbor, Michigan: Ann Arbor Science, pp. 507-520. (Original not seen; information taken from Marcus et al. 1983.)

Jones, H.G., M. Ouellet, and D.F. Braekke. 1980. The evolution of acidity in surface waters of Laurentides Park (Quebec, Canada) over a period of 40 years. In: Ecological Impact of Acid Precipitation, Proceedings of an International Conference, eds. D. Orablos and A. Tollan. 1980 March 11-14; Sandefjord, Norway; SNSF Project, 0s10, Norway; pp. 226-227.

Kaplan, E., H.C. Thude, and A. Protas-Rocks. 1981. Soils and water quality: relationships and implications for effects of acid precipitation on surface water in the northeastern United States. Environmental Science and Technology 15(5): 539-544.

Keene, W.C. and J.N. Galloway. 1985. Gran's titrations: inherent errors in measuring the acidity of precipitation. Atmospheric Environment 19: 199-202.

Keene, W.C. and J.N. Galloway. 1984. Organic acidity in precipitation of North America. Atmospheric Environment 18(11): 2491-2497.

Keller, W., J. Gunn, and N. Conroy. 1980. Acidification impacts on lakes in the Sudbury, Ontario, Canada area. In: Ecological Impact of Acid Precipitation, Proceedings of an International Conference, eds. D. Drablos and A. Tollan. 1980 March 11-14; Sandefjord, Norway; SNSF Project, 0s10, Norway; pp. 228-229.

Kerekes, J. and T. Pollock. 1983. Comment on evidence of acidification of some Nova Scotia Rivers and its impact on Atlantic salmon, Salmo salar. Canadian Journal of Fisheries and Aquatic Sciences 40: 2260-2261

Kerr, R.A. 1981. Is all acid rain polluted? Science 212: 1014.

Kling, G.W. and M.C. Grant. 1984. Acidic precipitation in the colorado front range: an overview with the prediction for significant events. Arctic and Alpine Research 16(3): 321-329.

Kramer, J. 1976. Geochemical and lithological factors in acid precipitation. USDA Forest Service General Technical Report NE-23. pp. 611-618.

Kramer, J. and A. Tessier. 1982. Acidification of aquatic systems: a critique of chemical approaches. Environmental Science and Technology 16: 606A-615A.

Kramer, J.R. 1981. Calcite saturation index, alkalinity, and alkalinity corrections to previous data. Environmental Geochemistry Report 1981/1, Department of Geology, McMaster University, Hamilton, Ontario, Canada. $8 \mathrm{pp}$.

Krug, E.C. and C.R. Frink. 1983a. Acid rain on acid soil: a new perspective. Science 221: 520-525. 
Krug, E.C. and C.R. Frink. 1983b. Effects of acid rain on soil and water. Bulletin 811 . The Connecticut Agricultural Experiment Station, New Haven. November 1983. 45 pp.

Krug, E.C., P.J. Isaacson, and C.R. Frink. 1985. Appraisal of some current hypotheses describing acidification of watersheds. Journal of the Air Pollution Control Association 35(2): 109-114.

Kwiatowski, R. and J. Roff. 1976. Effects of acidity on the phytoplankton and primary productivity of selected northern Ontario lakes. Canadian Journal of Botany 54: 2546-2561.

Laake, M. 1976. Effekter au lav pH pa produksjon, nedbrytning og stoffkretslop i littoralsonen. SNSF Project. Internal Report 29/76. 0sio-As, Norway.

LaChance, M., B. Bobee, and Y. Grimard. 1985. Sensitivity of southern Quebec lakes to acidic precipitation. Water, Air, and Soil Pollution 25: 115-132.

Lefohn, A.S. and G.0. Klock. 1985. The possible importance of forest soil processes in defining surface water $\mathrm{pH}$ depressions. Journal of the Air Pollution Control Association 35: 632-637.

Lefohn, A.S. and R.W. Brocksen. 1984. Acid rain effects research - a status report. Journal of the Air Pollution Control Association 34(10): 1005-1013.

Leibfried, R.T., W.E. Sharpe, and D.R. DeWalle. 1984. The effects of acid precipitation runoff on source water quality. Journal of American Water Works Association 76: $50-55$.

Leivestad, H., G. Hendrey, I.P. Muniz, and E. Snekvik. 1976. Effects of acidic precipitation on freshwater organisms. In: Impact of Acid Precipitation on Forest and Freshwater Ecosystems in Norway. SNSF Research Report No. 6, ed. F.H. Braekke. 0slo, Norway: SNSF Project. pp. 87-111.

Leonard, R.L., C.R. Goldman, and G.E. Likens. 1981. Some measurements of the pH and chemistry of precipitation at Davis and Lake Tahoe, California. Water, Air, and Soil Pollution 15: 153-167.

Lewis, W. 1982. Changes in pH and buffering capacity of lakes in the Colorado Rockies. Limnology and Oceanography 27: 167-172.

Lewis, W.M., Jr. and M.C. Grant. 1979. Changes in the output of ions from a watershed as a result of the acidification of precipitation. Ecology 60: 1093-1097.

Liaw, W.K. 1982. Chemical sensitivity of Northern Saskatchewan waters to acidification. In: Proceedings of Symposium/Workshop on Acid Forming Emissions in Alberta and Their Ecological Effects. Alberta Department of the Environment, Canadian Petroleum Association, 0 il Sands Environmental Study Group; 1982 March 9-12; Edmonton, Alberta; pp. 485-509.

Likens, G.E. and F.H. Bormann. 1974. Acid rain: a serious regional environmental problem. Science 184: 1176-1179.

Likens, G.E., F.H. Bormann, R.S. Pierce, J.S. Eaton, and N.M. Johnson. 1977. Biogeochemistry of a Forested Ecosystem. New York: Springer-Verlag. 146 pp.

Linthurst, R.A., ed. 1984. Direct and Indirect Effects of Acidic Deposition on Vegetation. Ann Arbor, Michigan: Ann Arbor Science. 117 pp.

Lunde, G.J., N.G. Gether, and M. Lande. 1977. Organic micropollutants in precipitation in Norway. Atmospheric Environment 11: 1007-1014. 
Lundquist, D. 1977. Hydrochemical modelling of drainage basins. Report IR $31 / 77$ (Norwegian), SNSF Project. 0s10, Norway: Norway Institute for Water Research. 27 pp. (Original not seen; information taken from Christophersen et al. 1984b.) Magnuson, J.J. 1983. 5.1 Introduction. In: Chapter E-5. Effects on Aquatic Biology. The Acidic Deposition Phenomenon and Its Effects. Critical Assessment Review Papers. Volume II - Effects Sciences. Public Review Draft, eds. A.P. Altshuller and R.A. Linthurst. US Environmental Protection Agency Report 600/8-83-016B. pp. 5-1 to 5-3.

Magnuson, J.J. and F.J. Rahe1. 1983. 5.2 Biota of naturally acidic waters. In: Chapter E-5. Effects on Aquatic Biology. The Acidic Deposition Phenomenon and Its Effects. Critical Assessment Review Papers. Volume II - Effects Sciences. Public Review Draft, eds. A.P. Altshuller and R.A. Linthurst. US Environmental Protection Agency Report 600/8-83-016B. pp. 5-3 to 5-14.

Malley, D., D. Findlay, and P. Chang. 1982. Ecological effects of acid precipitation on zooplankton. In: Acid Precipitation Effects on Ecological Systems, ed. F. D'Itri. Ann Arbor, Michigan: Ann Arbor Science, pp. 297-327.

Malley, D.F. 1980. Decreased survival and calcium uptake by the crayfish oronectes virilis in low pH. Canadian Journal of Fisheries and Aquatic Sciences 37: $364-372$.

Marcus, M.D., B.R. Parkhurst, and F.E. Payne. 1983. An assessment of the relationship among acidifying depositions, surface water acidification, and fish populations in North America. Volume 1. Prepared by Western Aquatics, Inc. for Electric Power Research Institute, as EA-3127, Research Project 1910-2. 105 pp.

Mashiko, K., K. Jozuka, and K. Asakura. 1973. Different types of chloride cells in the gills of Iribolodon hakonensis from Lake Osoresan-ko. Ann. Rep. Noto. Marine Lab 13: 33-37. In: Exceptional Tolerance to Low pH of Some Tropical Blackwater Fish, eds. W.A. Dunson, F. Swarts, and M. Silvestri. Journal of Experimental Zoology 201: 157-162.

Mason, J. and H.M. Seip. 1985. The current state of knowledge on acidification of surface waters and guidelines for further research. Ambio 14: 45-51.

Melack, J.M., J.L. Stoddard, and C.A. Ochs. 1985. Major ion chemistry and sensitivity to acid precipitation of Sierra Nevada lakes. Water Resources Research 21(1): $27-32$.

Melack, J.M., J.L. Stoddard, and D.R. Dawson. 1982. Acid precipitation and buffer capacity of lakes in the Sierra Nevada, California. Proceedings of the American Water Resources Association International Symposium on Hydrometeorology, eds. R. Hermann and A.I. Johnson; 1982 June; pp. 35-41.

Middleton, P. and S.L. Rhodes. 1984. Acid rain and drinking water degradation. Environmental Monitoring and Assessment 4: 99-103.

Miller, G.E., I. Wile, and G.G. Hitchin. 1982. Patterns of accumulation of selected metals in members of the soft-water macrophyte flora of central Ontario lakes. Aquatic Botany 15: 53-64.

Mills, K.H. 1982. Fish population responses during the experimental acidification of a small lake. Presented at American Chemical Society Meeting, Las Vegas, NV. 1982 March. 
Moore, I.D. 1983. Throughfall pH: effect of precipitation timing and amount. Water Resources Bulletin 19: 961-965.

Morgan, D. 1984. Acidification of headwater streams in the New Jersey pinelands. A re-evaluation. Limnology and Oceanography 29(6): 1259-1266.

Mosello, R. and G. Tartari. 1983. Effects of acid precipitation on subalpine and alpine lakes. Water Quality Bulletin 8: 96-100, 110.

Mount, D.I. 1973. Chronic effect of low pH on fathead minnow survival, growth and reproduction. Water Resources 7: 987-993.

Müller, P. 1980. Effects of artificial acidification on the growth of periphyton. Canadian Journal of Fisheries and Aquatic Sciences 37: 355-363.

National Wildlife Federation. 1984. Acid rain: Its state by state impacts. Washington, DC. Available from National Technical Information Service as NTIS PB84-198332. $101 \mathrm{pp}$.

Norton, S., R. Davis, D. Brakke, D. Hanson, K. Kenlan, and P. Sweets. 1981. Responses of northern New England Lakes to atmospheric inputs of acid and heavy metals. Completion Report, Project A-048-ME, Office of Water Research and Technology, Washington, $D C .90 \mathrm{pp}$.

Norton, S.A. 1980. Geological factors controlling the sensitivity of aquatic ecosystems to acidic precipitation. In: Atmospheric Sulfur Deposition: Environmental Impact and Health Effects. eds. D.S. Shriner, C.R. Richmond, and S.E. Lindberg. Ann Arbor, Michigan: Ann Arbor Science, pp. 521-529. (Original not seen; information taken from Marcus et al. 1983.)

Oden, S. 1976. The acidity problem. An outline of concepts. Water, Air, and Soil Pollution 6: 137-166.

Okland, K.A. 1980. Okologi og utbredelse til Gammarus lacustric G. O. Sars i Norge, med vekt pa forsuringsproblemer. SNSF Project, Internal Report 67/80. 0slo-As, Norway.

Overrein, L.N., H.M. Seip, and A. Tollan. 1980. Acid precipitation-effects on forests and fish. Final Report of the SNSF-Project 1972-1980. Research Report 19. Aas, Norway. $175 \mathrm{pp}$.

Paetz, M.J. and J.S. Nelson. 1970. The Fishes of Alberta. Edmonton, Alberta: The Queen's Printer. $272 \mathrm{pp}$.

Panel on Processes of Lake Acidification: Environmental Studies Board; Commission on Physical Sciences, Mathematics, and Resources. 1984. Acid deposition: processes of lake acidification. Available from the National Technical Information Service as PB84-216175. 11 pp.

Parent, S. and R. Cheetham. 1980. Effects of acid precipitation on Daphnia magna. Bulletin of Environmental Contamination and Toxicology 25: 298-304.

Patrick, R., V.P. Binetti, and S.G. Halterman. 1981. Acid lakes from natural and anthropogenic causes. Science 211: 446-448.

Pennak, R.W. 1978. Fresh-water Invertebrates of the United States. New York: John Wiley and Sons. $803 \mathrm{pp}$. 
Peverly, J.H. 1983. 5.4 Macrophytes and wetland plants. In: Chapter E-5. Effects on Aquatic Biology. The. Acidic Deposition Phenomenon and Its Effects. Critical Assessment Review Papers. Volume II - Effects Sciences. Public Review Draft, eds. A.P. Altshuller and R.A. Linthurst. US Environmental Protection Agency Report 600/8-83-0168. pp. 5-39 to 5-45.

Pfeiffer, M. and P. Festa. 1980. Acidity status of lakes in the Adirondack Region of New York in relation to fish resources. New York Department of Environmental Conservation Report FW-P168. Albany, NY. 36 pp.

Powers, E.B. 1929. Fresh water studies. 1. The relative temperature, oxygen content, alkali reserve, the carbon dioxide tension and $\mathrm{pH}$ of the waters of certain mountain streams at different altitudes in the Smoky Mountain National Park. Ecology 10(1): 97-111.

Rahe1, F.J. and J.J. Magnuson. 1983. Low pH and the absence of fish species in naturally acidic Wisconsin lakes: inferences for cultural acidification. Canadian Journal of Fisheries and Aquatic Sciences 40: 3-9.

Ramberg, L. 1981. Increase in stream pH after. a forest drainage. Ambio 10(1): 34-35.

Reuss, J.0. and D.W. Johnson. 1985. Effect of soil processes on the acidification of water by acid deposition. Journal of Environmental Quality 14: 25-31.

Richter, D.D. 1983. Comment on "acid precipitation in historical perspective" and "effects of acid precipitation". Environmental Science and Technology 17(9): 568-570.

Robinson, J.W. and P.M. Deano. 1985. The synergistic effects of acidity and aluminum on fish (Golden Shiners) in Louisiana. Journal of Environmental Science and Health A20(2): 193-204.

Rosenqvist, I.Th. 1980. Influence of forest vegetation and agriculture on the acidity of fresh water. Advances in Environmental Science and Engineering 3: 56-79.

Rosenqvist, I.Th. 1978a. Acid precipitation and other possible sources for acidification of rivers and lakes. The Science of the Total Environment 10: 271-272.

Rosenqvist, I.Th. 1978b. Alternative sources for acidification of river water in Norway. The Science of the Total Environment 10: 39-49.

Rosenqvist, I.Th., P. Jorgensen, and H. Reuslatten. 1980. The importance of natural $\mathrm{H}^{+}$production for acidity in soil and water. In: Ecological Impact of Acid Precipitation, Proceedings of an International Conference, eds. D. Orablos and A. Tollan. 1980 March 11-14; Sandefjord, Norway; SNSF Project, 0s10, Norway; pp. 240-241.

Saber, P.A. and W.A. Dunson. 1978. Toxicity of bog water to embryonic and larval anuran amphibians. Journal of Experimental Zoology 204: 33-42.

Sand-Jensen, K. and M. Sondergrad. 1979. Distribution and quantitative development of aquatic macrophytes in relation to sediment characteristics in 0ligotrophic Lake Kalgaard, Denmark. Freshwater Biology 9: 1-11.

Scheider, W.A., J. Jones, and B. Cave. 1976. A preliminary report on the neutralization of Nelson lake near sudbury, Ontario. Ontario Ministry of the Environment. Rexdale, Ontario. 
Schindler, D.W. 1980. Experimental acidification of a whole lake: A test of the oligotrophication hypothesis. In: Ecological Impact of Acid Precipitation, Proceedings of an International Conference, eds. D. Drablos and A. Tollan. 1980 March 11-14; Sandefjord, Norway; SNSF Project, 0s10, Norway; pp. 370-374.

Schindler, D.W. and T. Ruszczynski. 1983. A test of limnological data from the Experimental Lakes Area, Northwest Ontario for evidence of acidification. Canadian Technical Report of Fisheries and Aquatic Sciences No. 1147. Winnipeg, Manitoba. $17 \mathrm{pp}$.

Schindler, D.W., K.H. Mills, D.F. Malley, D.L. Findlay, J.A. Shearer, I.J. Davies, M.A. Turner, G.A. Lindsey, and D.R. Cruikshank. 1985. Long-term ecosystem stress: the effects of years of experimental acidification of a small 1ake. Science 228: 1395-1401.

Schofield, C.L. 1984. Surface water chemistry in the ILWAS basins. In: The Integrated Lake-Watershed Acidification Study. Volume 4. Summary of Major Results. Electric Power Research Institute, Report EPRI EA-3221, pp. 6-1 to 6-31.

Schofield, C.L. 1982. Historical fisheries changes as related to surface water pH changes in the United States. In: Acid Rain/Fisheries. Proceedings of an International Symposium on Acidic Precipitation and Fishery Impacts in Northeast North America, ed. R.E. Johnson. Ithaca, NY; pp. 57-67. (Original not seen; information taken from Havas et al. 1982.)

Schofield, C.L. 1978. Toxicity of metals. In: Limnological Aspects of Acid Precipitation, ed. G. Hendrey. Upton, New York: Brookhaven National Laboratory, Pp. $31-34$.

Schofield, C.L. 1976a. Acid precipitation: effects on fish. Ambio 5(5-6): 228-230.

Schofield, C.L. 1976b. Lake acidification in the Adirondack mountains of New York: causes and consequences. In: Proceedings of the First International symposium on Acid Precipitation and the Forest Ecosystem. US Department of Agriculture, USDA Forest Service General Technical Report NE-23, eds. L.S. Dochinger and T.A. Seliga. 1975 May 12-15; Columbus, Ohio; p. 477.

Schofield, C.L. and J.R. Trojnar. 1980. Aluminum toxicity to fish in acidified waters. In: Polluted Rain, eds. T. Toribara, M. Miller, and P. Morrow. New York: Plenum Press, pp. 341-366.

Scruton, D.A. 1983. A survey of headwater lakes in insular Newfoundland, with special reference to acid precipitation. Canadian Technical Report of Fisheries and Aquatic Sciences, No. 1195. $110 \mathrm{pp}$.

Seip, H.M. 1980a. Acid snow-snowpack chemistry and snowmelt. In: Effects of Acid Precipitation on Terrestrial Ecosystems, eds. T.C. Hutchinson and M. Havas. NATO Conference Series 1: Ecology, Volume 4. New York: Plenum Press, pp. 77-94.

Seip, H.M. 1980b. Acidification of freshwater: sources and mechanisms. In: Ecological Impact of Acid Precipitation, Proceedings of an International Conference, eds. D. Drablos and A. Tollan. 1980 March 11-14; Sandefjord, Norway; SNSF Project, Os 10, Norway; pp. 358-365.

Seip, H.M. and S. Rustad. 1984. Variations in surface water pH with changes in sulphur deposition. Water, Air, and Soil Pollution 21: 217-223. 
Semple, A.B., W.H. Perry, and D.E. Phillips. 1960. Acute copper poisoning. Lancet 2: 7152.

Shaffer, P.W. and J.N. Galloway. 1982. Acid precipitation: the impact on two headwater streams in Shenandoah National Park, Virginia. Proceedings of the American Water Works Association International Symposium on Hydrometeorology, eds. R. Herrmann and A.I. Johnson. 1982 June; pp. 43-53.

Shewchuk, S.R. 1982. An acid deposition perspective for northeastern Alberta and northern Saskatchewan. Water, Air, and Soil Pollution 18: 413-420.

Singer, R. 1983. 5.3 Benthic organisms. In: Effects on Aquatic Biology. The Acidic Deposition Phenomenon and Its Effects. Critical Assessment Review Papers. Volume II-Effects Sciences. Public Review Draft, eds. A.P. Altshuller and R.A. Linthurst. US Environmental Protection Agency, Report 600/8-83-0168. pp. 5-15 to 5-39.

Smith, R.A. 1872. Air and Rain: The Beginnings of a Chemical Climatology. London: Longmans, Green. (Original not seen; information taken from Cowling 1982.)

Smith, R.A. 1852. Memorandum. Literary and Philosophical Society, Manchester, Series 2 (10): 207-217. (Original not seen; information taken from Cowling 1982.)

Smith, R.F. 1957. Lakes and ponds. Fishery survey report number 3. New Jersey Department of Conservation and Economic Development, Division of Fish and Game. Trenton, New Jersey. 198 pp.

Sollins, P., C.C. Grier, F.M. McCorison, K. Cromack, and R. Foge1. 1980. The internal element cycles of an old growth Douglas-Fir ecosystem in Western Oregon. Ecological Monograph 50(3): 261-285. (Original not seen; information taken from Marcus 1983.)

Somers, K.M. and H.H. Harvey. 1984. Alteration of fish communities in lakes stressed by acid deposition and heavy metals near Wawa, Ontario. Canadian Journal of Fisheries and Aquatic Sciences 41: 20-29.

Stottlemyer, J.R. 1982. Variation in ecosystem sensitivity and response to anthropogenic atmospheric inputs, Upper Great Lakes Region. In: Proceedings of the American Water Resources Association. International Symposium on Hydrometeorology. eds. R. Herrmann and A.I. Johnson. 1982 June; pp. 79-83.

Strachan, W. and H. Huneault. 1979. Polychlorinated biphenyls and organochlorine pesticides in Great Lakes precipitation. Journal of Great Lakes Research 5: 61-68.

Sutcliffe, D.W. and T.R. Carrick. 1973. Studies on mountain streams in the English Lake District. Freshwater Biology 3: 437-462.

Svardson, G. 1976. Interspecific population dominance in fish communities of Scandinavian lakes. Report of the Institute of Freshwater Research at Drottningholm 55: $144-171$.

Tabatabai, M.A. 1985. Effect of acid rain on soils. Critical Reviews in Environmental Control 15: 65-110.

Tetra Tech Inc. 1984. The Integrated Lake-Watershed Acidification Study. Volume 3. Lake chemistry program. Electric Power Research Institute Report, EPRI EA-3221, pp. 7-7 to 7-7.

Tetra Tech Inc. 1983 and 1984. Volumes 1 to 4. The Integrated Lake-Watershed Acidification Study. Electric Power Research Institute Report, EPRI EA-3221. 
Thompson, M.E. 1982. The cation denudation rate as a quantitative index of sensitivity of eastern Canadian rivers to acidic atmospheric precipitation. Water, Air, and Soil Pollution 18: 215-226.

Tomlinson, G., R. Brouzes, R. McLean, and J. Kadlecek. 1980. The role of clouds in atmospheric transport of Mercury and other pollutants. In: Ecological Impact of Acid Precipitation, Proceedings of an International Conference, eds. $D$. Drablos and A. Tollan. 1980 March 11-14; Sandefjord, Norway; SNSF Project, Os 10, Norway; pp. 134-137.

Tonnessen, K.A. and J. Harte. 1982. Potential for acid precipitation damage to lakes of the Sierra Nevada, California. In: Proceedings of the American Water Resources Association. International Symposium on Hydrometeorology, eds. R. Herrmann and A.I. Johnson. 1982 June; pp. 75-78.

Trojnar, J.R. 1977. Egg and larval survival of white suckers Catostomus commersoni at low pH. Journal of the Fisheries Research Board of Canada 34: 574-579.

Troutman, D.E. and N.E. Peters. 1982. Deposition and transport of heavy metals in three lake basins affected by acid precipitation in Adirondack Mountains, New York. In: Energy and Environmental Chemistry, II; Acid Rain, ed. L.H. Keith. Ann Arbor, Michigan: Ann Arbor Science, pp. 33-61.

Turk, J.T. and D.B. Adams. 1983. Sensitivity to acidification of lakes in the Flat Tops Wilderness Area, Colorado. Water Resources Research 19: 346-350.

Ueno, M. 1958. The disharmonious lakes of Japan. Verhandlungen Internationale Vereinigung-Limnologie 13: 217-226.

Underwood, J.K., H.H. Vaughan, J.G. Ogdlen, and C.G. Mann. 1982. Acidification of Nova Scotia lakes. Nova Scotia Department of the Environment. Paper P-5-7, pp. 5-7. (Original not seen; information taken from krug et al. 1985.)

Van Breemen, N., C.T. Driscoll, and J. Mulder. 1984. Acidic deposition and internal proton sources in acidification of soils and waters. Nature 307: 599-604.

Vangenechten, J.H.D., S. Van Puymbroeck, and O.L.J. Vanderborght. 1984. Acidification in Campine bog lakes. In: Belgian Research on Acid Deposition and the Sulphur Cycle, ed. 0.L.J. Vanderborght. Belgium: SCOPE Publications, pp. 251-262.

Watt, W.D., C.D. Scott, and S. Ray. 1979. Acidification and other chemical changes in Halifax county lakes after 21 years. Limnology and Oceanography 24(6): 1154-1161.

Watt, W.D., C.D. Scott, and W.J. White. 1983. Evidence of acidification of some Nova Scotian rivers and its impact on Atlantic salmon, Salmo salar. Canadian Journal of Fisheries and Aquatic Sciences 40(4): 462-473.

Wetze1, R.G. 1975. Limnology. Philadelphia: W.B. Saunders Company. 743 pp.

Whitehead, D.R., S.E. Reed, and D.F. Charles. 1981. Late glacial and post glacial pH changes in Adirondack lakes. Bulletin of Ecological Society of America 62(2): 154.

Wiklander, L. 1946. Studies on ionic exchange with special reference to the conditions in soils. Kungliga Lantbrukshog-Skolans Annaler 14: 1-171. (Original not seen; information taken from Krug and Frink 1983b.)

Woodward, K.W. 1906. Forestry in Nova Scotia. Journal of Forestry 4: 10-13. 
Wright, R. and E. Snekvik. 1978. Acid precipitation chemistry and fish population in 700 lakes in southernmost Norway. Internationale Vereinigung für Theoretische und Angewandte Limnologie Verhandlungen 20: 765-775.

Wright, R.F. 1983. Input-output budgets at Langtjern, a small acidified lake in southern Norway. Hydrobiologia 101: 1-12.

Wright, R.F. and A. Henriksen. 1983. Restoration of Norwegian lakes by reduction in sulphur deposition. Nature 305: 422-424.

Wright, R.F. and E.T. Gjessing. 1976. Changes in the chemical composition of lakes. Ambio 5: 219-223.

Wright, R.F., N. Conroy, W.T. Dickson, R. Harriman, A. Henriksen, and C.L. Schofield. 1980. Acidification lake districts of the world: a comparison of water chemistry of lakes in southern Norway, southern Sweden, south western Scotland, and the Adirondack mountains of New York and southeastern Ontario. In: Ecological Impact of Acid Precipitation, Proceedings of an International Conference, eds. D. Drablos and A. Tollan. 1980 March 11-14; Sandefjord, Norway; SNSF Project, OS10, Norway; pp. 377-379.

Yan, N. and P. Stokes. 1978. Phytoplankton of an acidic lake, and its responses to experimental alterations of $\mathrm{pH}$. Environmental Conservation 5: 93-100.

Yan, N. and R. Strus. 1980. Crustacean zooplankton communities of acidic, metal contaminated lakes near Sudbury, Ontario. Canadian Journal of Fisheries and Aquatic Sciences 37: 2282-2293. 


\section{APPENDIX - ADDITIONAL REFERENCES}

Bates, R.G. 1964. Determination of PH, Theory and Practice. Chapter 2. New York: John Wiley and Sons, pp. 17-31.

Battarbee, R.W., R.J. Flower, A.C. Stevenson, and B. Rippey. 1985. Lake acidification in Galloway: a palaeoecological test of competing hypotheses. Nature 314: 350-352.

Binns, W.0. 1984. Acid Rain and Forestry. Forestry Commission, Edinburgh, Scotland, Research and Development Paper-134. ISBN-0-85538-177-9. $17 \mathrm{pp.}$

Bobee, B. and M. Lachance. 1983. A method for analyzing data on lake acidification and its application in Quebec, Canada. Water Quality Bulletin 8: 160-167.

Bockheim, J.G. 1984. Acidic deposition effects on forest soils and site quality. In: Forest Responses to Acidic Deposition, Proceedings of U.S.-Canadian Conference, ed. C.S. Cronan. 1983 August 3-4. Orono, Maine; pp. 19-35.

Boyd, C.E. 1980. Reliability of water analysis kits. Transactions of the American Fisheries Society 109: 239-243.

Boyd, C.E. 1977. Evaluation of a water analysis kit. Journal of Environmental Quality $6(4): 381-384$.

Braekke, F.H. 1981a. Hydrochemistry in low-pH-soils of South Norway. 2. Seasonal variation in some peatland sites. Meddelelser fra Norsk Institutt for Skogforskning 36(12): 1-22. (Reports of the Norwegian Forest Research Institute.)

Braekke, F.H. 1981b. Hydrochemistry of high aititude catchments in South Norway. 1. Effects of summer droughts and soil-vegetation characteristics. Meddelelser fra Norsk Institutt for Skogforskning 36(8): 1-26. (Reports of the Norwegian Forest Research Institute.)

Braekke, F.H. 1981C. Hydrochemistry of high altitude catchments in South Norway. 2. Water chemical gradients inside a catchment. Meddelelser fra Norsk Institutt for Skogforskning 36(9): 1-39. (Reports of the Norwegian Forest Research Institute.)

Braekke, F.H. 1981d. Hydrochemistry of high altitude catchments in South Norway. 3. Dynamics in waterflow, and in release-fixation of sulphate, nitrate, and hydronium. Meddelelser fra Norsk Institutt for Skogforskning 36(10): 1-21. (Reports of the Norwegian Forest Research Institute.)

Brakke, D.F. 1981. Historical changes in cladoceran communities associated with lake acidification. Bulletin of Ecological Society of America 62(2): 155.

Broberg, 0. 1984. Phosphate removal in acidified and limed lake water. Water Resources 18: $1273-1278$.

Broberg, 0. and G. Persson. 1984. External budgets for phosphorus, nitrogen, and dissolved organic carbon for the acidified Lake Gardsjon. Archiv Fue Hydrobiologie $99(2)$ : $160-175$. 
Brosset, C., L.S. Dochinger, and T.A. Seliga. 1976. Method of measuring airborne acidity: its application for the determination of acid content on long-distance transported particles and in drainage water from spruces. In: Proceedings of the First International Symposium on Acid Precipitation and the Forest Ecosystem, US Department of Agriculture, Forest Service General Technical Report NE-23, eds. L.S. Dochinger and T.A. Seliga. 1975 May 12-15; Columbus, Ohio; pp. 159-179.

Brown, D.J.A. 1983. The relationship between surface water acidification and loss of fisheries. In: Acid Precipitation - Origin and Effects, VDI-Berichte, $\mathrm{Nr}$. 500, Killoquium Lindau, 1983; Dusseldorf, W. Germany; pp. 365-371.

Burns, J.C., J.S. Coy, D.J. Tervet, R. Harriman, B.R.S. Morrison, and C.P. Quine. 1984. The Loch Dee project: a study of the ecological effects of acid precipitation and forest management on an upland catchment in south-west scotland. 1. Preliminary investigations. Fishery Management 15(4): 145-167.

Burton, T.M., R.M. Stanford, and J.W. Allan. 1985. Acidification effects on stream biota and organic matter processing. Canadian Journal of Fisheries and Aquatic Sciences 42: 669-675.

Carignan, R. and J.0. Nriagu. 1985. Trace metal deposition and mobility in the sediments of two lakes near sudbury, Ontario. Geochimica et Cosmochimica Acta 49: $1753-1764$.

Chang, F.H. and M. Alexander. 1984. Effects of simulated acid precipitation on decomposition and leaching of organic carbon in forest soils. Soil Science 138: 226-234.

Cogbill, C.V., G.E. Likens, and T.J. Butler. 1984. Uncertainties in historical aspects of acid precipitation: getting it straight. Atmospheric Environment 18: 2261-2270.

Cook, R.B. and D.W. Schindler. 1983. Biogeochemistry of sulfur in an experimentally acidified lake. In: Proceedings of the 5 th International Symposium on Environmental Biogeochemistry (ISEB); 1981 June 1-5; Stockholm, Sweden; pp. $115-127$.

Cosby, B.J., G.M. Hornberger, J.N. Galloway, and R.F. Wright. 1985. Time scales of catchment acidification. Environmental Science and Technology 19(12): $1114-1149$.

Cronan, C.S., ed. 1984. Forest responses to acidic deposition. Proceedings of U.S.Canadian Conference, 1983 August 3-4; University of Maine, Orono, Maine. 117 pp.

Cronan, C.S. and C.L. Schofield. 1979. Aluminum leaching response to acid precipitation: effects on high elevation watersheds in the Northeast. Science 204: 304-305.

Cronan, C.S. and G.R. Aiken. 1985. Chemistry and transport of soluble humic substances in forested watersheds of the Adirondack Park, New York. Geochimica et Cosmochimica Acta 49: 1697-1705.

Davis, A.0., J.N. Galloway, and K. Nordstrom. 1982. Lake acidification. Its effects on lead in the sediment of two Adirondack lakes. Limnology and Oceanography 27: $163-167$. 
Davis, M.J. 1981. Effects of atmospheric deposition of energy-related pollutants on water quality: a review and assessment. Argonne National Laboratory, Argonne, Illinois. Sponsored by US Department of Energy. Available as DE82 007036 from National Technical Information Service, Springfield, VA. 85 pp.

Davis, R.B., S.A. Norton, C.T. Hess, and D.F. Braekke. 1983. Paleolimnological reconstruction of the effects of atmospheric deposition of acids and heavy metals on the chemistry and biology of lakes in New England and Norway. Hydrobiologia 103: 113-123.

Dewalle, D.R., G.C. Ribblett, J.D. Helvey, and J. Kochenderfer. 1985. Laboratory investigation of leachate chemistry from six Appalachian forest floor types subjected to simulated acid rain. Journal of Environmental Quality 14: 234-240.

Dillon, P.J., D.S. Jeffries, W.A. Scheider, and N.D. Yan. 1980. Some aspects of acidification in Southern Ontario. In: Ecological Impact of Acid Precipitation, Proceedings of an International Conference, eds. D. Drablos and A. Tollan. 1980 March 11-14; Sandefjord, Norway; SNSF Project, 0s10, Norway; pp. 212-213.

Driscol1, C.T. and G.C. Schafran. 1984. Short-term changes in the base neutralizing capacity of an acid Adirondack lake, New York. Nature 310: 308-310.

Dumas, J.-P. and L. Pazdernik. 1983. Variations saisonnieres des composantes de l'akalinite des eaux dans le haut-estuaire du Fleuve Saint-Laurent (Quebec). Water, Air, and Soil Pollution 20: 413-424.

Feller, M.C. 1977. Nutrient movement through Western Hemlock-Western Red Cedar ecosystems in southwestern British Columbia. Ecology 58: 1269-1283.

Forsberg, C., G. Morling, and R.G. Wetzel. 1985. Indications of the capacity for rapid reversibility of lake acidification. Ambio 14(3): 164-166.

Galloway, J.N., C.L. Schofield, G.R. Hendrey, E.R. Altwicker, and D.E. Troutman. 1980. An analysis of lake acidification using annual budgets. In: Ecological Impact of Acid Precipitation, Proceedings of International Conference, eds. D. Drablos and A. Tollan. 1980 March 11-14; Sandefjord, Norway; SNSF Project, 0s10, Norway; pp. 254-255.

Galloway, J.N., C.L. Schofield, N.E. Peters, G.R. Hendrey, and E.R. Altwicker. 1983. Effect of atmospheric sulfur on the composition of three Adirondack lakes. Canadian Journal of Fisheries and Aquatic Sciences 40: 799-806.

Garfield, E. 1985a. Acid rain. Part 1. What is it and what does it do? Current Contents 9: $3-12$.

Garfield, E. 1985b. Acid rain. Part 2. Public issues and proposed solutions. Current Contents 10: $3-11$.

Goldstein, R.A., C.W. Chen, S.A. Gherini, and J.D. Dean. 1980. A framework for the integrated lake-watershed acidification study. In: Ecological Impact of Acid Precipitation, Proceedings of an International Conference, eds. D. Drablos and A. Tollan. 1980 March 11-14; Sandefjord, Norway; SNSF Project, 0s10, Norway; pp. $252-253$. 
Gorham, E., W.W. McFee, T.C. Hutchinson, and M. Havas. 1980. Effects of acid deposition upon outputs from terrestrial to aquatic ecosystems, In: Effects on Acid Precipitation on Terrestrial Ecosystems. eds. T.C. Hutchinson and M. Havas. NATO Conference Series 1: Ecology, Volume 4. New York; Plenum Press. pp. 465-480.

Grahn, 0. and K. Rosen. 1983. Deposition and transport of metals in some acid catchment areas in Sweden. Solna: National Swedish Environmental Protection Board. SNV-PM-1687. $46 \mathrm{pp}$.

Gran, G. 1952. Determination of the equivalence point in potentiometric titrations. Part II. International Congress on Analytical Chemistry 77: 661-671.

Grennfe1t, P., C. Bengtson, and L. Skarby. 1978. An estimation of the atmospheric input of acidifying substances to a forest ecosystem. Swedish Water and Air Pollution Research Laboratory, Gothenburg, Sweden. Presented at NATO ARI Meeting on Effects of Acid Precipitation on Terrestrial Ecosystems. 1978 May 22-26; Toronto, Ontario; $14 \mathrm{pp}$.

Ha11, R.J. and G.E. Likens. 1981. Chemical flux in an acid-stressed stream. Nature 292: 329-331.

Hansen, D.A. and G.M. Hidy. 1982. Review of questions regarding rain acidity data. Atmospheric Environment 16(9): 2107-2126.

Hanson, D.W. and S.A. Norton. 1982. Spatial and temporal trends in the chemistry of atmospheric deposition in New England. In: International Symposium on Hydrometeorology, eds. R. Herrmann and A.I. Johnson. American Water Works Association, pp. 25-31.

Hay, G.W., J.H. James, and G.W. VanLoon. 1985. Solubilization effects of simulated acid rain on the organic matter of forest soil; preliminary results. Soil science $139(5): 422-430$.

Heit, M., Y. Tan, C. Klusek, and J.C. Burke. 1981. Anthropogenic trace elements and polycyclic aromatic hydrocarbon levels in sediment cores from two lakes in the Adirondack acid lake region. Water, Air, and Soil Pollution 15: 441-464.

Henriksen, A. and D.D. Richter. 1984. Comment on comment on "acid precipitation in historical perspective" and "effects of acid precipitation." Environmental Science and Technology 18(8): 631-634.

Henriksen, A. and R.F. Wright. 1978. Concentrations of heavy metals in small Norwegian lakes. Water Research 12: 101-112.

Herron, M., C. Langway, M. Weiss, and J. Cragin. 1977. Atmospheric trace metals and sulfate in the Greenland ice sheet. Geochimica et Cosmochimica Acta 41: 915-920.

Hultberg, H. and A. Wenblad. 1980. Acid groundwater in southwestern Sweden. In: Ecological Impact of Acid Precipitation, Proceedings of an International Conference, eds. D. Drablos and A. Tollan. 1980 March 11-14; Sandefjord, Norway; SNSF Project, 0s 10, Norway; pp. 220-221.

Hultberg, H., P. Grennfelt, and B. 01sson. 1983. Sulphur and chloride deposition and ecosystem transport in a strongly acidified lake watershed. Water science and Technology 15: 81 . 
Jackson, T.A. and R.E. Hecky. 1980. Depression of primary productivity by humic matter in lake and reservoir waters of the boreal forest zone. Canadian Journal of Fisheries and Aquatic Sciences 37: 2300-2317.

Jackson, T.A., G. Kipphut, R.H. Hesslein, and D.W. Schindler. 1980. Experimental study of trace metal chemistry in soft-water lakes at different pH levels. Canadian Journal of Fisheries and Aquatic Sciences 37: 387-402.

James, B.R. and S.J. Riha. 1984. Soluble aluminum in acidified organic horizons of forest soils. Canadian Journal of Soil Science 64: 637-646.

Jeffries, D.S. and A.P. Zimmerman. 1980. Comments on the analysis and sampling of low conductivity natural waters for alkalinity. Canadian Journal of Fisheries and Aquatic Sciences 37: 901-902.

Jeffries, D.S. and R.G. Semkin. 1983. Changes in snowpack, stream and lake chemistry during snowmelt in the Turkey Lakes watershed. In: Acid Precipitation Origin and Effects, VDI-Berichte, Nr. 500, Killoquium Lindau, 1983; Dusseldorf, W. Germany; pp. 377-386.

Jeffries, D.S. and W.R. Snyder. 1981. Atmospheric deposition of heavy metals in central Ontario. Water, Air, and Soil Pollution 15: 127-152.

Jenkins, T. 1984. The dilemma of an acidic sky. American Water Works Association Journal 76: 42-49.

Johannes, A.H., J.N. Galloway, and D.E. Troutman. 1980. Snowpack storage and ion release. In: Ecological Impact of Acid Precipitation, Proceedings of an International Conference, eds. D. Drablos and A. Tollan. 1980 March 11-14; Sandefjord, Norway: SNSF Project, 0s10, Norway; pp. 260-261.

Johannessen, A. 1980. Aluminium, a buffer in acidic waters. In: Ecological Impact of Acid Precipitation, Proceedings of an International Conference, eds. D. Drablos and A. Tollan. 1980 March 11-14; Sandefjord, Norway; SNSF Project, 0s10, Norway; pp. 222-223.

Johnson, D.W., G.S. Henderson, D.D. Huff, S.E. Lindberg, D.D. Richter, D.S. Shriner, D.E. Todd, and J. Turner. 1982. Cycling of organic and inorganic sulphur in a chestnut oak forest. 0ecologia 54: 141-148.

Johnson, D.W., H. Van Miegroet, D.W. Cole, and D.D. Richter. 1983. Contributions of acid deposition and natural processes to cation leaching from forest soils: a review. Oak Ridge National Laboratory, Environmental Sciences Division, Research Paper 83-34.2. 20 pp.

Johnson, D.W., I.S. Nilsson, J.0. Reuss, H.M. Seip, and R.S. Turner. 1985. Predicting soil and water acidification. Proceedings of a workshop held in Knoxville, Tennessee. 1984 March 26-29. Funded by the National Acid Precipitation Assessment Program by the US Environmental Protection Agency. Hosted by Oak Ridge National Laboratory, Oak Ridge, Tennessee. 47 pp.

Johnston, S.E., S.A. Norton, C.T. HesS, R.B. Davis, and R.S. Anderson. Chapter 10. Chronology of atmospheric deposition of acids and metals in New England, based on the record in lake sediments. In: Energy and Environmental Chemistry. Acid Rain. Volume 2, ed. L.H. Keith. Ann Arbor, Michigan: Ann Arbor Science, pp. $177-187$. 
Kel1y, J.M. 1980. Sulfur distribution and flux in two forested watersheds in eastern Tennessee. In: Ecorogical Impact of Acid Precipitation, Proceedings of an International Conference, eds. D. Orablos and A. Tollan. 1980 March 11-14; Sandefjord, Norway; SNSF Project, 0s10, Norway; pp. 230-231.

Kel1y, T.J., D.H. Stedman, W.M. Lewis, Jr. and M.C. Grant. 1980. Effect of urban sources on acid precipitation in the western United States. Science 210: 1043.

Kerekes, J.J. 1980. Preliminary characterization of three lake basins sensitive to acid precipitation. In: Ecological Impact of Acid Precipitation, Proceedings of an International Conference, eds. D. Drablos and A. Tollan. 1980 March 11-14; Sandefjord, Norway; SNSF Project, 0s10, Norway; pp. 232-233.

Lewis, W.M., Jr. and M.C. Grant. 1979. Relationships between stream discharge and yield of dissolved substances from a Colorado mountain watershed. Soil Science 128: $353-363$.

Lewis, W.M., Jr., M.C. Grant, and J.F. Saunders. 1984. Chemical patterns ofbulk atmospheric deposition in the state of Colorado. Water Resources Research 20(11): $1691-1704$.

Lewis, W.M., Jr., M.C. Grant, T.J. Kelly, and D.H. Stedman. 1980. Effect of urban sources on acid precipitation in the western United States. Science 210: 1043.

Lindmark, G.K. 1982. Acidified lakes: sediment treatment with sodium carbonate-a remedy? Hydrobiologia 92: 537-547.

Mahler, R.L., A.R. Halvorson, and F.E. Koehler. 1985. Long-term acidification of farmland in northern Idaho and eastern Washington. Soil Science Plant Analysis $16(1): 83-95$.

McFee, W.W., J.M. Kelly, and R.H. Beck. 1977. Acid precipitation effects on soil pH and base saturation of exchange sites. Water, Air, and Soil Pollution 7: 401-408.

Menz, F.C. and C.T. Driscoll. 1983. An estimate of the costs of liming to neutralize acidic Adirondack surface waters. Water Resources Research 19(5): 1139-1149.

Mitchel1, M.J., D.H. Landers, and D.F. Brodowski. 1981. Sulfur constituents of sediments and their relationship to lake acidification. Water, Air, and Soil Pollution 16: $351-359$.

Mohn, E., E. Joranger, S. Kalvenes, B. Sollie, and R. Wright. 1980. Regional surveys of the chemistry of small Norwegian lakes: a statistical analysis of the data from 1974-1978. In: Ecological Impact of Acid Precipitation, Proceedings of an International Conference, eds. D. Drablos and A. Tollan. 1980 March 11-14; Sandefjord, Norway; SNSF Project, 0slo, Norway; pp. 234-235.

Morling, G., C. Forsberg, and R.G. Wetzel. 1985. Lake Anketjarn, a non-acidified lake in an acidified region. 0ikos 44: 324-330.

Mose110, R. 1980. Chemical characteristics and buffer capacity of fifty alpine lakes (Italy, Pennine-Lepontine Alps). In: Ecological Impact of Acid Precipitation, Proceedings of an International Conference, eds. D. Drablos and A. Tollan. 1980 March 11-14; Sandefjord, Norway; SNSF Project, 0s10, Norway; pp. 236-237.

Nilssen, J.P. 1982. Acidification in southern Norway: seasonal variation of aluminium in lake waters. Hydrobiologia 94: 217-221. 
Noggle, J.C., H.C. Jones, J.M. Kelly, J.D. Joslin, H. Olem, R.W. Garber, and P.F. Brewer. 1984. Investigations of the role of internally generated $\mathrm{H}+$ and $\mathrm{Al+++}$ soil and surface water acidification. APCA 77th Conference; 1984 June 24-29; San Francisco, CA.

Nuckols, J.R. and I.D. Moore. 1983. Atmospheric deposition of nitrogeneous compounds and its relationship to stream nitrogen chemistry. Proceedings of "Acid Rain in Kentucky: Workshop on Acid Deposition." University of Kentucky, Institute for Mining and Minerals Research, Lexington, KY, USA; pp. 81-90.

O'Sullivan, D.A. 1985. European concern about acid rain is growing. Chemistry and Engineering News 28: 12-18.

0liver, B.G. and J.R.M. Kelso. 1983. A role for sediments in retarding the acidification of headwater lakes. Water, Air, and Soil Pollution 20(4): 379-389.

0liver, B.G., E.M. Thurman, and R.L. Malcolm. 1983. The contribution of humic substances to the acidity of colored natural-waters. Geochimica et Cosmochimica Acta 47: 2031-2035.

01sson, H. 1983. Origin and production of phosphatases in the acid Lake Gardsjon. Hydrobiologia 101: 49-58.

Oppenheimer, M., J.N. Galloway, G.E. Likens, and S.A. Norton. 1984. Letters: Acid deposition. Science 227: 1154-1156.

ouellet, M. and H.G. Jones. 1983. Historical changes in acid precipitation and heavy metals deposition originating from fossil fuel combustion in eastern North America as revealed by lake sediment geochemistry. Water Science and Technology 15(12): $115-130$.

Paces, T. 1985. Sources of acidification in central Europe estimated from elemental budgets in small basins. Nature 315: 31-36.

Perry, J.A. 1984. Current research on the effects of acid deposition. American Water Works Association Journal 76: 54-59.

Pylypec, B. and R.E. Redmann. 1984. Acid-buffering capacity of foliage from boreal forest species. Canadian Journal of Botany 62: 2650-2653.

Rao, S.S., A.A. Jurkovic, and J.0. Nriagu. 1984. Bacterial activity in sediments of lakes receiving acid precipitation. Environmental Pollution (Series A) 36: 195-205.

Rebsdorf, A. 1980. Acidification of Danish soft-water lakes. In: Ecological Impact of Acid Precipitation, Proceedings of an International Conference, eds. D. Drablos and A. Tollan. 1980 March 11-14; Sandefjord, Norway; SNSF Project, 0slo, Norway; pp. 238-239.

Richardson, C.J. 1985. Mechanisms controlling phosphorus retention capacity in freshwater wetlands. Science 228: 1424-1427.

Robinson, J.W. and H. Ghane. 1983. Continued studies of acid rain and its effects on the Baton Rouge area. Journal of Environmental Science and Health A18(2): 165-174.

Rosenquist, I.Th. 1983. Role of ion exchange reactions and natural, $\mathrm{H}^{+}$-containing soils in the acidification and aluminum enrichment of rivers and lakes (Deutsch). In: Acid Precipitation. Duesseldorf, Germany, FR: VDI-Verlang, pp. 393-398.

Ryznar, J.W. 1944. A new index for determining amount of calcium carbonate scale formed by a water. Journal of American Water Works Association 36: 472-486. 
Schindler, D.W. and M.A. Turner. 1982. Biological, chemical and physical responses of lakes to experimental acidification. Water, Air, and Soil Pollution 18: 259-272.

Schindler, D.W., R. Wagemann, R.B. Cook, T. Ruszczynski, and J. Prokopowich. 1980. Experimental acidification of Lake 223, Experimental Lake Area: background data and the first three years of acidification. Canadian Journal of Fisheries and Aquatic Sciences 37: 342-354.

Schindler, D.W., R.H. Hesslein, R. Wagemann, and W.S. Broecker. 1980. Effects of acidification on mobilization of heavy metals and radionuclides from the sediments of a freshwater lake. Canadian Journal of Fisheries and Aquatic Sciences 37: 373-377.

Schindler, D.W., R.W. Newbury, K.G. Beaty, and P. Campbe11. 1976. Natural water and chemical budgets for a small precambrian lake basin in central Canada. Journal of the Fisheries Research Board of Canada 33: 2526-2543.

Seip, H.M. and A. Tollan. 1978. Acid precipitation and other possible sources for acidification of rivers and lakes. The Science of the Total Environment 10: 253-270.

Skartveit, A. 1980. Observed relationships between ionic composition of precipitation and run-off. In: Ecological Impact of Acid Precipitation, Proceedings of an International Conference, eds. D. Drablos and A. Tollan. 1980 March 11-14; Sandefjord, Norway; SNSF Project, 0s10, Norway; pp. 242-243.

Smith, R.A. and R.B. Alexander. 1983. Evidence for acid-precipitation-induced trends in stream chemistry at hydrologic bench mark stations. US Department of the Interior, Geological Survey Circular 910. 12 pp.

Sposito, G., A.L. Page, and M.E. Frink. 1980. Effects of acid precipitation on soil leachate quality: computer calculations. United States Environmental Protection Agency, Report No. EPA-600/3-80-015. 38 pp.

Sprules, W.G. 1975. Midsummer crustacean zooplankton communities in acid-stressed lakes. Journal of the Fisheries Research Board of Canada 32: 389-395.

Thompson, M.E., F.C. Elder, A.R. Davis, and S. Whitlow. 1980. Evidence of acidification of rivers of eastern Canada. In: Ecological Impact of Acid Precipitation, Proceedings of an International Conference, eds. D. Drablos and A. Tollan. 1980 March 11-14; Sandefjord, Norway; SNSF Project, 0s 10, Norway; pp. 244-245.

Troutman, D. and N. Peters. 1980. Comparison of lead, manganese and zinc transport in three Adirondack lake watersheds, New York. In: Ecological Impact of Acid Precipitation, Proceedings of an International Conference, eds. D. Drablos and A. Tollan. 1980 March 11-14; Sandefjord, Norway; SNSF Project, Oslo, Norway; pp. 262-263.

US Environmental Protection Agency, Office of Research and Development. 1985. National surface water survey, western wilderness area lakes: Environmental assessment. Draft. March 1, 1985. Report No. EPA-910/9-85-125. Seattle, WA. 170 pp. Available from NTIS.

Ugolini, F.C., R. Minden, H. Dawson, and J. Zachara. 1977. An example of soil processes in the Abies amabilis zone of central Cascades, Washington. Soil Science $124(5): 291-302$. 
Ulrich, B., R. Mayer, and P.K. Khanna. 1980. Chemical changes due to acid precipitation in a loess-derived soil in central Europe. Soil Science 130: 193-199.

Vangenechten, J.H.D. 1983. Acidification des lacs de l'Europe de l'Ouest et adaptation physiologique des habitants naturels des lacs a l'agression acide. Water Quality Bulletin 8: 150-155.

Vangenechten,J.H.O. and O.L.J. Vanderborght. 1980. Acidification of Belgian Moorland Pools by Acid Sulphur-Rich Rainwater. In: Ecological Impact of Acid Precipitation, Proceedings of an International Conference, eds. D. Drablos and A. Tollan. 1980 March 11-14; Sandefjord, Norway; SNSF Project, 0s10, Norway; pp. 246-247.

Webb, A.H. 1982. Weak acid concentrations and river chemistry in the Tovdal River, southern Norway. Water Research 16: 641-648.

Wollast, R., L. Chou, V. Debbaut, A. Wollast, and J. Zobrist. 1984. The influence of acid rains on the geochemistry of aluminium. In: SCOPE Belgian Research on Acid Deposition and the Sulphur Cycle, ed. O.L.J. Vanderborght. SCOPE Publications, Pp. $277-286$.

Wright, R.F. and M. Johannessen. 1980. Input-output budgets of major ions at gauged catchments in Norway. In: Ecological Impact of Acid Precipitation, Proceedings of an International Conference, eds. D. Drablos and A. Tollan. 1980 March 11-14; Sandefjord, Norway; SNSF Project, 0s 10, Norway; pp. 250-251.

Wright, R.F., R. Harriman, A. Henriksen, B. Morrison, and L.A. Caines. 1980. Acid lakes and streams in the Galloway area, Southwestern Scotland. In: Ecological Impact of Acid Precipitation, Proceedings of an International Conference, eds. D. Drablos and A. Tollan. 1980 March 11-14; Sandefjord, Norway; SNSF Project, 0s 10, Norway; pp. 248-249.

Yan, N.D. 1983. Effects of changes in $\mathrm{pH}$ on transparency and thermal regimes of Lohi Lake, near Sudbury, Ontario. Canadian Journal of Fisheries and Aquatic Sciences 40: $621-626$.

Zurbuch, P.E. 1984. Neutralization of acidified streams in west Virginia. Fisheries $9(1): 42-47$. 




ISBN 0-921625-03-0 (Volume 1) ISBN 0-921625-02-2 (Set of 11) 